Portland State University

PDXScholar

\title{
Perceptions of Hmong Parents in a Hmong American Charter School: a Qualitative Descriptive Case Study on Hmong Parent Involvement
}

Kirk T. Lee

Portland State University

Follow this and additional works at: https://pdxscholar.library.pdx.edu/open_access_etds

Part of the Asian Studies Commons, Bilingual, Multilingual, and Multicultural Education Commons, Curriculum and Instruction Commons, Educational Leadership Commons, Elementary and Middle and Secondary Education Administration Commons, Elementary Education Commons, and the South and Southeast Asian Languages and Societies Commons

Let us know how access to this document benefits you.

\section{Recommended Citation}

Lee, Kirk T., "Perceptions of Hmong Parents in a Hmong American Charter School: a Qualitative Descriptive Case Study on Hmong Parent Involvement" (2016). Dissertations and Theses. Paper 3103. https://doi.org/10.15760/etd.3100

This Dissertation is brought to you for free and open access. It has been accepted for inclusion in Dissertations and Theses by an authorized administrator of PDXScholar. Please contact us if we can make this document more accessible: pdxscholar@pdx.edu. 
Perceptions of Hmong Parents In A Hmong American Charter School: A Qualitative Descriptive Case Study On Hmong Parent Involvement

by

Kirk T. Lee

A dissertation submitted in partial fulfillment of the requirements for the degree of

Doctor of Education

in

Educational Leadership: Curriculum and Instruction

Dissertation Committee:

Yer J. Thao, Chair

Micki M. Caskey

Dannelle D. Stevens

Roberto M. De Anda

Portland State University

2016 
C 2016 Kirk T. Lee 


\begin{abstract}
Parental involvement plays an essential role in the United States (U.S.) educational system. However, parental involvement poses many challenges for Hmong parents in American schools. Many assumptions are made on the parts of teachers, staff, and Hmong parents about parents' roles pertaining to their involvement in their children's education. Hmong parents who had little formal education struggle to reconcile beliefs, attitudes, and values that they bring with them from Laos with the expectations found in the U.S. due to their unfamiliarity with the U.S. educational system.
\end{abstract}

This study employed the used a qualitative, descriptive case study approach to examine the perceptions of Hmong parents involvement at a K-6 Hmong American charter school in Northern California. The primary data collection method used in this study was interviews with four school-community stakeholder groups.

The purposeful-selected interview participants included two administrators, four teachers, six parents, and four students. The interviews were dialogically coded and nine themes were developed related to parental involvement. These nine themes were: communication with parents, committee involvement, flexibility of staff, enrichment programs non-traditional school schedule, importance of field trips, cultural events and presence of other cultures, recommend school to others, and positive behavioral reinforcement. The study concludes with a presentation of the implications of the nine themes on the design of parent involvement models and recommendations are offered related to policies and connected strategies for how to design culturally relevant supports for parent involvement in American schools. 


\section{Dedication}

This dissertation is dedicated to: Pachor (Pajtxos) Lee, Yee (Yiv) Cha Lee, Cha (Txoojtsab Lee, Lue (Txawjtuam) Lee, Xee (Ntxhi) Lee-Thao, Willie (Soobyeeb) Lee, Nyua (Nyuam) Lee-Xiong, Vince (Faivvws) Lee, Kia (Kiab) Lee-Peden, Mai (Mais) LeeFlowers, Kim (Kha) Yang; my parents, my siblings, and my wife. You are all my inspiration. 


\section{Acknowledgements}

I wish to express my sincere appreciation to Dr. Yer J. Thao, chairperson of my dissertation committee, who inspired me to great heights and motivated me to pursue in this educational endeavor. Dr. Thao's continuous reassurances during these challenging times brought me back to life.

I want to thank the dissertation committee members, Dr. Micki M. Caskey, Dr. Dannelle D. Stevens, and Dr. Roberto M. De Anda, who graciously sacrificed their time and their expertise on this manuscript. Additionally, I want to thank the superintendent, principal, teachers, parents, and students at Sunny charter school (pseudonym), for their time, participation, and support. Due to confidentiality statutes, they shall remain nameless; however, without your participation and perspectives this study would not have been possible.

Finally, I am indebted to my wife, Kim (Kha) Yang, for her love, endless support, encouragement, patience, sacrifice, and forgiveness during this arduous journey. I want to thank my children, Marissa (Mos) Lee, Jessica (Kab) Lee, Kyle (Khais) Lee, Joyce (Ntsuab) Lee, Dorothy (Dawb) Lee, and Corey (Kob) Lee, for sticking with me through some of the most challenging times. Lastly, I want to thank my brother, Willie (Soobyeeb) Lee, whose wisdom, advice, and encouragement inspired me to be the person I am today. 
Table of Contents

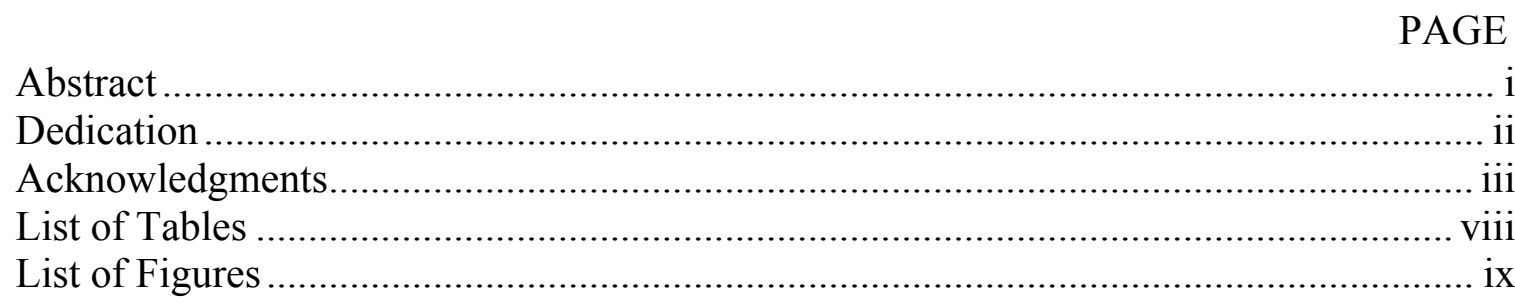

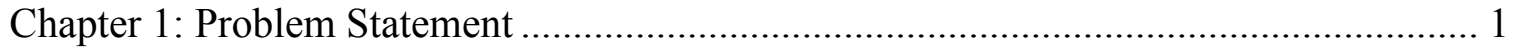

The Need to Engage Hmong Parent Volunteers ................................................ 3

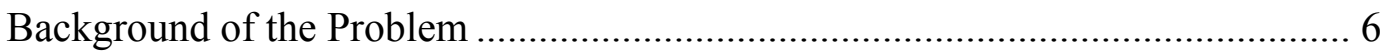

The Importance of Parental Involvement to Student Success. ................. 8

Barriers to Hmong Parental Involvement ....................................................... 10

The gap between the transmission mode of education and modes used in

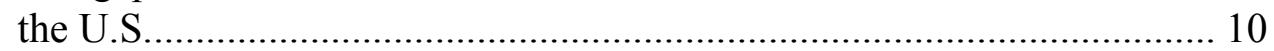

Lack of literacy skills..................................................................... 11

The role of the patriarchal perspective............................................... 13

Understanding the role of parents in U.S. schools................................. 15

Conflicting perception of the role of the teacher. ................................. 16

Culturally-based assumptions. ...................................................... 17

Mistaken assumptions................................................................ 19

Impact of being a political refugee. ................................................... 20

Examining Systems of Education Specifically Designed to Bridge Cultural

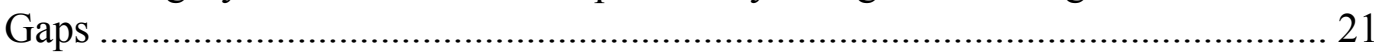

Hmong American Charter Schools ............................................................ 21

The Sunny charter school............................................................. 22

Statement of the Research Problem .................................................................. 23

Significance of the Research Problem ............................................................. 23

Presentation of the Methods and Research Questions ....................................... 24

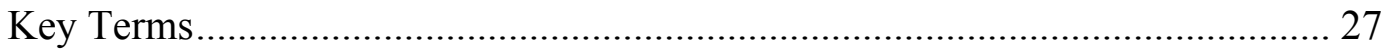

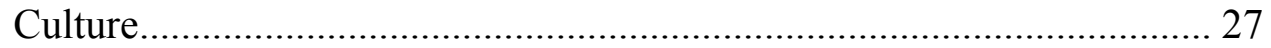

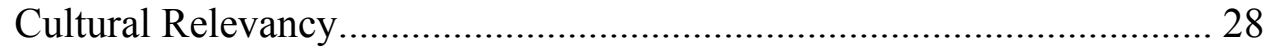

Hmong Culture .......................................................................... 29

Political Refugee ...................................................................... 29

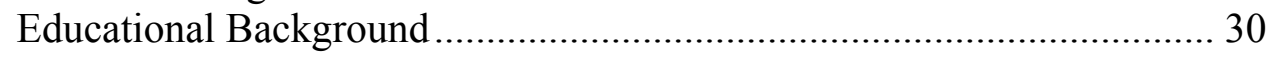

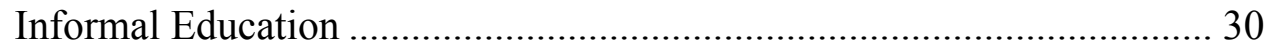

Lack of Formal Educational Background ............................................. 32

Preliterate .................................................................................. 32

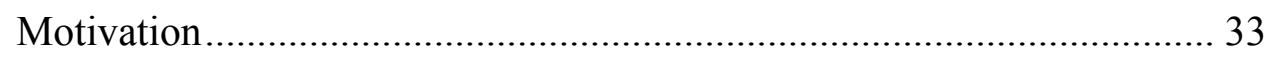

Parental Involvement ................................................................. 33

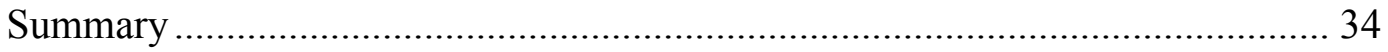

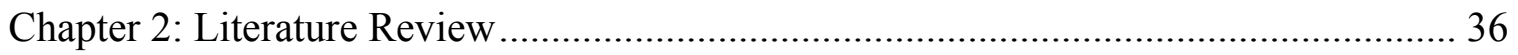




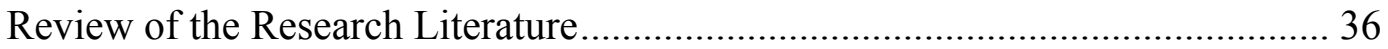

The Need to Help Bridge the Cap for Parents ..................................................... 41

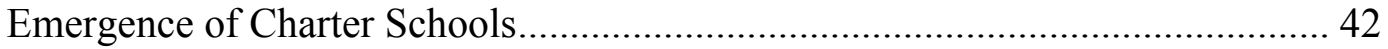

Motivation for Hmong Charter Schools ............................................................ 43

Charter schools in Minnesota, Wisconsin and California...................... 45

Hmong charter school model......................................................... 49

Theoretical Framework: Social, Human, and Cultural Capital Theory ................ 52

Theoretical Framework: Zone of Proximal Development (ZPD)............ 54

ZPD and Parental Involvement ................................................................ 56

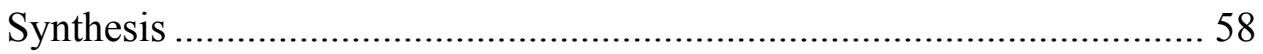

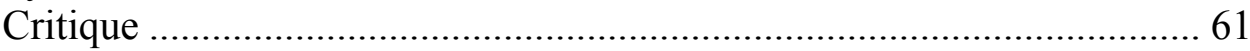

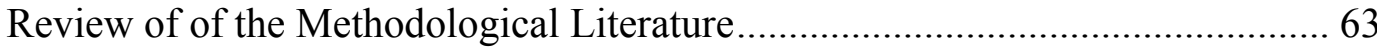

Constructivist Research Paradigm ...................................................... 63

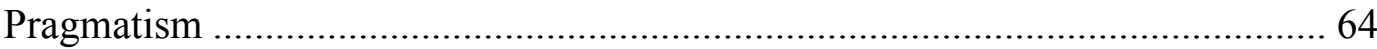

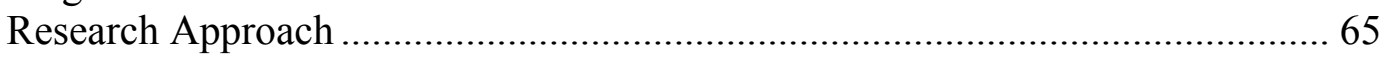

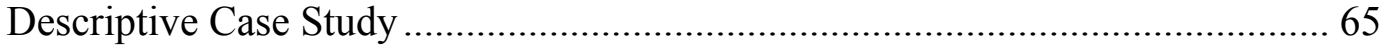

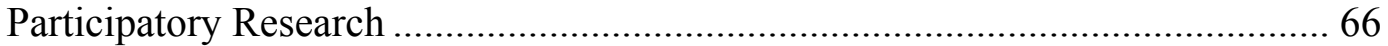

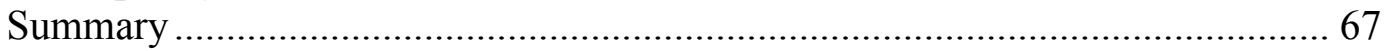

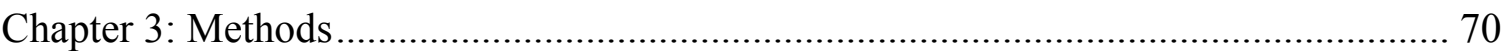

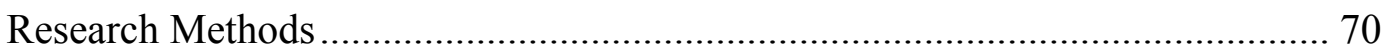

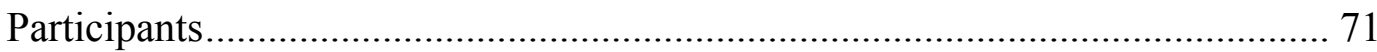

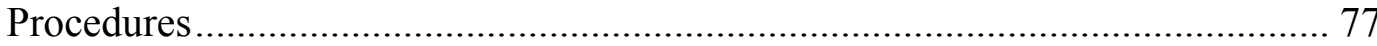

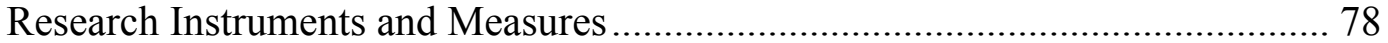

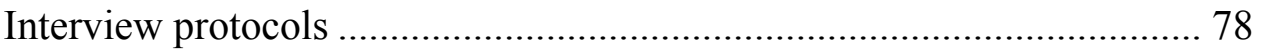

School artifacts...................................................................... 82

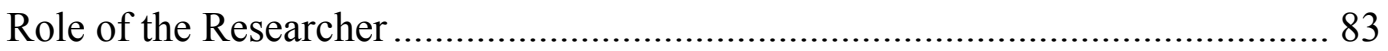

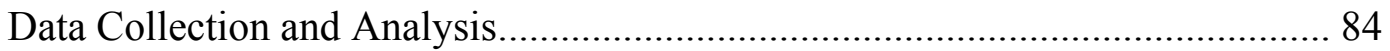

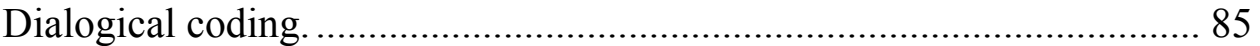

Analysis of school artifacts............................................................. 87

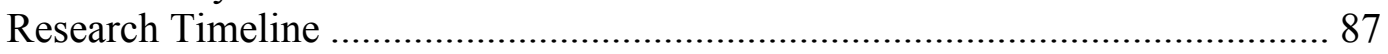

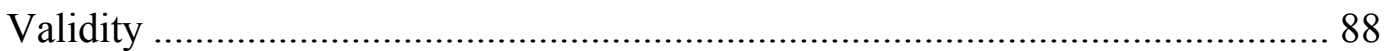

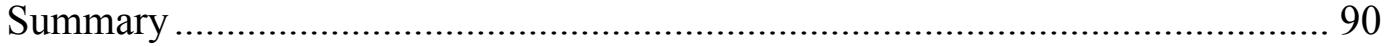

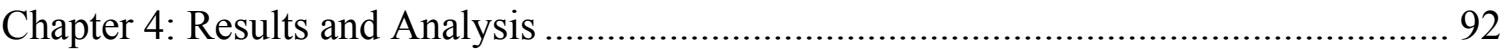

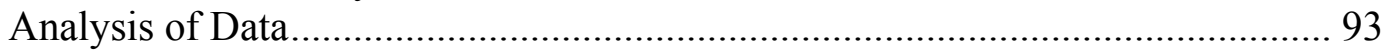

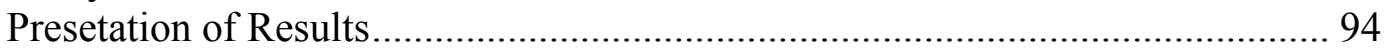

Stakeholder Groups and Their Perspectives ................................................ 95

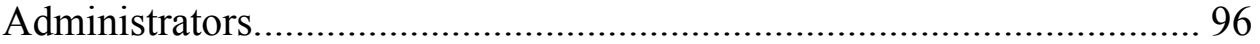

Administrators' perspectives of parental involvement outreach in the

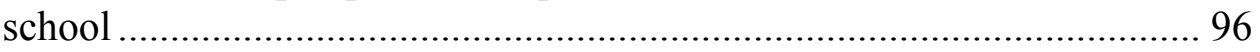

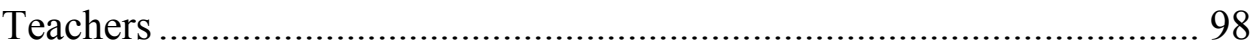

Teacher perspectives of parental involvement outreach in the school. .... 98

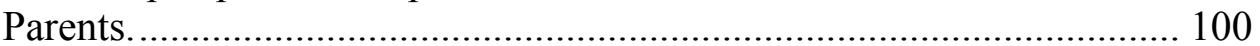

Parents' perceptions of parental involvement................................... 101 


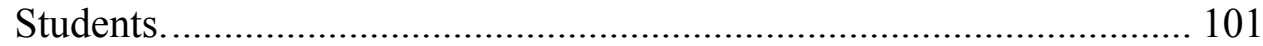

Student perceptions of parental involvement at their school................ 102

Culturally Relevant Approaches to Parental Involvement.............................. 102

Interpretation of Findings ....................................................................... 103

The Four Stakeholder Groups' Perceptions Related to Parent Involvement ...... 104

Communication and importance of bilingual staff ............................... 105

Enrichment programs .................................................................... 106

Impact of the non-traditional school schedule .................................. 107

Committee involvement ................................................................. 108

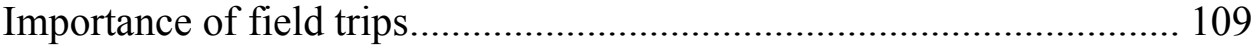

Cultural events or presence of other cultures.................................... 109

Recommendation of school........................................................... 110

Behavioral reinforcement............................................................. 110

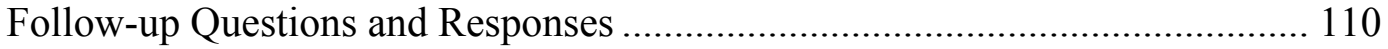

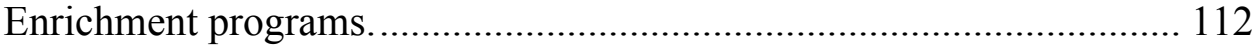

Impact of the non-traditional school schedule.................................. 112

Culturally appropriate communication and importance of bilingual staff1 13

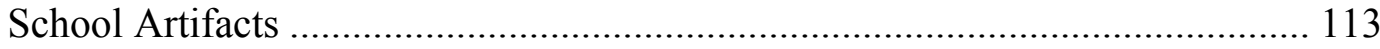

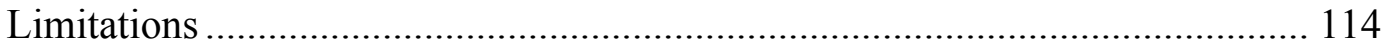

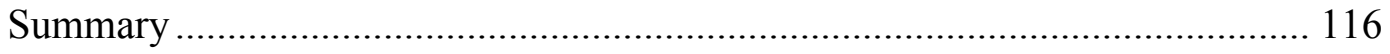

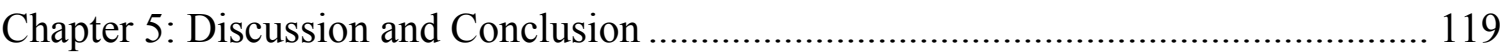

Follow-up Questions and Responses ..................................................... 121

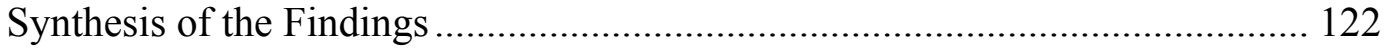

Enrichment Programs.................................................................... 122

Impact of the Non-Traditional School Schedule .................................. 124

Culturally Appropriate Communication ........................................... 124

In-school Volunteering Activities........................................................... 126

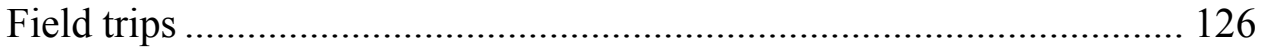

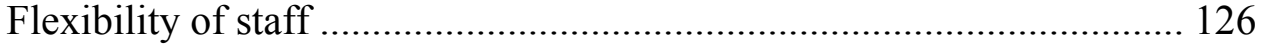

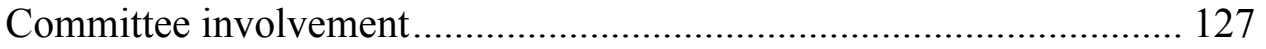

Cultural events ............................................................................. 127

Relevance of School in the Community ...................................................... 128

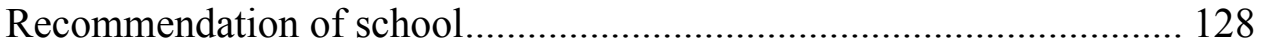

Behavioral reinforcement.............................................................. 129

Implications of the Findings for School Administrators and School

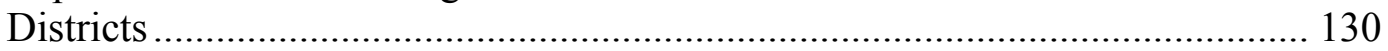

The importance of bilingual and bicultural school staff members ......... 131

The importance of culturally sensitive modes of communication.......... 131

Consider non-tradition school schedules ........................................... 132

Implications of the Nine Themes for Teachers ........................................... 132

Situated in the Larger Context ................................................................. 133

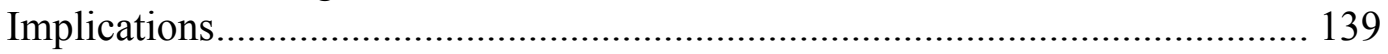

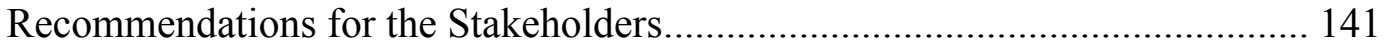

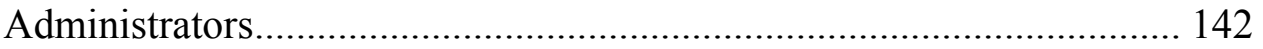


PERCEPTIONS OF HMONG PARENTAL INVOLVEMENT vii

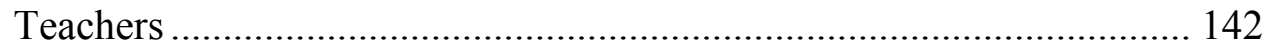

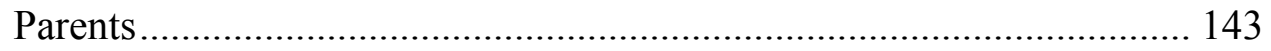

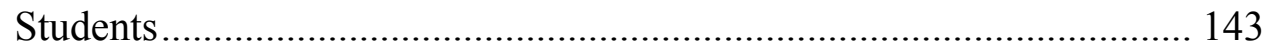

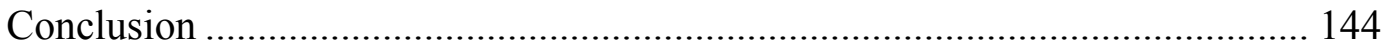

Final Thoughts on the Themes and Contribution to Research.......................... 146

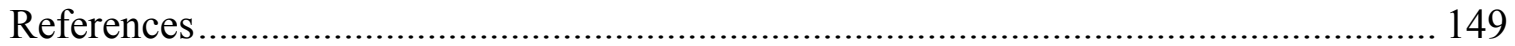

Appendices

Appendix A Consent to Participate in Research..................................................... 155

Appendix B Parental Permission ......................................................................... 158

Appendix C Student Permission ........................................................................... 160

Appendix D Open-ended and Follow-up Interview Questions for Administrators .. 160

Appendix E Open-ended and Follow-up Interview Questions for Teachers ............ 162

Appendix F Open-ended and Follow-up Interview Questions for Parents............... 163

Appendix G Open-ended and Follow-up Interview Questions for Students ............ 165

Appendix H Individual Respose to Open-ended Questions ................................... 166

Appendix I Individual Response to Follow-up Questions ...................................... 169

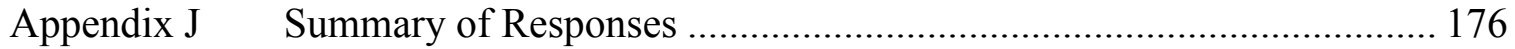




\section{List of Tables}

TABLE

PAGE

1. Characteristics of Charter Schools...............................................45

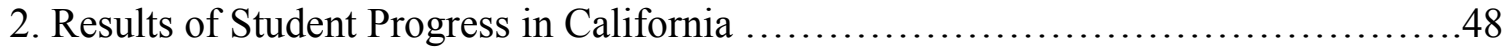

3. Epstein's Model of School, Family, and Community Partnerships ..................51

4. Research Timeline .......................................................... 88

5. Frequency of Responses Related to the Nine Themes......................... 104

6. Summary of Follow-up Questions Results...................................111 


\section{List of Figures}

FIGURE

PAGE

1. Comparison between Sunny charter school, District, and California..............49 


\section{Chapter 1: Problem Statement}

Parents play an important role in their children's learning and academic success. However, navigating involvement within foreign systems of education is difficult for immigrant parents who lack familiarity with schools and models of parental involvement found in the U.S. (Epstein, 1988, 2005; Epstein, Sanders, \& Sheldon, 2007).

According to Epstein (2005), most immigrant parents to this country feel that they are left to figure out how to become involve in their children's schooling on their own due to a lack of culturally relevant outreach models. This is particularly true for political refugees from Laos living in the U.S. who are largely unfamiliar with formal systems of education and parental involvement models designed for parents who are native to this country.

When the first wave of Hmong refugees came to the U.S. from the war-torn Southeast Asian nation of Laos in 1975, the majority of these immigrants lacked knowledge of formal education necessary to support their children in schools. However, some refugees were somewhat familiar with formal modes of education having worked closely with American soldiers and attending vocational schools in Laos and abroad, the majority had experienced the transmission mode of education common to traditional agrarian societies (K. L. Lee \& Green, 2008) rather than the modes of education typically found in U.S. schools.

In a traditional Hmong agrarian society, the informal transmission of traditional rituals or chants or even methods of farming and descriptions of social hierarchies often requires repetition and memorization. Due to the inability to write down information, 
this form of knowledge transmission can be ineffective because certain nuances of the practices are lost over time.

The first wave of Hmong refugees arrived in the U.S. between 1975 and 1994 as political refugees. In 1994, when the refugee camps in Thailand closed, a second large wave of Hmong refugees came to the U.S. With the closure of refugee camps, many Hmong refugees were repatriated to Laos and others slipped out to nearby Thai villages or provinces. In 2004, the U.S. decided to resettle the remaining Hmong refugees. In 2005, the third and most recent wave of Hmong refugees began to arrive in the U.S. According to Pfeifer and Thao (2013), as of the 2010 U.S. Census, the overall Hmong population in the U.S. stood at 260,073, primarily centered in Minnesota, Wisconsin and California. In recent years, Hmong populations have spread throughout the U.S. seeking employment, business, and educational opportunities. In Minnesota, with a Hmong population of 66,181 (Pfeifer \& Thao, 2013) the cities of St. Paul and Minneapolis have seen significant growth of Hmong populations, as is the case in the state of Wisconsin with 49,240 Hmong people (Pfeifer \& Thao, 2013).

In California, the state with the largest number of Hmong refugees, the population 91,224 (Pfeifer \& Thao, 2013) is concentrated along the Central Valley region, mainly in Fresno and Sacramento, where the warmer weather is better suited for farming. In fact, Hmong students makes up the third largest Limited English Proficient group in California, behind only the Hispanic and Vietnamese students (Vang, 2005).

In spite of having been driven out as political refugees, the majority of those among the older Hmong generation have always considered Laos as their homeland and 
aspired to return one day to live their own traditional way of life. For many of them, the

U.S. will always be considered a temporary resettlement and a foreign country with unfamiliar language and culture. As a member of the Hmong community, I generally share the sentiment with many Hmong refugees, which seemed to affect their motivation to pursue long-term educational goals.

Even though some of the Hmong refugees have resettled in the U.S. for more than 30 years, the American educational system remains unfamiliar to many parents from all three waves of immigrations from Laos. This is especially true for those refugees who came in the last wave of immigration. From the very beginning of the arrival of Hmong refugees in the U.S., Hmong parents and students have struggled to learn in schools.

The majority of the first-generation Hmong parents who came to the U.S. without any experience of formal education found that they could not successfully advocate for their children in schools. In turn, some second-generation Hmong parents continue to lack the knowledge and skills to help their children navigate the U.S. system of education. The lack of a formal educational background and institutional inexperience among Hmong parents continues to act as a barrier to parental involvement in schools to the detriment of their children.

\section{The Need to Engage Hmong Parent Volunteers}

Researchers and educators have praised parental involvement programs as playing essential roles in improving students' levels of academic achievement, reducing student dropout rates, increasing college admissions rates and success, and improving behavioral issues that act as barriers to learning (Bjork, Lewis, Browne-Ferrigno, \& Donkor, 2012; 
Epstein, 1988, 2005; Epstein et al., 2007; Hernandez, 2011). However, the concept of parental involvement is new to many Hmong parents who arrived in the U.S. from a different educational system, with limited formal educational experience, and low English literacy skills. These educational limitations are obstacles to many Hmong parents' ability to volunteer in their children's classrooms, go on field trips, help with children's schoolwork, and relate Hmong culture and history to an American context. As a result, many Hmong parents and students are at a disadvantage.

In Laos, a rigid structural hierarchy dictates the nature of the relationship between the teachers and parents. For the Hmong parents, teachers are viewed experts and teaching should be left to them (Vang, 2005). To insert one's will upon the school in any sense is to challenge the authority of the professional educator, an unthinkable breach of the traditional social order (Vang, 2005).

Based on this paradigm, the majority of Hmong parents of students enrolled in schools within the U.S. remain as outsiders not knowing when or how to get involved in their children's education. According to Vang (2005), unfortunately students of parents who lack formal educational experience tend to receive less support both in terms of formal educational opportunities and exposure to informal learning experiences.

Hmong students' academic struggles over the past 30 years in the U.S. demonstrate the need for schools and parents to build strong partnerships to better serve the needs of Hmong children. Therefore, it is essential that school administrators, schools of education, teachers, and parents collaborate to create and support a culture of 
academic success for Hmong students. A key vehicle for this type of collaboration is a culturally sensitive parental involvement program.

This dissertation examined parental involvement in schools in the U.S. In particular, this qualitative descriptive case study (Creswell, Plano-Clark, Gutmann, \& Hanson, 2003) described a parent involvement model found within a Hmong charter school located in Northern California, on the west coast of the U.S.

My study contributes foundational descriptive knowledge related to common obstacles and affordances to parental involvement in the U.S. system of education among those of Hmong descent. The research describes the perspectives of four stakeholder groups related to this topic; school administrators, teachers, parents, and students.

I posit that knowledge of barriers and affordances to parental involvement in education is essential to the development of culturally relevant models of parent involvement in the U.S. educational system. The principal argument of this study is that with culturally sensitive forms of support for parents in place, Hmong parents and schools could better prepare themselves to help Hmong children in the classroom, support students' learning at home, and improve parents' abilities to effectively communicate with school administrators and teachers to better address students' needs. Such supports are important for Hmong students' academic and social success in school (Thao, 2003).

In addition, in the multicultural environment of American schools, Hmong history, language, culture, and arts provide a significant opportunity to enrich curricula. 
Parental involvement is key to accessing these valuable cultural resources that have the potential to enrich the lives of entire communities.

In chapter 1, I highlight some of the key educational challenges Hmong refugees typically face after resettling in the U.S. and the implications of these issues on parental involvement in schools and on their children's education. The chapter presents key terms and constructs central to this piece of research. In chapter 2, I examine literatures on parental involvement in education in general and then focus on the implications of parental involvement for Hmong children. In chapter 3, I outline the methodologies that informed the research design used in this study. In chapter 4, I report the research data and finally, chapter 5 provides an interpretation of these data, a discussion related to the implications of these findings and offer policy and strategy recommendations, and suggestions for future research.

In chapter 5, I describe how my study contributes to a foundation of knowledge for how people perceive parental involvement models. The manuscript concludes with reflections on how this work contributes to efforts to put culturally sensitive forms of support for parents in place so that Hmong parents and schools can better prepare themselves to help Hmong children in the classroom and through cultural enrichment activities, support students' learning at home, and improve parents' abilities to effectively communicate with school administrators and teachers to better address students' needs.

\section{Background of the Problem}

The first day of school is often filled with excitement and anxiety for a child. As a child of Hmong refugees living in the U.S., when I found out which school I would 
attend as a small boy, I was rather eager and looked forward to see the school, make new friends, meet the teachers, and ultimately learn to speak English. I was intent on learning to read and write in English as soon as possible.

However, as the first day approached, my mind swirled with excitement and anxiety. I wanted to ask someone about the school, but who? Should I ask my parents, my older brothers, or my uncle? I could not ask any of them! When the day finally came, I went to school with many unanswered questions, which I had to learn to navigate on my own.

This personal story illustrates the dilemma many Hmong children experienced when they first arrived in the U.S. Hmong students would question their parents about the U.S. schools or the curriculum, but most Hmong parents could not explain how U.S. schools functioned because few had ever experienced formal education in Laos, much less in American schools.

After being in the U.S. for more than three decades, Hmong parents continue to struggle with the best ways to support their children's education. With few avenues by which to access the social realities of formal education in this country, Hmong parents typically shy away from volunteering in the schools or helping children with their schoolwork.

In contrast, most Caucasian parents have benefitted from a key U.S. legislative mandate under Title I of the Elementary and Secondary Education Act (ESEA) of 1965 that was reauthorized in 2010, revised and reauthorized under the new name of Every Student Succeeds Act (ESSA) in 2015 (Epstein, 2005; Hernandez, 2011; Trumbull, 
Rothstein-Fisch, Greenfield, \& Quiroz, 2001). According to Taylor and Christ (2010), ESEA broadly stated, "The purpose of ESEA was to improve educational opportunities for children from lower socioeconomic backgrounds" (p. 420). Furthermore, Smith, Wohlstetter, Kuzin, and Pedro (2011) stated, "ESEA has long mandated parent involvement in disadvantaged communities through parent advisory councils" (p. 73). In addition, Epstein (2005) noted that the No Child Left Behind (NCLB) Act of 2002 specifically wants school districts and states to organize programs to involve parents and the public.

Since passage of this legislation in the mid-1960s, parental involvement programs have been a vital part of U.S. educational policy (Hernandez, 2011; Smith et al., 2011). With the support of public policies and well-established models of parental involvement programs, active involvement of parents in many U.S. schools continues to persist among mainstream parents (Vang, 2005). Yet, a crucial element, sensitive cultural inclusion, severely limits access to parental involvement in education among non-mainstream populations. In the revised and reauthorized version of NCLB, the ESSA (2015) also included many of the parental involvement requirements.

\section{The Importance of Parental Involvement to Student Success}

Parental involvement is typically described as the encouragement and commitment of parents to provide resources and educational supports to aid their children's academic efforts and school success in related areas like extracurricular activities (Bjork et al., 2012; Pomerantz, Moorman, \& Litwack, 2007). However, there is a wide range of interpretations of what parental involvement actually looks like. 
For example, P. Xiong (2000) defined parental involvement as the provision of parental supports and participation at home, in the community, and at the school site. More specifically, Hoover-Dempsey, Bassler, and Brissie (1987) suggested that parental involvement entails daily parent-child discussions, supports, and participation in the home, in the community, or at the school site. Hoover-Dempsey et al. (1987) further characterized parental involvement as participation in the school's Parent Teacher Association, helping children with their homework, and taking an active role in school governance. These authors extended the definition to include activities that benefit more than just their own children such as chaperoning children on field trips, helping with school fundraising activities, participating in social events, and volunteering in the classroom. In other words, total involvement in the society and culture of American schooling.

Additionally, Hernandez (2011) provided six examples of parental involvement: "Parenting, communicating, volunteering, learning at home, decision-making, and collaborating with the community" (p. 7). In other words, parental involvement includes many subtle activities pertaining to schooling. For example, involved parents prepare meals each morning or ensure that healthy meal choices are otherwise available to their children. They transport their children to and from school every morning and afternoon or ensure that they get on the school bus on time. Involved parents remind children to complete their schoolwork daily and assist them when they need help, attend parentteacher conferences, volunteer in the classroom, and socially interact with other adults associated with the school. As Vang (2005) stated, parents with an educational 
background tend to get more involved in these subtle activities with their children at school and at home.

Although mainstream educators and parents commonly associate parental involvement with promoting and supporting students' academic and social success, Hmong parents continue to struggle to understand the concept of parental involvement. To begin to understand the barriers to Hmong parental involvement, it is important to recognize three underlying problems described in the literature: differing educational systems, lack of formal educational opportunities, and culturally related barriers.

\section{Barriers to Hmong Parental Involvement}

When Hmong parents arrived in the U.S. in the late 1970s, they learned that the U.S. and Lao educational systems were vastly different. These differences often discouraged Hmong parents from entering the classrooms and continue to largely inhibit their participation in school-related activities altogether (Hoover-Dempsey, Walker, Jones, \& Reed, 2002). Hoover-Dempsey et al. (2002) asserted that low participation of Hmong parents is due to "low senses of efficacy for helping children learn" (p. 3). The following sub sections describe some of the key reasons for this lack of self-efficacy on the part of parents in regards to their involvement in their children's education.

The gap between the transmission mode of education and modes used in the U.S. Arias and Morillo-Campbell (2008) purported that Hmong parents' lack of a formal educational background contributes to their low participation in their children's education. Historically, formal education was inaccessible to and perhaps undesired by Hmong parents because of cultural, political, historical, and geographical barriers. 
Thao (2003) observed that for Hmong parents in Laos, formal education was not a common practice. The lack of access to formal education was exacerbated by the warfare that engulfed the culture and the country for more than three decades. Thao stated that in fact, rather than be presented with opportunities to attend school in the formal sense, during this period many Hmong teens were forced to bear arms or be killed. Those who evaded the war were left to tend the family farms and given the destructive disruption of the war, children did not have opportunities to attend schools even in situations wherein they were not forced to become child-soldiers.

Indeed, for the most part, schools for the Hmong children simply did not exist in Laos during the war and subsequent persecution of the Hmong, which lasted a generation (Thao, 2003). Most of those who fled Laos to seek refuge in the U.S. grew up with little to no access to formal education, but rather had learned as countless generations of Hmong people had learned before them through a transmission mode of education focused on cultural survival. In other words, their education was restricted to learning only what they needed to know to literally survive in an agrarian society and in war.

Lack of literacy skills. Another significant barrier to Hmong parents' involvement in their children's education is the lack of language literacy experience. In 1975, when Hmong first came to the U.S., only 5\% of the Hmong population could read and write (M. Lee, 1998; Y. S. Xiong, 2012). The percentage was lower among Hmong women than in the general Hmong population.

P. Xiong (2000) contended that Hmong education and the learning of practical skills in Laos were passed down orally because Hmong did not perceive that they needed 
a written language until presented with the opportunity to develop one in the 1950s.

M. Lee (1998) observed that in 1953, Protestant missionaries Dr. Smalley and Dr. Barney used the French alphabet and grammar system to create the Hmong Alphabet. However, even after the creation of the writing system, very few people were given the opportunity to learn to read or write. P. Xiong (2000) said, "Most education in Laos was informal, and skills needed for village life were passed on informally from one generation to the next" (p. 15).

In fact, the utility of written Hmong was considered minimal within an agrarian culture. Notwithstanding, farmers certainly do use a great many highly sophisticated unwritten systems in their daily life. For example, they often have to estimate the right size field to clear, when to burn, and what crops to plant based on generational knowledge the crop rotation routines, fertilization regimes and careful measurements so that the whole family can get through the year. This knowledge is transmitted to their children in a hands-on manner, within a situated learning environment that allows them to problem solve, and plan despite not having a written language.

While the oral culture has an under-rated and unrecognized potential for accurately communicating ideas, it is one of the reasons few Hmong elders can or need to read and write in the Hmong language (Thao, 2006). Maintaining ancient oral traditions, Hmong elders have learned to master many important ceremonial events involving precise recitation of verses, such as courting songs, shamanistic rituals, death chants, and healing rituals (Thao, Conquergood, \& Thao, 1989). They recognize and know how to calculate and communicate harvest yields, figure the cost of production and interpret 
market conditions that inform choices from short and long term perspectives despite the lack of written records.

The Hmong elders' ability to retain and transmit these forms of knowledge and skills to the younger generation seem to be underrated by today's younger generation. However, many quite vital elements of Hmong culture and identity were likely encoded in this oral literacy, which appeared to be a way of knowing worth passing down the generations and worth building upon with new knowledge (Thao, 2006).

However, despite the merits of learning through a transmission mode of education, crossing over from an oral culture to a written culture does involve negotiating a significant gap for parents as well as children. Ngo and Lee (2007) found that Hmong parents in the U.S. "face linguistic and cultural barriers and this keeps them from being involved" and as a result of misunderstanding the nature of the barriers that Hmong are struggling with "Hmong students and parents have (been) held to lower expectations by teachers" (pp. 429-430) in comparison of what they expect from other immigrant cultures and children native to the U.S.

There persists an underlying assumption on the part of many educators in the U.S. that Hmong parents do not care about their children's education based on what they see parents not doing. However, if the educational establishment knew more about the cultural background of their Hmong families, they would see that Hmong parents care differently.

The role of the patriarchal perspective. There are cultural factors to consider, as well. For example, the Hmong tradition is based on a patriarchal society wherein 
education is more prevalent for men than for women (Mote, 2004). That said, while growing up, I personally observed that for the most part, the young Hmong males who did chose to attend school were oftentimes deemed as being lazy and unfit to be husbands by the elders in the community. However, those Hmong men who went against the elders' wishes and went away to school were highly revered upon their return by the greater community. That was not the case with Hmong women.

In contrast, my father told me he saw a significant number of Hmong boys and men sent to school and war, for the most part the Hmong girls and women were left to tend to the family, household chores, the farm, not to mention deal with many the vicissitudes of the all-consuming war. It was evident that traditionally, the Hmong culture discouraged Hmong women from attending school because those who did were deemed lazy and nonconformists. Thus, very few Hmong women had the opportunity to experience schools before the mid-1970s.

However, after the Vietnam War ended in 1975, many Hmong people fled Laos and resettled in Thai refugee camps. While in the camps, many Hmong elders began to realize the benefits of having Hmong men or women able to communicate with American personnel and non-governmental organization workers. With the encouragement of their elders, these young Hmong men or women ended up working alongside foreign workers and being compensated for their services. Because of these experiences, the attitudes of many Hmong elders towards written language seem to have changed since then. However, change is slow for many, especially since access points into formal education 
are difficult to negotiate without formal language skills and a basic understanding of the structures of formal education.

Indeed, Xiong (2000) pointed out that Hmong parents' lack of formal educational experiences impedes their ability to engage in dialogue with their children's teachers and school administrators in the U.S. Furthermore, in reference to families of English Language Learners (ELLs) in general, Arias and Morillo-Campbell (2008) stated, "These barriers, which include the inability to understand English, unfamiliarity with the school system, and differences in cultural norms and cultural capital, can limit parents' communication and school participation (p. 1).

These are but a few of the significant obstacles Hmong parents need to overcome so that they can participate in their children's western style of education here in the U.S. Next, I describe another cultural gap that Hmong parents should negotiate to be involved in their children's education.

Understanding the role of parents in U.S. schools. Traditionally, Hmong parents have been taught to accept Lao formal education passively. This mindset creates a dilemma for many Hmong parents. On one level, they are encouraged to become involved in their children's classroom in the U.S. despite their lack of formal education experiences and lack of experience volunteering in schools in any manner. Yet on another level, Hmong parents were essentially culturally invisible to the school districts they came to where people understood very little about the culture belief, values and paradigms that influence Hmong refuges' perspectives about their role as parents in children's education. 
Problems created by this paradox continue to persist even after more than three decades in the U.S., where Hmong parents and children continue to struggle with school and navigating their roles within the system that in many ways, remain quite foreign to them. While school systems aspire to support equity for all students, few have deeply sensitive visions of the cultural diversity in their school populations or how to adapt in culturally sensitive ways to meet the needs of the multicultural populations.

Conflicting perception of the role of the teacher. Recall that in the Lao educational system, schools are hierarchical; schools employ a strict, top-down social structure deeply rooted in tradition (Bolman \& Deal, 2008). In a top-down pedagogical system, instructors are highly revered; parents rarely question the school curricula, administrators, or instructors.

Indeed, during my brief experience as a student in a Lao school, I found the teachers to be highly respected. Parents rarely questioned the schools, instructors, or pedagogical practices. Instruction was conducted in a teacher-centered model; students learned by emulating what the teacher modeled. Materials were generally written on the board for students to copy. After the materials were transcribed, students recited the materials at home until they memorized them and then recited the new knowledge at school through rote practice and drill until the learners achieved the satisfaction of the teacher. In fact, when interviewed, T. P. Bliatout (personal communication, January 25, 2016), one of the first Hmong students to study in the U.S. in the 1960s, affirmed this pedagogical practice as widely used throughout Laos during his experiences there. 
In the U.S., instruction is primarily student-based; students learn cooperatively and interact freely with their peers and instructors. In addition, parents in the U.S. are encouraged to interact with the teachers and participate in their children's education. This approach stands in stark contrast to what most Hmong parents have experienced or understand.

When Hmong parents arrived in the U.S., they were introduced to very different social and educational systems than the ones that they knew in Laos. The majority of the Hmong refugees simply lacked a frame of reference to understand how schools in the U.S. value parents' involvement and inputs (Adler, 2004).

For many, it remains quite difficult to see beyond the boundaries of long-standing Laotian educational paradigms that define the roles of school personnel and parents' roles dependent upon proscribed social hierarchies. Because of this, it is difficult for first and even second-generation parents to understand democratic models of parent involvements found in U.S. schools. The mismatch of social values creates a great deal of confusion for parents and students, and indeed for educators working to adapt to the needs of Hmong families.

Culturally-based assumptions. In studying Asian American parents, Sy (2006) learned that, as with most Asian parents, Hmong parents did not want to volunteer in schools and classrooms because they considered such activity "inappropriate or disrespectful for teachers, who have primary responsibility for children's learning" ( $p$. 109). This finding partly explains why, after three decades in the U.S., many Hmong parents still do not attempt to become involved in their children's classrooms. 
M. Lee (1998) further described Hmong parents' perspective in this regard. [They] "believed that [Lao] teachers know more than they do because of their high [levels of] education, and so they (teachers) are to be responsible for teaching and disciplining the students in the right way" (p. 8). In my brief experience with the Lao and Thai school, my parents often reminded me that the teachers were always right.

Indeed, many Hmong parents praise this pedagogical model because in many ways, the underlying beliefs implicit in this model align well with the informal, transmission modes of education that most Hmong parents experienced during their own youth and because this perception is indicative of attitudes found within throughout the formal system of education in Laos. Sy (2006) noted that Hmong parents who had knowledge of the Lao educational system "endorsed a clear separation of parent and teacher responsibilities and recognized teachers as the educational authority figures" ( $p$. 109). Due in part to their lack of formal educational experiences and narrow exposure to foreign travel, and partly to allegiances to the traditions of a homeland many wish to return to one day, Hmong parents generally assume the responsibilities of teachers in the U.S. education are the same as in the Lao system.

This attitude of allegiance to traditional ways of thinking is also a reflection of how Hmong refugee families are dealing with profoundly traumatic encounters with other American institutions as refugees that are here in this country fleeing from longstanding persecution of their people at home and because of their full participants in the U.S. Central Intelligence Agency's so-called Secret War in Laos. A resulting sense of disequilibrium and lack of self-efficacy in navigating unfamiliar institutions, including 
systems of education found within the U.S., are examples of the traumatizing effects of war, escape, refugee camp experiences, and resettlement.

Mistaken assumptions. Another barrier to parental involvement stems from the failure of school personnel in U.S. schools to distinguish between the Hmong culture and other Asian cultures. School administrators and teachers in the U.S. tend to assume that parental involvement is widely practiced across all Asian ethnic groups. They often mistakenly apply the so-called Model minority success stereotype to the Hmong (Ngo \& Lee, 2007) and believe that all Asian parents are culturally influenced to participate at very high levels in their children's education, including promoting and actively supporting both formal and informal education experiences. As a result, Hmong students were mistakenly grouped with other high achieving Asian students, such as Chinese, Japanese, or Korean. Outreach materials are frequently not adapted to be culturally relevant to Hmong parents within the ELLs community who are unsure of their proper roles within the context of an unfamiliar institution.

Another common misperception of Hmong refugees is that they came to the U.S. well prepared with English language skills that they could draw upon to adapt and transition into American schools and seamlessly enter the work force. Educators in the U.S. often incorrectly assume that Hmong parents have sufficient literacy skills to be involved in supporting their children academically and socially.

In fact, the educational gap between Hmong and mainstream parents' involvement significantly widens throughout the course of their children's education (Bondioli, 2000; Pomerantz et al., 2007). Oftentimes, when teachers learn that Hmong 
students are woefully under-supported at home to learn literacy skills, teachers lower their expectations for what Hmong students can learn and therefore the rigor of instruction for these students declines.

Impact of being a political refugee. An important point to recognize is the distinction between a political refugee and another type of immigrant; Ogbu (1998) worked to clarify this point by naming some important differences.

As part of his cultural-ecology theory, Ogbu (1998) observed that immigrants voluntarily leave a country, whereas refugees are involuntarily displaced by nation-state conflict. My experience has been that refugees are more traumatized by the experience of leaving their country than they would be had they chosen to leave at their own accord. He noted that as refugees were involuntarily displaced from their homeland following the Vietnam War, many had to cope with the loss of family members, comprises to their dignity and pride, and the uncertainty of starting a new life in a foreign country. As involuntary refugees, many felt helplessness as they were forced to work to acculturate to a new context and were encouraged by other immigrants to choose to assimilate into the dominant U.S. culture (Ogbu, 1998).

One of the most important distinctions between Hmong refugees and other immigrants is the wide spread desire to return to their homeland. Despite the fact that the return to Laos can carry serious risks, many Hmong refugees are still waiting for the right time to return to Laos when they are able. For some, this deep-seated hope makes acculturation while they are in the U.S. either undesirable or a low priority. 


\section{Examining Systems of Education Specifically Designed to Bridge Cultural Gaps}

When the Hmong refugees arrived in the U.S. and their children enrolled in public schools, parents began to see a void in curricula that did not address their language and culture. As was the case with other cultural groups, Hmong parents' frustration grew in response to the general lack of accommodations they found in schools for their culture.

In response, parents and teachers began to organize specialized schools. In the 1990s, with the endorsement of educators and researchers, states began issuing school vouchers for charter schools specifically designed to bridge cultural gaps (Kahlenberg \& Potter, 2014/2015). In 1992, Minnesota became the first state to open a charter school (Bailey \& Cooper, 2009). In subsequent years, Minnesota became a favorite destination for many Hmong refugees due to employment opportunities involving manual labor that did not require formal educational knowledge and skills. In addition, Hmong refugees find that living in the states with high concentration of Hmong in Minnesota offers many educational opportunities for their children that would help them to maintain their language and cultural identities. Today, Minnesota has the second largest Hmong population and the most Hmong charter schools in the nation.

\section{Hmong American Charter Schools}

Hmong charter schools were started by Hmong educators as an example of efforts to provide an alternative to Hmong families who felt that mainstream schools lacked cultural sensitivity. In most cases, Hmong educators who founded the charter schools are culturally competent themselves and are well prepared to design, test, and refine curricula that are culturally relevant to their students while at the same time providing knowledge 
and skills that will serve them well regardless of the culture they decide to live within as adults.

The Sunny Charter School. Interestingly, the mission statement of Sunny Charter School, a Hmong charter school acknowledges this goal of affording students' broad exposure to learning. Their mission statement reads, "To grow and nurture underserved scholars to become high-performing individuals through a brain-compatible education" (Xiong, 2015).

The participants of this study are four stakeholder groups associated with the Sunny Charter School (pseudonym) located in the Northern Californian region of the western U.S. I chose this Hmong charter school as the context of this study because the school exemplifies a charter school program that offers Hmong language and culture and "brain-compatible learning" that the four stakeholder groups involved in this studyadministrators, teachers, parents, and student - strongly identify with as a central feature of their school design.

Sunny Charter School and the community construct the teaching pedagogy around a brain-compatible learning that embodies hands-on and experiential learning (McGeehan, 2001). The approach is also known as brain-based learning and informs a set of principle for how people learn. It is believed that people's learning and daily activities are shaped by their experience rather than from genetic as previously thought (McGeehan, 2001). According to McGeehan, the brain and body are inseparable and interdependent, which explained why an activity that was done by hand could trigger the brain to recall the information in an instructional setting. Brain-compatible learning 
curricula typically involve active and kinesthetic learning such as learning involving physical exercise and emotional development involving the use of multiple senses such as practicing Taekwondo.

\section{Statement of the Research Problem}

The purpose of this mixed method descriptive case study is to examine what influences administrators, teachers, parents, and students to be involved in educational activities at a Hmong American charter school and how different stakeholders view parental involvement in education. Part of the problem that this research addresses is that very little research has been conducted to date that examines culturally appropriate parent involvement models involving Hmong families in U.S. public schools (Moua, 2004). Therefore, this study contributes to an emerging body of literature that will lay the foundation of understanding about culturally specific perceptions of the role of Hmong parents in education and the nature of one Hmong charter school community's efforts to support parents to become involved.

\section{Significance of the Research Problem}

Lack of parental involvement is problematic for schools, Hmong parents, and Hmong children in the U.S. (Bondioli, 2000). If teachers and schools do not address this issue in collaboration with Hmong families, Hmong parents will continue to refrain from interacting with their children's schools and from supporting them at home, to the detriment of their children's retention of knowledge of Hmong language and culture and to their overall academic success (Moua, 2004). 
Advocates for equity such as Arias and Morillo-Campbell (2008) claimed that it is important that schools incorporate culturally relevant programs that support and value parental involvement. Researchers such as Ngo and Lee (2007) and Moua (2004) advocated that programs prepare to effectively involve Hmong parents through strategies such as having people on staff that can relate to parents' needs and speak their native language, organizing activities that explicitly include parents, and welcoming cultural celebrations where parents and students see the importance of sharing their native cultures. To realize this goal, it is essential that school districts recognize the significant contributions that Hmong parents have to offer schools and the potential for what these families could contribute to enrich the educational experience for all students.

\section{Presentation of the Methods and Research Question}

My study used a qualitative, descriptive case study research design to examine attitudes and perceptions related to parental involvement in a Hmong charter school (Creswell, 2012; Plano-Clark \& Creswell, 2010). Qualitative research is an approach to case study that commonly used to explain a situated activity the researcher examines a highly contextualized situation because "a problem or issue needs to be explored" (Creswell, 2013, p. 47).

In the case of my study, the lack of Hmong parental involvement in public schools within the U.S. is a problem. Using a qualitative descriptive case study approach to elicit and examine situations surrounding the problem as it exists in one Hmong charter school provides the opportunity to develop a rich, thick description of the perspectives of 
multiple stakeholders in a particular context. Creswell (2013) explained why qualitative research presents a useful approach to such a study:

[Qualitative research] begins with assumptions and the use of interpretive/theoretical frameworks that inform the study of research problems addressing the meaning individuals or groups ascribe to a social or human problem. To study this problem, qualitative researchers use an emerging qualitative approach to inquiry, the collection of data in a natural setting sensitive to the people and places under study, and data analysis that is both inductive and deductive and establishes patterns or themes. The final written report of presentation includes the voices of participants, the reflexivity of the research, a complex description and interpretation of the problem, and its contribution to the literature or a call for change. (p. 44)

Creswell's (2013) description of qualitative research highlights the importance of addressing societal or human problems. Qualitative research examines and illuminates the meaning individuals and groups ascribe to their experiences. Based on a more complex understanding of the nuances of perspectives related to a societal problem, change agents are better prepared to address issues from a more culturally sensitive position than they would otherwise be prepared to do.

In the case of my study, qualitative research tools were helpful to elicit perspectives that may otherwise not be surfaced or addressed otherwise, such as misconceptions that school personnel frequently have regarding Hmong parental involvement in education. For example, teachers often make erroneous assumptions about Hmong parents' low involvement, falsely attributing their behavior to a lack of interest in their children's education. Teachers and administrators often fail to understand the issues many Hmong parents face; they assume Hmong parents are familiar with the U.S. educational system, have some formal educational background, and think 
that parents possess basic literacy skills necessary to engage in activities such as assisting children with homework (Thao, 2003).

On the contrary, as the case study approach in my study revealed, Hmong parents living in the U.S. tend to value education for their children highly. However, a key barrier that exists is that many Hmong parents do not know how to access the resources available through U.S. schools and the informal education community (Thao, 2003). Misconceptions and barriers such as those just described tend to lead to a stalemate wherein school personnel fails to provide assistance to parents to overcome barriers to involvement and parents assume that they have no role in contributing to their children's education (Adler, 2004).

Qualitative research is well suited for a study of parental involvement because it uses the "natural setting, the researcher as the key instrument, multiple methods, has complex reasoning, allows participants' meanings, enables an emergent design, offers reflexivity, and has a holistic view" (Creswell, 2013, p. 45). Conducting this descriptive research at a Hmong charter school provided a natural setting to elicit the perceptions of administrators, teachers, parents, and students.

In contrast to a typical situation found within a conventional public school setting, the Hmong charter school I studied was specifically designed with knowledge of some of the barriers and affordances for adapting supports to the needs of people of the Hmong culture living in the U.S. Therefore, using qualitative tools to elicit and describe some of the perceptions of those operating within this parental involvement model makes an important contribution towards efforts to develop an understanding of what works and 
what approaches have proven to be less successful in efforts to increase and support parental involvement among Hmong families and why.

With the goal of examining the situation found with a particular Hmong charter school, four research questions were designed to elicit the perceptions of multiple stakeholder groups; first to learn about the school's parental involvement model and then to learn about parent and student perceptions within the context of the model. The four researcher questions were:

1. What activities do you use to promote parental involvement in your school? (For administrators)

2. What activities have you used to promote parental involvement in your school? (For teachers)

3. What activities has this school offered for you to get involved in your children's education? (For parents).

Translation: Lub tsev kawmntawv no tau ua tejyam abtsi los pab rau koj paub txoj kev txhawb koj tus menyuam txoj kev kawm?

4. What school activities have you seen that influence your parents' involvement in your education? (For students)

Translation: Lub tsev kawmntawv no tau ua tejyam abtsi rau koj pom ua rau koj niam/txiv muaj siab koom koj txoj kevkawm?

\section{Key Terms}

In this section, I provide descriptions of 10 key terms that are highly relevant to this study. I begin by providing a definition of culture.

\section{Culture}

Culture is defined as knowledge, beliefs, art, morals, laws, customs, habits, and capabilities acquired by members of a given society (Trueba, Jacobs, \& Kirton, 1990; 
2014). While the majority of Hmong parents lacked basic knowledge of American culture when they arrived in the U.S., they possessed knowledge and skills bourn of the experiences of being a part of an agrarian society living within the context of a protracted war at home. Their worldview of the country they were forced to flee to, involved a warskewed vision of American goals, ideals, practices, and concepts.

Lacking basic culture awareness of their new home that many considered temporary, Hmong parents and children experienced a significant amount of culture shock. This absence of awareness combined with misconceptions of American culture extended to the American educational system. Many Hmong parents did not know how American schools function and could not adequately express their concerns about their children's education because of the cultural divide they experienced.

\section{Cultural Relevancy}

Cultural relevancy is a teaching pedagogy that embeds content, language, and practices that are sensitive to the background and culture of the learners. Involving instructional approaches that are inclusive and adaptive to people's worldviews to support students' ability to relate to curricula and to each other in social, situated learning environments. According to Ladson-Billings (1995), cultural relevant pedagogy should meet three criteria: “(1) the learner may 'experience academic success,' (2) build cultural competency, and (3) be conscious of the learning environment through "challenging the status quo"" (p. 160). 


\section{Hmong Culture}

Hmong culture is a largely homogenous culture that places great emphasis on long-standing traditions established by ancestors who are looked upon as guides who continue to inform the values, beliefs, and behavior of the living. There are two major groups of Hmong, the White, and Green or Blue Hmong, whose dialects and modes of dresses differ (Thao et al., 1989). However, the major distinctions between these two groups in terms of worldviews are quite similar.

For example, both involve rigid social hierarchies rooted in a patriarchal system wherein the male elders have the final say in decision-making and worldviews are slow to change. Both place great emphasis on stories and songs that provide guidance for right living and examples of problems that arise when people step outside of the bounds of tradition (Thao, 2006).

\section{Political Refugee}

Political refugee is a term that refers to a person who has left his or her homeland due to political pressures. Beyer (1981) defined a political refugee as (1) "persons or categories of persons who have left the territory of the state of which they are nationals; and (2) they become refugees as a result of their relationship with the existing government (ruling class)” (p. 27).

The Hmong people were allied with the American forces during the Vietnam War. In addition to the under-educated farmers, many Hmong came to the U.S. as soldiers, teachers, and police officers. Once the U.S. government withdrew from Laos, educators or public official were viewed as a threat to the Laotian government. Not only 
that, after the U.S. withdrew from Southeast Asia, the Communist Lao government pledged to wipe out every Hmong from Laos. This was a pledge that was taken seriously and resulted in wide spread persecution and the forced displacement of thousands of Hmong, regardless of their places within the social order before the war (HamiltonMerritt, 1993).

Again, the distinction between a refugee and an immigrant is that an immigrant voluntarily moves or resettles for economic or other reasons whereas a refugee is forced to flee for their very lives in search of protection from persecution. In the case of the Hmong people, they were forced to leave Laos because to stay would mean almost certain death or serious harm.

\section{Educational Background}

Educational background is the knowledge and skills people bring to their current situation (Bondioli, 2000). This background may include formal education, informal experiences or both acquired through institutions of learning, family upbringing, and cultural experiences. The term educational background as it appears in educational literature usually refers to the amount and type of formal educational experiences a person has had that affects the depth and range of what a person knows and is able to do.

\section{Informal Education}

Informal education is the learning that takes place outside of a typical classroom. In contrast with formal education, which typically takes place in a classroom or laboratory setting, informal education often refers to the oral transmission of educational knowledge and practices from one generation to the next in private homes, places of 
work, and in community gathering places such as temples and places where the arts are practiced.

For example, in many of the Hmong traditions, songs and chants are taught informally in private family homes and temples. The Hmong have used this oral approach to the transmission of knowledge from an elder to a protégé due to the lack of a written language and based upon long-standing tradition (Thao, 2003).

Despite the lack of a written language until recent times, the Hmong are quite sophisticated in accurately transmitting traditional knowledge. For example, in an agrarian society, farmers use a great deal of math to fertilize their crops, plan planting and rotations, and set and negotiate prices for their products. This knowledge is typically transmitted to children in a hands-on manner wherein young people are typically present for the discussions and problem solving related to routines such as buying and selling products and negotiating prices. From an early age, children engage in problem solving and planning such as performing measurements, analyzing and communicating results in every day applications in places such as on the farm or in the kitchen and comparing outcomes in highly practical ways. They would gradually acquire more advanced problem-solving skills through careful observations of phenomena such as crop responses to water and fertilization regimes, pest management strategies, and planting schedules.

In terms of human management, agrarian communities have highly structured hierarchies and decision-making protocols that largely dictate behaviors. Children come to understand roles and job descriptions/responsibilities through modeling; in other words, situated learning environments involving hands-on demonstration, practice and 
refinement of skills and knowledge in a manner that is oftentimes highly proscribed by tradition.

\section{Lack of Formal Educational Background}

Lack of formal educational background is an important factor in Hmong parent involvement. Only a very small percentage of Hmong refugees experienced formal education of any sort before coming to the U.S. In fact, most of the adults and their children who have come to the U.S. have not only never attended school, many are also unfamiliar with so-called free-choice educational experiences such as visiting museums, participating as audiences in community lectures outside of ceremonial events or events such as science fairs and professional conferences. Researchers have found that Hmong parents' lack of educational background contributes to their low participation in their children's education in part because they have no personal frame of reference for the types of educational activities they are typically invited to support in the U.S. (Arias \& Morillo-Campbell, 2008).

\section{Preliterate}

Preliterate refers to a culture in which reading and writing abilities are absent (Duffy, 2000). The Hmong did not have a reading and writing system until the 1950s, when French missionaries came to Laos and helped to develop a writing system using the Romanized Alphabets (Duffy, 2000). Even after the development of this writing system, most Hmong continued to live in remote villages and many were not introduced to the written language. Indeed, at the beginning of the first wave of refugees from Laos to the U.S. in 1975 , approximately $5 \%$ of the Hmong population could read and write in any 
language, a fact that explains why many Hmong parents find it difficult if not impossible to help their children with their schoolwork in English (M. Lee, 1998; P. Xiong, 2000).

\section{Motivation}

Motivation, as used in this context, is the aspiration and willingness to learn and support others to learn (Gonzalez-DeHass, Willems, \& Doan-Holbein, 2005). Every person is motivated - the desire or willingness to learn something. Research indicates that parental involvement positively motivates students to learn and achieve high academic performance levels (e.g., Cheung \& Pomerantz, 2012). An essential characteristic of parental involvement is that it motivates children to understand the benefits of acquiring new knowledge and skills that may help to advance their lives socio-economically (Gonzalez-DeHass et al., 2005).

\section{Parental Involvement}

Parental involvement refers to how parents engage in schools to facilitate children's success (Bondioli, 2000; Cheung \& Pomerantz, 2012; Epstein, 2005). The term is used interchangeably with parental support, participation, and engagement in the home, in the community, and at the school site (Larocque, Kleiman, \& Darling, 2011). Daily parent-child discussion about learning is one form of parental involvement. Other examples of parental involvement include helping children with homework, taking them to museums, supporting their involvement in team sports, and seeking out internship opportunities for them (Hernandez, 2011). Taking an active role in school governance, participating in school Parent Teacher Associations, helping teachers and administrators with field trips, fundraising, organizing social events, and volunteering in classroom 
activities are all typical examples of parental involvement in education that benefits more than just their own children.

\section{Summary}

The experience of being refugees has had a lasting effect on Hmong parents' adjustment in the U.S. In spite of having been in the U.S. for more than 30 years and having become parents themselves, the majority of the first-generation and even secondgeneration Hmong parents continue to struggle and be involved in their children's education. Those who arrived in the last migration in 2004 struggle to adapt despite the presence of potential Hmong mentors, mainly because those who have been in the U.S. much longer are still working to figure out how best to thrive within the U.S. system of education.

Because the formal system of education in the U.S. is radically different from what they knew in Lao, understanding of the American educational system among most Hmong parents is unclear. Hmong parents' inaccessibility to formal modes of education in Laos contributes to their lack of involvement in U.S. schools. In fact, the majority of Hmong parents had not been exposed to written Hmong or other languages before moving to the U.S. and thus, they lack basic skills to assist their children with homework or to volunteer in the classroom.

Cultural beliefs such as the proper role of teachers and parents and traditional attitudes related to the girls and education as well as misconceptions on the part of Americans toward the Hmong, continue to greatly influence perceptions that serve as 
barriers to parental involvement. For these reasons, Hmong parents are frequently reluctant to participate in their children's education.

With the goal of providing baseline descriptive data from multiple stakeholder perspectives to enable groups of teachers, administrators, and parents to design culturally sensitive and relevant parent involvement models. My case study examined perceptions related to parental involvement in their children's education at a Hmong American charter school in Northern California, located on the west coast of the U.S. My study offers a look at some of the key influences on the four types of stakeholders' perspectives related to parental involvement at Sunny Charter School.

In the next chapter, I present a literature review of the theories that significantly guide my study; the theories of social, human, and cultural capital and Vygotsky's (1978) zone of proximal development, the theories' applications and limitations. In chapter 2, I also present a review of literature that related to parental involvement. Specifically, I present literature linked to parent involvement among parents of ELLs and Hmong people. I present a brief history of parental involvement programs in the U.S. and the perspectives that brought about charter schools, including the Hmong charter school that was the focus of my study. 


\section{Chapter 2: Literature Review}

The purpose of this mixed method descriptive case study is to examine what influences administrators, teachers, parents, and students to be involved in educational activities at a Hmong American charter school and how different stakeholders view parental involvement in education. In this chapter, I provide a review of the literature on the major legislation relevant to the study of parent involvement. Next, I review the literature from Bjork, Lewis, Browne-Ferrigno, and Donkor (2012) on the theory of social, human, and cultural capital and Vygotsky's (1978) zone of proximal development (ZPD) to parental involvement and describes how these theories informed my study. Then I provide a synthesis on the parental involvement literature to understand some of the key cultural and educational boundaries Hmong people should navigate around. Finally, I review the methodological literature that informed and guided the study that aimed at helping administrators, teachers, and Hmong parents provide more support for their children's academic success.

\section{Review of the Research Literature}

Promoting parental involvement in the U.S. has been an important educational policy since 1965 under Title I of the ESEA (1965; Ngo \& Lee, 2007). The importance of parental involvement was reiterated with the passage of NCLB (2002), which reauthorized the 1965 legislation (Epstein, 2005; Hernandez, 2011) and then again with the revised ESSA passed in 2015. While NCLB represented a major step forward in many respects, for the first time the government legislated the explicit goal to support academic achievement for students regardless of race, income, zip code, disability, home 
language, or background (ESSA, 2015). As noted by ESSA, NCLB turned a bright light on where students were making progress and where they need additional support.

However, it was noted that the NCLB provisions turned out to be too restrictive in many ways, thus the ESSA (2015) legislation built in new support for innovative approaches to supporting equitable educational opportunities for all students. Examples of these new provisional include providing wrap-around support for vulnerable populations and support for developing culturally sensitive charter school programs (ESSA, 2015).

Importantly, Part E of the ESSA (2015) entitled Family Engagement in Education Programs involves two elements specifically designed to support parent involvement in education. The SEC. 4501, Purposes section reads as follows:

1. To provide financial support to organizations to provide technical assistance and training to State educational agencies and local educational agencies in the implementation and enhancement of systemic and effective family engagement policies, programs, and activities that lead to improvements in student development and academic achievement.

2. To assist State educational agencies, local educational agencies, communitybased organizations, schools, and educators in strengthening partnerships among parents, teachers, school leaders, administrators, and other school personnel in meeting the educational needs of children and fostering greater parental engagement.

3. To support State educational agencies, local educational agencies, schools, educators, and parents in developing and strengthening the relationship between parents and their children's school in order to further the developmental progress of children. (ESSA, 2015, Sec. 4501, Purposes)

This part of the legislation is based upon a well-established body of literature that supports the argument that parental involvement in education is important to students' academic success. For example, Epstein $(1988,2005$; Epstein et al, 2007) is a well- 
known researcher and parental involvement advocate who have contributed seminal work to the field showing evidence of positive outcomes of parental involvement in education. Other researchers have also demonstrated the significance of parental involvement in U.S. education (Bjork et al., 2012; Cheung \& Pomerantz, 2012; Larocque et al., 2011).

These researchers have demonstrated that effective parental involvement in children's education can take a number of different forms, such as the commitment of any resource "to the academic arena of children's lives" (Pomerantz et al., p. 374). This may involve parental support and participation at home, in the community, and at school (P. Xiong, 2000). Interactions such as daily parent-child discussions around learning particular topics and skills and negotiating social situations, supporting children with homework, participating in the school Parent Teacher Association, getting involved in school governance, and assisting teachers or staff on field trips, helping with fundraising; and volunteering in classroom activities are all powerful signals to children that parents are invested in their education and in the success of the school (Cheung \& Pomerantz, 2012; Hernandez, 2011; Hoover-Dempsey et al., 1987; Larocque et al., 2011).

In well-educated families, parental involvement often means "cognitiveintellectual involvement" (Pomerantz et al., 2007, p. 375). Pomerantz et al. (2007) cited examples of cognitive-intellectual involvement beyond participating in support schoolrelated activities such as "visiting the library, taking children to plays and museum or historical sites" (p. 375). However, although taking their children to such public activities is common in among families who are well acculturated to the western way of thinking about education, Hmong parents are only beginning to familiarize themselves 
with various informal education opportunities that are at their disposal to make available to their children. Their awareness of the importance of such experiences to their children's cognitive development is only recently emerging. However, just knowing about such resources and the importance of the experiences is not enough. As is the case with other families who speak English as a second language, given the fact that most of informal exhibits are very text-rich, most Hmong families need assistance with interpreting the meaning and implications of what they observe in these settings.

Pomerantz et al. (2007) noted that well-educated parents who accompany children to these sites and activities understand the educational values of informal education experiences and help children with "skill development and motivational development" (p. 376). Hmong parents and students, on the other hand, would concur that they do not generally engage in these activities, which places Hmong children at a disadvantage in comparison to their counterparts in school (Bondioli, 2000).

For example, my own under-educated parents who came to the U.S. as refugees from Laos did not have any stake in my education, nor was there a model in place within my own school-community that would have assisted my parents in learning about educational resources available in our community and how to access such resources. Thus, like most of the other parents of Hmong children, my parents were unaware of the importance of exposing me to informal educational experiences or accessing such opportunities. This story is not unique. Indeed, even after 30 years since the first Hmong refugees arrived in the U.S., there remains a dearth of culturally appropriate parental 
involvement models with elements specifically adapted to support families from different educational cultures from those found within this country (Vang, 2005).

In addition, Pomerantz et al. (2007) found that concerning skill development, children of well-educated parents are typically better off in comparison to children of under-educated parents because well-educated parents are better able to interpret regularly updated information on their children's progress in school. This ability informs their evidence-based choices as to how to supplement what is offered at school with skillbuilding experiences at home and in the community. Students with well-educated parents typically have more opportunities to learn from guided practice because their parents have firsthand knowledge about how to support children, access external supports to the family and school and purposely develop their children's cognitive skills.

Regarding motivation, parents who are involved in their children's education motivate their children to do well by emphasizing the value of education, actively participating in decision-making regarding their children' education, and modeling behaviors that serve to enable their children to prepare for the challenges they face in school and in the community (Pomerantz et al., 2007). Being able to support their children as they make important school decisions is critical for many well-educated parents, whereas Hmong refugee parents do not consider such support system essential for their children's educational success because they think of the responsibility of education as being situated solely with the school (Epstein et al., 2007). This is especially true with under-educated Hmong parents due to low levels of formal educational experience and unfamiliarity with the subject matter taught in modern, 
western schools. Painfully aware of their lack of preparation for supporting their children's education, most Hmong feel that it is wise to simply trust teachers and school staff such as college counselors to be the expert (Pomerantz et al., 2007).

\section{The Need to Help Bridge the Gap for Parents}

Research that demonstrates the importance of parental involvement in education and studies that show the lack of appropriate supports for parents to promote active involvement suggest a need to develop culturally appropriate parental involvement models in U.S. schools (Cheung \& Pomerantz, 2012). However, even though federal legislation mandates parental involvement, school districts rarely consider fostering such involvement a priority in the face of today's emphasis on high-stakes testing and accountability.

The failure of school officials to develop and implement parental involvement programs for children who are member of vulnerable populations most in need of support will only widen the achievement gap between Hmong children and other students (Larocque et al., 2011). Underserved students with under-educated parents are likely to suffer most from the absence of culturally appropriate parental involvement programs. This situation is exacerbated by the relative paucity of any consistent attempt by educational institutions to become aware of the diverse cultural capital of the student cultures they allegedly serve.

The growing need to better serve families in the face of school districts' lack of prioritization of parental involvement and issues impacting parents prompted a charter school movement in the U.S. in the 1990s (Kahlenberg \& Potter, 2014/2015). In the next 
section, I describe the emergence of the charter school movement and efforts within this movement to adapt models of parental involvement in culturally relevant ways.

\section{Emergence of Charter Schools}

In 1983, when A Nation at Risk was published, the report "prompted a wave of educational reform movements" emphasizing the improvement of science and math education (Bailey \& Cooper, 2009, p. 274). In 1988, education reformer Albert Shanker made a historic presentation at the National Press Club in Washington, DC, proposing a new kind of public school, a charter school (Kahlenberg \& Potter, 2014/2015). Shanker's proposal for creating less bureaucratic charter schools was met with optimism.

Charter schools are publicly funded by states and independently managed to try fresh and new approaches to teaching and learning (Kahlenberg \& Potter, 2014/2015). If a charter school improved the performance of students, the authorizing agency will renew its charter status. However, if the charter school does not succeed to improve levels of academic achievement among their students, the agency could revoke its charter status.

Charter school advocates cited frustrations and dissatisfactions with the traditional "factories, where students moved at the sound of a bell from class to class, teachers lectured to them for hours on end, and students were expected to learn in the same way at the same pace" (Kahlenberg \& Potter, 2014/2015, p. 6). Under the new charter school system, teachers were empowered and encouraged to collaborate, share ideas, teach as coaches, and allow students to learn at a pace at which they were comfortable (Kahlenberg \& Potter, 2014/2015). Given that teachers were empowered to try new teaching practices and students had the choice to choose what school they would attend, 
charter schools became popular for low-income, underserved, and minority students (Kahlenberg \& Potter, 2014/2015).

According to Zimmer et al. (1999), since the initial charter school movement in the 1990s, charter schools have become the fastest growing phenomenon in U.S. education. For example, before 1992, there was not a single charter school in the U.S. In 1992, the first charter school opened in St. Paul, Minnesota and after that, California quickly followed (Bailey \& Cooper, 2009). Since then the numbers of charter schools have steadily increased (Bailey \& Cooper, 2009; Kahlenberg \& Potter, 2014/2015).

With the backing of well-known educators and teachers, the number of charter schools grew " $43 \%$ in 2002 to $68 \%$ in 2013 " (Kahlenberg \& Potter, 2014/2015, p. 5). In fact, during the past two decades, the number of charter schools has exceeded 6,400 , serving more than 2.5 million students (Bailey \& Cooper, 2009; Kahlenberg \& Potter, 2014/2015). Currently more than 40 states and the District of Columbia have charter schools (Bailey \& Cooper, 2009; Kahlenberg \& Potter, 2014/2015).

\section{Motivation for Hmong Charter Schools}

The general reason for the establishment of charter schools was the desire to instill "pride; source of motivation; and a sense of understanding between students, teachers, parents, and community leaders" (Bailey \& Cooper, 2009, p. 282). Charter school advocates felt they needed to do more than what mainstream schools have done for low-income, at-risk, minority, and immigrant groups in racially diverse neighborhoods. Charter school proponents "sought to bring the benefits of their schools to the students most in need" (Kahlenberg \& Potter, 2014/2015, p. 11). In doing so, 
charter school educators felt that establishing alternative schools was one of many ways to close the achievement gap between white, middle class students, and historically underrepresented populations of color.

To provide a sense of the high level of diversity found in modern charter schools, Table 1 provides data related to 12 randomly selected charter schools found throughout the U.S. A high percentage of students in each school qualify free or reduced-price lunch and the high percentages of people of color. This demographic patterns found in these schools indicate that these particular schools attract significant numbers of families of color from low socio-economic backgrounds seeking innovative alternatives to the conventional public schools found in their neighborhoods. 
PERCEPTIONS OF HMONG PARENTAL INVOLVEMENT

Table 1

Characteristics of Charter Schools

\begin{tabular}{|c|c|c|c|c|c|c|c|}
\hline School & Location & $\begin{array}{l}\text { Year } \\
\text { Begun }\end{array}$ & $\begin{array}{l}\text { Grades } \\
\text { Served }\end{array}$ & $\begin{array}{l}\text { Number of } \\
\text { Students }\end{array}$ & $\begin{array}{l}\text { \% Free/ } \\
\text { Reduced } \\
\text { Lunch }\end{array}$ & $\begin{array}{l}\% \\
\text { ELLs }\end{array}$ & $\begin{array}{l}\text { Student } \\
\text { Ethnicity }\end{array}$ \\
\hline $\begin{array}{l}\text { Community of } \\
\text { Peace } \\
\text { Academy }\end{array}$ & $\begin{array}{l}\text { St. Paul, } \\
\text { MN }\end{array}$ & 1995 & $\mathrm{~K}-12$ & 684 & $83 \%$ & $60 \%$ & $\begin{array}{l}60 \% \text { Hmong } 30 \% \\
\text { African American } \\
10 \% \text { Latino } \\
\text { /Caucasian }\end{array}$ \\
\hline $\begin{array}{l}\text { D. Huerta } \\
\text { Learning } \\
\text { Academy }\end{array}$ & $\begin{array}{l}\text { Oakland, } \\
\text { CA }\end{array}$ & 1999 & $\mathrm{~K}-8$ & 215 & $90 \%$ & $92 \%$ & $\begin{array}{l}97 \% \text { Latino } 2 \% \\
\text { African American }\end{array}$ \\
\hline EC Reams & $\begin{array}{l}\text { Oakland, } \\
\text { CA }\end{array}$ & 1999 & $\mathrm{~K}-8$ & 344 & $45 \%$ & $12 \%$ & $\begin{array}{l}81 \% \text { African } \\
\text { American } 18 \% \\
\text { Latino }\end{array}$ \\
\hline $\begin{array}{l}\text { Erie Charter } \\
\text { School }\end{array}$ & Chicago, IL & 2005 & $\mathrm{~K}-3$ & 160 & $88 \%$ & $3 \%$ & $\begin{array}{l}69 \% \text { Latino } 17 \% \\
\text { African American }\end{array}$ \\
\hline $\begin{array}{l}\text { International } \\
\text { Community } \\
\text { School }\end{array}$ & $\begin{array}{l}\text { Decatur, } \\
\text { GA }\end{array}$ & 2002 & $\mathrm{~K}-6$ & 383 & $63 \%$ & $22 \%$ & $\begin{array}{l}56 \% \text { African } \\
\text { American } 10 \% \\
\text { Asian American }\end{array}$ \\
\hline $\begin{array}{l}\text { Lighthouse } \\
\text { Community } \\
\text { Charter }\end{array}$ & $\begin{array}{l}\text { Oakland, } \\
\text { CA }\end{array}$ & 2001 & $\mathrm{~K}-12$ & 359 & $79 \%$ & $63 \%$ & $\begin{array}{l}81 \% \text { Latino } 13 \% \\
\text { African American }\end{array}$ \\
\hline $\begin{array}{l}\text { IVY } \\
\text { Preparatory } \\
\text { Academy }\end{array}$ & $\begin{array}{l}\text { Norcross, } \\
\text { GA }\end{array}$ & 2008 & 6 & 120 & Data N/A* & $\begin{array}{l}\text { Data } \\
\text { N/A }\end{array}$ & $\begin{array}{l}\text { All girls; } \\
\text { Ethnicity data } \\
\text { N/A }\end{array}$ \\
\hline $\begin{array}{l}\text { Manzanita } \\
\text { Charter }\end{array}$ & $\begin{array}{l}\text { Richmond, } \\
\text { CA }\end{array}$ & 2000 & $6-8$ & 149 & $48 \%$ & $33 \%$ & $\begin{array}{l}70 \% \text { Latino } 9 \% \\
\text { African American }\end{array}$ \\
\hline $\begin{array}{l}\text { Neighbor- } \\
\text { hood House }\end{array}$ & $\begin{array}{l}\text { Boston, } \\
\text { MA }\end{array}$ & 1995 & PreK-8 & 399 & $72 \%$ & $66 \%$ & $\begin{array}{l}55 \% \text { African } \\
\text { American } 14 \% \\
\text { Latino 4\% Asian } \\
\text { American }\end{array}$ \\
\hline $\begin{array}{l}\text { Partnership } \\
\text { Academy }\end{array}$ & $\begin{array}{l}\text { Richfield, } \\
\text { MN }\end{array}$ & 2002 & $\mathrm{~K}-6$ & 192 & $97 \%$ & $76 \%$ & $\begin{array}{l}87 \% \text { Latino } 12 \% \\
\text { African American }\end{array}$ \\
\hline Rise Academy & Miami, FL & 2008 & $\mathrm{~K}-8$ & 200 & Data N/A & $\begin{array}{l}\text { Data } \\
\text { N/A }\end{array}$ & Data N/A \\
\hline $\begin{array}{l}\text { Univ. of } \\
\text { Chicago CS - } \\
\text { Donoghue } \\
\text { Campus }\end{array}$ & Chicago, IL & 2005 & $\mathrm{~K}-5$ & 320 & $73 \%$ & $\begin{array}{l}\text { Data not } \\
\text { re- } \\
\text { corded }\end{array}$ & $\begin{array}{l}97.4 \% \text { African } \\
\text { American }\end{array}$ \\
\hline
\end{tabular}

Note: Modified from Smith, J., Wohlstetter, P., Kuzin, C. A., \& Pedro, K. D. (2011). Parent involvement in urban charter schools: New strategies for increasing participation. School Community Journal, 21(1), 71-94.

Charter schools in Minnesota, Wisconsin, and California. The state of Minnesota's progressive charter school law has been a boon for Hmong families and 
other ethnic groups. As a result of progressive public policy, Minnesota has come to "host some 30 charter schools focused on students from specific ethnic or immigrant groups, such as Somali, Ethiopian, Hmong, and Latino populations" (Kahlenberg \& Potter, 2014/2015, p. 9).

In fact, the state of Minnesota is home to a number of schools serving the Hmong communities. For example, one of the earliest charter schools established in the country is a Hmong charter school established in 1995 called Community of Peace Academy located in St. Paul, Minnesota. Altogether, the Twin Cities alone has seven charter schools geared towards serving the area's Hmong population. California has the second largest number of charter schools, though well behind Minnesota and Wisconsin in the number of Hmong charter schools (Zimmer et al., 1999).

In addition, a study conducted by Bailey and Cooper (2009) found that Minnesota is the foremost state in supporting religious charter schools. These researchers found that the "religious line is not as apparent with a Hmong charter school; however, components of the animistic religious rituals and traditions are certain to prevail as students attend these schools" (p. 281). Bailey and Cooper (2009) noted that the Hmong charter schools “creates a sense of ownership of the community's education that establishes high expectation for every student, personalized fullest potential; maintains strong schoolcommunity partnerships; develops students' self-identity and learning of languages and cultures; and maintains positive behavioral standards" (p. 283). According to Epstein et al. (2007), these elements motivate parents to participate in their children's education. 
Bailey and Cooper (2009) found positive claims of student achievement in the charter schools they examined. They pointed out that students' academic achievement improved exponentially when the students were placed in the predominantly Hmong charter schools. The Hmong Times, an online publication of Hmong news and articles, published extensive reviews on Hmong charter schools in Minnesota pointing out the charter schools' positive impact on children's learning experiences (Ferdig, 2015). In contrast to the stories found in conventional public schools, parent involvement in Hmong charter schools stand out as an important element of the schools' design.

Bailey and Cooper's 2009 report on their research provided detailed accounts of parental involvement in Hmong charter schools. Importantly, their study identified potential triggers that stimulated unusually high levels of Hmong parental involvement found in the Hmong charter schools involved in their study. In the current study, parents and students reported that the Hmong language class triggered them to interact more with the language. Another potential trigger is the cultural events the school put on throughout the year. The findings provide an excellent starting point for qualitative research on the perceptions and attitudes of parents, students, teachers, and administrators in one Hmong charter school, including their perceptions and behaviors regarding parental involvement.

In recent years, California has joined other states in the charter school movement, becoming the second largest state with the numbers of charter schools, yet well behind Minnesota and Wisconsin in the number of Hmong charter schools (Zimmer et al., 1999). Indeed, the advent of charter schools in California appeared to be making a difference in 
terms of improving the levels of student achievement. Table 2 compares the student performances between charter and non-charter schools throughout California in a fouryear period.

Table 2

Results of Student Progress in California

\begin{tabular}{ccc}
\hline & Improvement of all Students & \\
\hline Year & Charter Students & Non-Charter Students \\
1999 API & 597.28 & 621.13 \\
2000 API & 626.7 & 649.13 \\
2001 API & 633.98 & 661.75 \\
2002 API & 648.55 & 672.75 \\
'99-02 improvement & 51.27 & 51.66 \\
Improvement of Socioeconomically Disadvantaged (SD) Students \\
Year & Charter Students & Non-Charter Students \\
1999 API & 485.02 & 503.56 \\
2000 API & 517.36 & 538.31 \\
2001 API & 533.95 & 557.23 \\
2002 API & 555.7 & 576.08 \\
'99-02 improvement & 70.68 & 72.60 \\
Improvement of Socioeconomically Disadvantaged (SD) Students in High SD Schools \\
Year & Charter Students & Non-Charter Students \\
1999 API & 457.51 & 481.81 \\
2000 API & 492.6 & 517.27 \\
2001 API & 510.73 & 539.79 \\
2002 API & 540.5 & 562.21 \\
'99-02 improvement & 82.99 & 80.40 \\
\hline
\end{tabular}

Notes: Modified from Rogosa, D. (2003). Student progress in California charter schools, 1999-2002. (Unpublished manuscript), Stanford University. Stanford, CA.

In addition, Figure 1 illustrates patterns of student achievement as indicated by statewide test scores for Sunny Charter School, the subject of my study. Data such as those depicted in this graph are one of the many reasons why Hmong parents are optimistic about Hmong charter schools and the potential benefits that these schools offer to their children. 
As the Figure shows, the Hmong charter school standardized test scores started out lower in comparison to state averages in the first year that the school was in existence. However, these statewide test scores improved significantly from the first year to the second year, falling slightly in the third year, but still exceeding the average test scores of school found throughout the state.

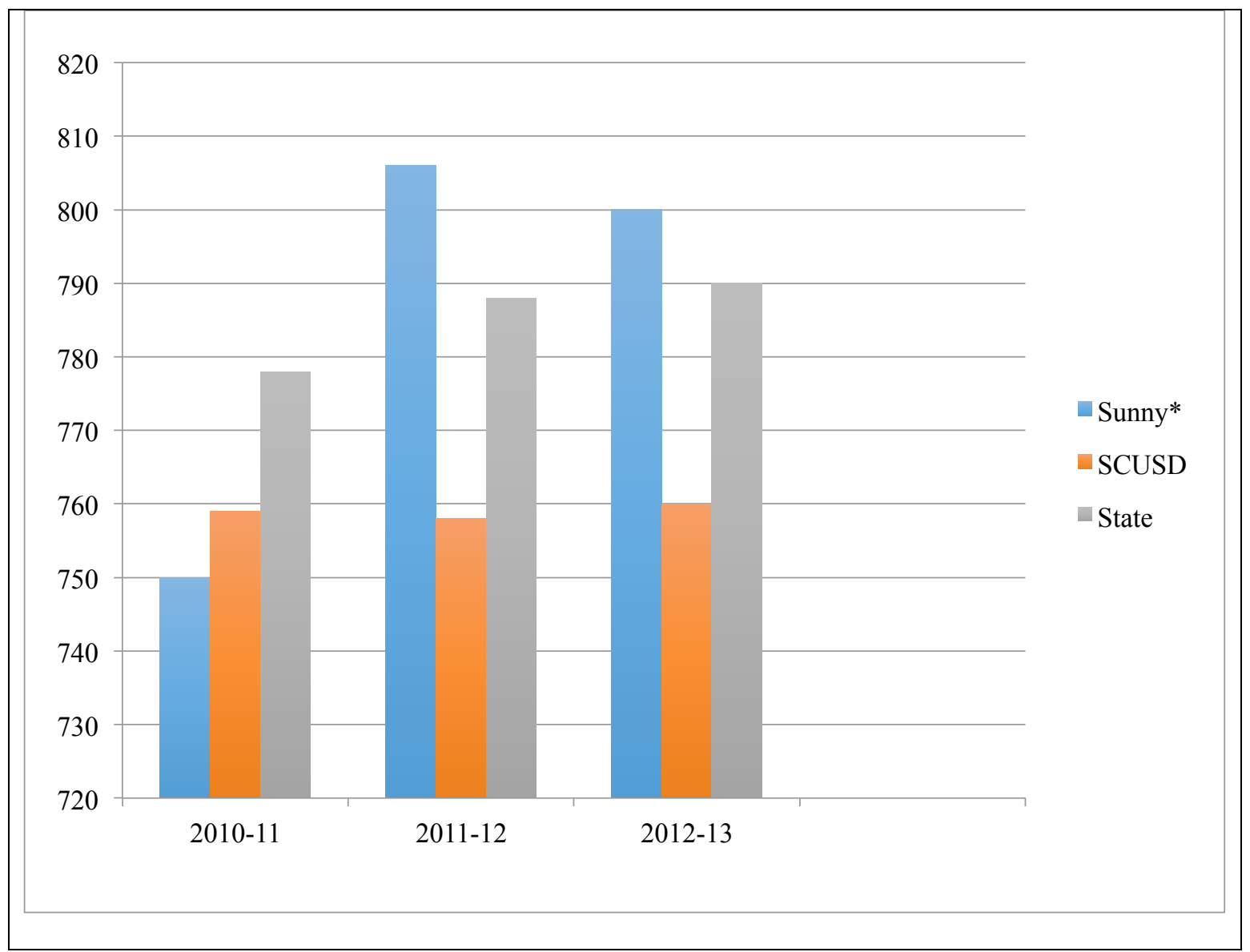

Note: Modified from Xiong, V. (2015). Yav pem suab academy: Independent charter. Presentation pamphlet to CSUSD Board, Sacramento, CA

Figure 1. Comparison between Sunny Charter School, district, and California schools.

Hmong charter school model. What should a Hmong charter look like?

Although there are differing opinions as to how a school should be designed, it is 
surprising to see that the Hmong charter in my study is not significantly different from other charter schools. In fact, most of the curricula used for core courses offered through the school are the same or similar to that found in all charter schools. However, in addition to the core courses, Hmong charters schools offer many extra-curricular or enrichment programs. For example, the Sunny Charter School's curriculum focuses heavily on body-brain compatible learning, a hands-on experiential learning approach (McGeehan, 2001) and Hmong language and culturally relevant pedagogy, elements that educators in the field of culturally relevant pedagogy strongly endorsed (e.g., LadsonBillings, 1995).

A difference found in the design of Sunny Charter School in comparison to conventional public schools with large numbers of Hmong students is this school's heavy emphasis on supporting Hmong parental involvement. According to Epstein (1995), there are six types of parental involvement in schools, each of which are purposely addressed by the Hmong charter school community I studied. Table 3 shows the six types of parental involvement described by Epstein. 
Table 3

Epstein's Model of School, Family, and Community Partnerships

\begin{tabular}{lll}
\hline Type & Description of Type & Examples \\
\hline Type 1 & $\begin{array}{l}\text { Basic obligations of } \\
\text { families } \\
\text { Basic obligations of } \\
\text { schools }\end{array}$ & $\begin{array}{l}\text { Providing children with basic needs such as health and safety } \\
\text { Communication between school and family such as memos, phone } \\
\text { calls, report cards, and parent-teacher conferences }\end{array}$ \\
Type 3 & $\begin{array}{l}\text { Involvement at school } \\
\text { Volunteering at the school to assist teachers in the classroom or } \\
\text { attending school events }\end{array}$ \\
Type 4 & $\begin{array}{l}\text { Involvement in learning } \\
\text { activities at home } \\
\text { Involvement in } \\
\text { decision- making, } \\
\text { governance, and } \\
\text { advocacy } \\
\text { Typelping children with homework } \\
\text { eollaboration and } \\
\text { comanges with } \\
\text { organizations }\end{array}$ & $\begin{array}{l}\text { Serving in a parent-teacher association (PTA), on committees, or in } \\
\text { other leadership positions }\end{array}$ \\
Type 6 & $\begin{array}{l}\text { Making connections with organizations that share responsibility for } \\
\text { children's education, such as afterschool programs, health services, } \\
\text { and other resources }\end{array}$ \\
\hline
\end{tabular}

Note: Adapted from Epstein, J. L. (1995). School/family/community partnerships. Phi Delta Kappan, $76(9), 701$.

Each school administrator, staff member, teacher, and parent that participated in my study understood their role at school and in the home; and each one reported that they frequently follow through to ensure that all six means of support to children's education is well attended to on a regular basis. Indeed, Sunny Charter School is unique; the high level of commitment to supporting and facilitating parent involvement set the school apart from schools that have been examined in other studies.

That said, I have yet to discover any studies that examined parental involvement within multicultural public schools that explicitly focused on adaptations for supporting under educated parents. Additionally, there is a lack of established tradition of using the same procedures and methods used in my study to examine similar social phenomena in other Hmong American charter schools found in the U.S. 


\section{Theoretical Framework: Social, Human, and Cultural Capital Theory}

Social, human, and cultural theory each provides useful lenses for examining the benefits of a strong relationship between Hmong parents and schools (Bjork et al., 2012). For two or more cultures to coexist peacefully_ in this case, Hmong parents and schools - the parties should build positive relationships with one another so that each group may access and leverage the social capital that each offer to make the school environment a healthy, supportive environment (Bjork et al., 2012).

Bjork et al. (2012) described social capital as "cohesion among members of a society and their collective ability to act on behalf of a common good" (p. 244). Social capital acts as a tool enabling schools to enhance students' academic success by facilitating parental empowerment to advance social justice, promote educational discourse, and provide multiple forms of support for students' education (Bjork et al., 2012). In essence, cohesion signifies a connection of social network between the schools and parents; parents can gain access to individuals in the school with powerful ties or associations that would expedite their children's movement along the social, academic, and economic ladder (Bjork et al., 2012).

Social capital first recognizes that people possess knowledge, skills and are able to do things that contribute to the greater good when working together to realize goals. Providing practical structures of support is critical to leverage social capital within any community. Providing well-design, culturally relevant supports in a school situation provides entry points for parents and other volunteers to invest in and join school staff, 
community organizations, and occupational institutions to realize benefits for parents and students and those who work with them (Bjork et al., 2012).

Bjork et al. (2012) defined human capital as the "stored body of productive skills, technical and intellectual knowledge, and psychological and judgmental capacities embodied in members of the society" (p. 247). These stored productive skills are fixed, however, unlike capital assets of money, land, or houses, human capital is an "investment in people, including education, training, and health to expand opportunities and choices that might otherwise be unavailable to them" (Bjork et al., 2012, p. 247). The capital is considered fixed because, unless the individual ages beyond his/her employability, after an individual obtains the capital, it remains with the person. Therefore, the difference between social and human capital is that social capital acts as cohesion between individual members in a community while human capital encompasses the total intellectual knowledge of a person within a productive society.

Cultural capital is the process of using "competencies, skills or qualifications, and symbolizes capital (e.g., prestige, honor, right to be heard) as important sources of power" (Bjork et al., 2012, p. 248). Culture is important to every society; it exists even in simple organisms. However, the difference between some other organisms and human culture is that humans cannot survive without culture.

Certainly, it goes without saying, Hmong cultural capital is a vast untapped reserve. The relationship between these three forms of capital is that a person can connect one's social capital to the individual's stored knowledge and transmit to the 
larger culture. Thus, people both draw upon and contribute to cultural capital based on the amount of social and human capital they have available to contribute.

\section{Theoretical Framework: Zone of Proximal Development (ZPD)}

Vygotsky's (1978) theory of the zone of proximal development or ZPD refers to "the distance between the actual developmental level (of a learner) as determined by independent problem solving and the level of potential development determined through problem solving under adult guidance or in collaboration with more capable peers" (Chaiklin, 2003, p. 40). In other words, it is the area between what the learner is able to do independently and what the learner can reasonably do with some help.

Chaiklin (2003) explained the concept as, "What the child is able to do in collaboration today he will be able to do independently tomorrow" (p. 40). ZPD operates on the premise that before a complex task can be learned, students should learn within their own zone with developmentally supports that gradually fall away and allow the learner increasing degrees of independence (Bruner, 1984; Kroll, 2004; Veresov, 2004; Vygotsky, 1978). Veresov defined ZPD as "the concrete and particular description of the relations between instruction and development" (2004, p. 1).

Vygotsky (1978) asserted that child development has two levels; he referred to these two levels of potential and actual. The potential level of development is the zone in which the process of maturation takes place (buds), and the actual level of development is the zone of matured development (fruits), (Veresov, 2004). During the potential level phase of development, the learner works his or her way through problems with help from other, more knowledgeable people. In the actual level of development, the learner is well 
prepared to solve learning tasks individually, thus learning scaffolds gradually removed, as the learner is able to operate independently.

Vygotsky’s (1978) concept of ZPD has many instructional pedagogical applications. Not only does ZPD apply to children as Piaget (1964) and Vygotsky (1978) suggested, but can also used to explain adult learning behavior. According to the age theorist, a person's learning does not stop simply because he or she has aged (Trotter, 2006). The age theory stated that learning is a lifelong activity, which it is worth noting that Vygotsky and Piaget's theories do not simply apply to child development but to adults as well (Piaget, 1964; Trotter, 2006; Vygotsky, 1978). In fact, Stevens and Cooper (2009) contended that adults continue to learn and scaffold knowledge as they age.

Stevens and Cooper (2009) further stated, “A central assumption of adult development is that development does not stop at childhood's end, but continues throughout the lifetime" (p. 34). I concur with Piaget and Vygotsky, who asserted that learning continues beyond age eighteen. For example, as refugee, Hmong parents construct scaffolding based on what they already know and are able to do. Their ZPD entry points regarding their transition to U.S. is determined in large part by what they already know about U.S. schools, the assumptions they bring about the roles of teachers and parents and their willingness to adapt to the new situation found within systems of education that are quite foreign to them. When parents draw on their experiences to reinterpret their roles and build new skill sets, they become more confident in helping their children in the home and for some, the heightened sense of self-efficacy extended to volunteer at school. 
The process of drawing on and building upon foundational knowledge and skills holds true for teachers and administrators as well; as administrators and teachers collaborate with Hmong parents, they gain the parents' trust and understanding that facilitates the continuous development of culturally appropriate adaptive supports to learning for all parties involved in children's education. Thus, the collaborative process becomes circular and the people involved become interconnected in multiple, complex ways. In the Hmong case, the scaffold of knowledge contains many new planks of support where Hmong construct concepts actively support cross-cultural learning and success.

\section{ZPD and Parental Involvement}

Vygotsky's (1978) concept of zone of proximal development (ZDP) offers a way for school administrators, teachers, parents, and students to understand some of the key issues related to barriers to and affordance of Hmong parental involvement in a charter school setting. Parental involvement entails a learning progression; just as children learn on a regular basis in the classroom through an interactive process that builds upon existing knowledge and skills, so do adults learn in a gradual manner (Knowles, 1970).

The concept of ZPD is applicable to Hmong parental involvement in U.S. schools because there is a distance, a zone, between what the parents know from their experiences in Laos and what is true of schools in the U.S. In the process of learning about appropriate forms of involvement in their children's education in the U.S., parents build what they want to know on what they already know (Vygotsky, 1978). Scaffolding is the process of building on previous knowledge. Teachers work with parents to build on parents' prior knowledge by providing forms of support explicitly adapted in a manner 
that draws upon social, human and cultural capital, making parents' ability to access and interpret more complex situations easier and requiring less support over time. Ultimately, by providing developmentally appropriate supports to parents according to their entry points as adults functioning with the Hmong charter school system, the array of supports provided may be gradually decreased while still helping parents to self-regulate (Zimmerman, 1990) their learning to reach their potential as parents involved in their children's education (Vygotsky, 1978).

Designing structures of support that consider social, human, and cultural forms of capital requires that teacher, administrators, and parents work together to learn how to scaffold supports to parental involvement in an adaptive manner. It is particularly challenging for schools working with highly intercultural populations given that the ZDP for the parents from different ethnic and cultural backgrounds may be highly diverse. However, in the case of Sunny charter school, which comprised primarily of bicultural Hmong teachers and families, the ZDP range for the group of parents appeared to be much narrower than one may see in more culturally diverse settings, which would make the school an excellent context for studying parental involvement structures adapted for working with the particular cultural group. That said, recall from chapter one that the Hmong people are strictly a homogenous group, and therefore understanding the construct known as zones of proximal development is a powerful tool for facilitating understanding of the range of Hmong adult learning progressions related to parental involvement from different stakeholder perspectives. In the next section, I discuss the review of the research literature that is relevant to parental involvement. 


\section{Synthesis}

Social capital is relevant for parental involvement as a person's ability to connect with the school or larger community is an essential predictor of the degree to which a parent is likely to become involved in their children's education. Without a sense of possessing social capital, parents have a low sense of self-efficacy. Therefore, without any supports for parents to understand what they have to offer their children and help develop skills to work in a collaborative manner with others to do activities, such as serve on committees and chaperone field trips, parents experience a sense of low social capital and are less able to contribute to not only their own children's education, but to serve the greater good for the school and other educational programs.

Thus, building up of social capital also involves building up human capital. For example, providing information to parents about school activities that require parental involvement using multiple modalities of communication such as audio-recordings of information spoken in Hmong and English and speaking directly to individuals' or groups of parents on a regular basis supports the development of parents' understanding of how or what they have to offer the school community. For example, specific ways that they can be involved and promote opportunities for near-peer mentorship wherein parents help each other in highly practical ways to become more involved in their children's school (Moua, 2004). In terms of cultural capital, these types of mentorship opportunities leverage Hmong parents' knowledge and skills related to how to present information to other Hmong parents in a culturally sensitive manner and cultivate a sense of trust and 
understanding of how they can adapt to U.S. modes of education while maintaining their linguistic and other cultural traditions.

These three forms of capital are vital to my study because of their relevance to the research questions. Recall that the questions were: what activities do you use to promote parental involvement in your school (for administrators); what activities have you used to promote parental involvement in your school (for teachers); what activities has Sunny charter school offered for you to get involved in your children's education (for parents); and what school activities have you seen that influence your parents' involvement in your education (for students)?

Each of these questions assume that Hmong parents do have important forms of the capital to offer, that effective charter schools recognize the importance of supporting the development of these forms of capital and leveraging capital as an important element of the school design, and that there is work to be done to realize these forms of capital for the good of the school communities. The open-ended nature of the research questions in my study reflect the ideas expressed in the few pieces of research that have examined Hmong charter schools thus far (Moua, 2004; Smith et al., 2011). For those involved in Hmong charter schools, people are viewed as collective communities where parents ought to be explicitly provided with resources to help them acquire the skills, mindset, and knowledge necessary to support their children in a gradual manner that recognizes that people operate within zones of proximal development. Therefore, knowledge of people's perceptions is necessary to adapt supports to effectively meet the developmental needs of parents as individuals and as a group (Moua, 2004). 
Social, human, and cultural capitals are important components in building positive relationships between schools and Hmong parents. Having prior knowledge that parents possess these three types of capitals provide common entry points for teachers and administrators to have conversations with Hmong parents about ways in which parents may be involved with their children's education. Bjork et al. (2012) emphasized that the two-way flow of communication helps "students improve academically, regardless of socioeconomic status, ethnic or racial background, and parents' educational level" (p. 244).

Bjork et al. (2012) suggested that the benefit of developing social capital extend beyond the social group, community, or society. For example, after Hmong parents learned how to read, write, and/or speak English, the acquired knowledge will remain with them for their lifetime if they continue to use and nurture the development of their language skills. When parents acquire and model their knowledge, they can influence other family members to read, and they can impart to their children the skills, values, and habits they themselves have learned (Bjork et al., 2012).

Social, human, and cultural capital theory applies to Hmong parents because it explains how they can mobilize their skills to benefit their children's education. For the parents at Sunny charter school, Hmong parents have numerous types of volunteering opportunities at the school. For example, Hmong parents can assist teachers by helping in the classroom, helping to organize culturally relevant events, chaperoning the students on field trips and school dances, or joining the Parent Teacher Association and fundraising events (Hernandez, 2011). With the bilingual-bicultural staff in place, 
parents and staff can more easily bridge communication issues that typically serve as barriers to parents choosing to get involved in these and other forms of involvement in their children's education.

However, Hmong parents did not always had the opportunity to freely express themselves in other school setting. For example, when Hmong parents first arrived in the U.S. in the mid-1970s and enrolled their children in mainstream schools, parents encountered a school culture that is very different from what they experienced. In contrast, providing culturally relevant activities and modes of communication that had been mostly absent in other schools provides with parents at Sunny charter school supports that access their cultural capital. As a result, Hmong charter school parents can access the resources that were only a distant dream not long ago.

\section{Critique}

Although the concepts of social, human, and cultural capital are useful in understanding Hmong parental involvement, each of these constructs do have limitations. Each of these theories tend to paint very positive scenarios wherein once people recognize and acknowledge the forms of capital that may be leveraged and built upon to work towards meeting a goal, progress is made in a very straightforward manner. However, in reality, people do not always progress in a straightforward pattern in the process of capital acquisition and realization of the potential of these three forms of capital. The concept of ZPD may illustrate the underlying developmental progressions involved when scaffolding in various types of parental involvement over time. However, the ZPD construct has its limitations too. 
For example, Vygotsky’s (1978) explanation of ZPD does not specifically address how the concept accounts for Hmong parents who have never been exposed to any formal education and lacks the foundational skills to work with and build upon. For instance, teachers and administrators who apply the ZPD construct when designing parent involvement models may assume that Hmong parents have some knowledge of school, at least of reading and writing, or some language proficiency in their own language.

However, in fact, due to political turmoil, geographical isolation, and educational beliefs, not all Hmong adults have had the opportunity to experience formal education and lack basic language acquisition skills. Therefore, teachers and administrators may incorrectly assume an entry point into parental involvement when in reality foundational literacy skills are simply not available to build upon.

Additionally, ZPD does not specifically explain how the process of transitioning from one learning zone to the next zone takes place. Because the majority of Hmong parents came from a preliterate society, many have never learned how to read or write in any language. As Ogbu (1998) indicated, the adaptation process for involuntary immigrants is much more complicated than the process for voluntary immigrants, and it is even more difficult for refugees. The traumatic experience of displacement without prior knowledge upon which to scaffold has left Hmong parents facing an uphill battle in acquiring new knowledge such as linguistic skills that in their prior experience, was widely viewed as unnecessary.

On top of coping with many daily challenges, parents faced unfamiliar schoolwork beyond their zone of knowledge development, leaving them overwhelmed, 
and frustrated (Veresov, 2004; Vygotsky, 1978). For Hmong parents to become involved in their children's schooling, they need to scaffold through the problems themselves within developmentally appropriate stages (Veresov, 2004). Therefore, Hmong parents need to develop learning strategies to help themselves move through each stage, or receive outside assistance to help to structure a gradual process of acquiring new skills and knowledge (Vygotsky, 1978). Given their limited personal experiences with learning within formal education contexts combined with limited experience serving as a mentor or guide to others negotiating new knowledge and skills, Hmong parents are at a great disadvantage.

\section{Review of the Methodological Literature}

Creswell (2009) identified four worldviews that shape and guide researchers' notions of truth and knowledge: post-positivism, constructivism, participatory, and pragmatism. Each of these worldviews, or paradigms, involves a basic set of beliefs and assumptions that guide action and research. Although different paradigms are used to explore this research problem, two of these research paradigms are involved in this study: the constructivist research paradigm and pragmatism (Mackenzie \& Knipe, 2006).

\section{Constructivist Research Paradigm}

The focus of this research is on the perceptions and attitudes of administrator, teachers, parents, and students toward parental involvement. Guba and Lincoln (1985) suggested that the constructivist research paradigm is useful for exploring the types of varied and complex perceptions of experiences involved in this type of research problem because constructivism regards the nature of reality and perceptions of reality as complex 
and multidimensional. The paradigm explicitly states that new knowledge is not constructed in a vacuum, but rather the ability to construct new meaning is dependent upon existing foundations of knowledge.

Epistemologically, knowers and the known are inseparable in the constructivist research paradigm because constructivists make a distinction between what people believe to be true and what is actually true, or whether people can determine the truth as obscure and unclear because the knowers and the known are inseparable (Guba \& Lincoln, 2005). Thus, constructivism does not seek to generalize, but to specify the situated problem. The constructivist research paradigm typically employs the use of qualitative research methods or mixed methods, which, in this case, serve to foster the development of understanding of the complexities of Hmong parental involvement.

\section{Pragmatism}

This research paradigm involves utilitarian research that explicitly promotes acceptance and understanding relevance (Vogt, Gardner, \& Haeffele, 2012). It is appropriate for this research because it "is not committed to any one system of philosophy or reality" but rather has the express goal of eliciting multiple perspectives shaped by the values, beliefs and attitudes of each knower (Mackenzie \& Knipe, 2006). In contrast to approaches such as the Critical Theory or transformational perspectives, pragmatic researchers use context and behavior to seek to access and understand perceptions of truth related to a particular matter under investigation without a predetermined social agenda in mind. 
Pragmatic researchers use mixed methods for the collection of data, such as interviews and observations, and often use analytical approaches that resist imposing predetermined biases that shape the interpretation of data. For example, in this case of this descriptive case study, by interviewing a number of participants who bring to the situation various perspectives as stakeholders, and developing a more contextualized understanding of their ideas by examining school materials designed to communicate key pieces of background data about the Hmong charter school, this research provides new knowledge that advances work in the field to develop understanding of what inspires Hmong parents to become involved in their children's education. From a pragmatic perspective, consideration of multiple perspectives within specific contexts is critical to efforts to develop culturally sensitive, relevant parent involvement models that are both inclusive and adaptive.

\section{Research Approach}

This study was conducted as a descriptive case study. Here, I will present a brief discussion about the descriptive case study approach and how it was used in this study followed by a description of participatory research and reason and why this approach was not selected as the most appropriate choice for this study.

\section{Descriptive Case Study}

The purpose of my descriptive case study is to explore what influences administrators, teachers, parents, and students to get involve in school activities at a Hmong American charter school. According to Stake (1978), case study is "useful in the study of human affairs because they are down-to-earth and attention-holding but that they 
are not a suitable basis for generalization" (p. 5). In this essence, my case study proscribed to understand the participants' perspectives on parental involvement in a Hmong charter school, not to generalize the perceptions of parents in the conventional schools. In addition, Yin (1981) stated that case study "can be used for exploratory purposes, either descriptive or explanatory to describe a situation, or test explanations" (p. 97). In my study, I sought to describe the activities that the Hmong charter school provides to the parents and students. Furthermore, Maxwell (2013) explained that case study research is an approach that "involves the study of a case within a real-life, contemporary context or setting" (p. 97). Thus, in my descriptive case study, I conduct an intensive examination of a small sample of cases at a Hmong charter school (PlanoClark \& Creswell, 2010; Vogt et al., 2012).

A descriptive case study may not necessarily look into the causes of phenomena per se, but oftentimes simply focuses on elucidating perceptions related to a problem. I employed this approach in this dissertation research because my goal was to examine the perceptions of a small group of participants to with the goal of describing perspectives about parental involvement from stakeholder groups in one small charter school designed for Hmong families rather than looking into a much more broad group of Hmong refugees (Vogt et al., 2012). To obtain the data, I followed Yin's (1981) data collection procedures, which include interviews, review of school artifacts, and observations.

\section{Participatory research}

This approach arose in the 1980s as a reaction against the male-dominant research paradigms of the time (Mackenzie \& Knipe, 2006). The participatory paradigm falls 
under the broad transformative worldview, which often involves the use of both qualitative and quantitative research methods.

This research did not involve the use of the participatory view because this study of Hmong parental involvement did not explicitly seek to address sexism or racism in the classroom or school community from a transformative perspective. Rather, this case study research was conducted with the goal of examining and describing multiple stakeholders' perspectives on parental involvement within a Hmong school, not to transform any of the participants or necessarily transform the perspectives of those reading this manuscript.

\section{Summary}

Although parental involvement researchers (e.g., Bjork et al., 2012; Bondioli, 2000; Cheung \& Pomerantz, 2012; Epstein, 1988, 2005; Epstein et al., 2007; Hernandez, 2011; Hoover-Dempsey et al., 1987; Larocque et al., 2011; Pomerantz et al., 2007; Xiong, 2000) have advocated for the implementation of parental involvement programs, many states have yet to fully comply because there is little accountability for fulfilling the policy. Despite clear mandates to implement parental involvement programs, schools have been slow to respond to the need despite the increasing numbers of second language speakers in the U.S. who are at a distinct disadvantage without well-designed programs that facilitate parental involvement.

The lack of attention to the issues and Hmong parents' unfamiliarity with the concepts of parental involvement widens the achievement gap between children with well-educated and under-educated parents. The lack of responsiveness to acute needs 
inspired educators to consider alternative ways to improve academic achievement through the development of the charter school system.

The U.S. has experienced a wave of development of charter schools in the last 10 years (Bailey \& Cooper, 2009; Kahlenberg \& Potter, 2014/2015; Zimmer et al., 1999). Bailey and Cooper (2009) and Zimmer et al. (1999) conducted a study that suggested positive academic outcomes among students enrolled in charter schools. The successes of charter schools prompted Hmong parents and students to choose the more progressive schools over the traditional schools. Due to the success of Hmong charter schools, more Hmong students and teachers may elect to support these progressive schools over conventional schools.

Given that Hmong charters schools are characterized by high levels of sensitivity to culturally appropriate approaches to educating children, it makes sense that they may also be sensitive to adapting their parent involvement models in culturally relevant ways. The social, human, and cultural capital theory and the ZPD theory have provided useful constructs for understanding and studying Hmong parental involvement in education in my study. Thus, my study explicitly builds upon existing knowledge of the importance of parental involvement and strategies that effectively support children's cognitive and social development by adding the perspectives of a program specifically designed to support Hmong families and communities.

In the following chapter, I present the methods used in my descriptive case study. I discuss the rationale for the choice of research methods, describe the research 
participants and how they were selected, explain the procedures, instruments and measures used, and describe how the data were collected and analyzed. 


\section{Chapter 3: Methods}

The purpose of my descriptive case study research was to examine what influences Hmong parents to be involved in supporting their children's education. The focus of my study was on the perceptions of four stakeholder groups associated with a Hmong American charter school, hereafter known by the pseudonym Sunny Charter School, specifically designed by Hmong educators and community members to facilitate culturally responsive pedagogy and parental involvement for 415 elementary students in grades kindergarten through six. These stakeholders or participants included parents, students, teachers, and school administrators associated with a Hmong charter school located in Northern California on the west coast of the U.S.

In this chapter, I present the research methods used in my study and explain the rationale for the selection of instruments and analytical approaches. Next, I include a section that describes the participants and how they were identified and recruited to the study. What follows is a description of the research design, the instruments, and procedures used in the study. I also describe issues related to validity, the role of the researcher, data collection, and analysis and finally, provide a summary.

\section{Research Methods}

My study used a qualitative, descriptive case study research design to examine attitudes and perceptions related to parental involvement in a Hmong charter school (Creswell, 2013; Plano-Clark \& Creswell, 2010). An approach to case study research is commonly used to explain a situated activity; the researcher examines a highly 
contextualized situation because "a problem or issue needs to be explored" (Creswell, 2013, p. 47).

With the goal of examining the situation found with a particular Hmong charter school, four research questions were designed to elicit the perceptions of multiple stakeholder groups; first to learn about the schools' parental involvement model and then to learn about parent and student perceptions within the context of the model. Recall that the open-ended research questions for my study were:

1. What activities do you use to promote parental involvement in your school? (For administrators)

2. What activities have you used to promote parental involvement in your school? (For teachers)

3. What activities has this school offered for you to get involved in your children's education? (For parents).

Translation: Lub tsev kawmntawv no tau ua tejyam abtsi los pab rau koj paub txoj kev txhawb koj tus menyuam txoj kev kawm?

4. What school activities have you seen that influence your parents' involvement in your education? (For students)

Translation: Lub tsev kawmntawv no tau ua tejyam abtsi rau koj pom ua rau koj niam/txiv muaj siab koom koj txoj kevkawm?

\section{Participants}

Again, my study took place at Sunny Charter School, a Hmong American charter school located in Northern California. The school is situated in a semi-urban area with a 
neighborhood park on the south, a busy front street to the east, and residential homes on the north. The back of the school has a gate surrounding a yard of green grass on the outer area where students often play kickball or other organized game. Closer to the school has a concrete area on the inside behind several portable buildings. The front of the school has several large trees hovering over a green yard. Overall, the school has a modern appearance and seemed to be in a relatively safe neighborhood.

Four categories of stakeholders were included in the study: two administrators, four teachers, six parents, and four students from the school. I describe the stakeholders in the following paragraphs.

The two administrators were first-generation Hmong males who came to the U.S. during the first waves of refugees. Both were in their mid-40s, bilingual and bicultural, highly educated, and well respected in the community. The superintendent had previously held other superintendent and principal positions. The principal was a bilingual schoolteacher before taking his current role at Sunny Charter School.

Two of the teachers were male and two females. These four Hmong teachers were first-generation, but two of the teachers came to the U.S. during the first wave while two came during the latter part of the second wave. One of the male teachers was the physical education teacher who received his undergraduate degree from a nearby university. He had been the physical education teacher for two years. At the time of my research, he was working on his Master's degree and plans to pursue his doctoral degree in the future. The other male teacher was a math teacher, who also came to the U.S. before the largest refugee camp in Thailand closed in 1994. The math teacher has a 
Master's degree from a nearby university and had been teaching three years. He also planned to enroll in medical school in the future. The two female Hmong teachers were also first-generation and came to the U.S. in the earlier part of the first wave. One of the female teachers has taught kindergarten for four years. The kindergarten teacher was in her mid-40s and had worked many years as a teacher's aide before returning to school to get her teaching credential. The kindergarten teacher also has a Master's degree. The other female Hmong teacher taught the Hmong language class who was in her early 40s. She also earned an undergraduate degree from a nearby university and had been teaching for four years.

Two of the six parents were first generation Hmong American males; both were in their mid-40s. One of the males came to the U.S. in the early 1990s, while the other male parent came to the U.S. during the last wave in 2004. One of these male parents had a full-time job, while the other was not employed. One of these two male parents graduated from a vocational training while the other parent had several years of schooling in Thailand but did not have any formal English education. The four female parents were first generation in their early 40s and mid-40s. Two of the female parents came to the U.S. in the last wave in 2004. These two parents had limited education in the refugee camp but did not have any formal English schooling. Both were stay-at-home mothers who cared for the children. The other two mothers came to U.S. in the earlier wave; both were employed full-time. These two parents had formal educational experience in the U.S. 
The last group of stakeholders included four students. The first student was a first-generation Hmong American female in the sixth grade. She was the student treasurer and seemed to be very motivated; she aspired to be a medical doctor. She was very talkative and appeared to be highly outgoing. The second student was a secondgeneration female in the fifth grade. She served as one of the secretaries of the student government. She was very active in Taekwondo, though she was unsure about her future career goals. The third student was a second-generation female in the third grade. She very shy and did not converse very much. She also served as a secretary for the student government. She was the only non-Hmong student being of Chinese descent. The fourth student was a second-generation male in the sixth grade. He served as the mayor of the student government. He was also very shy and did not converse much.

Overall, the administrators and teachers were successful first-generation Hmong educators. These administrators and teachers were also parents with children enrolled at Sunny Charter School. All of the six parents were first-generation with five of them coming to the U.S. during the latter wave. All of the students were first or secondgeneration.

I employed several sampling methods in my study, namely I used snowball, purposeful, and convenience. According to Vogt et al. (2012), snowball sampling is "asking individuals who have agreed to be interviewed whether they would suggest other individuals who might be willing to be interviewed" (p. 152). Purposeful sampling is the intentional selection of the site and participants (Plano-Clark \& Creswell, 2010; Vogt et al., 2012). Convenience is "a method of selecting phenomena (places, events, person, 
or documents) to study based solely on what is easy for the researcher" (Vogt et al., 2012, p. 339).

I chose Sunny Charter School because I want to conduct my research study at a Hmong American charter school, which was started by Hmong educators and the community. Before selecting Sunny Charter School, I sent requests to other charter schools in Minnesota and Wisconsin but they did not approve of my study. I purposefully selected Sunny Charter School because the school was the only Hmong charter school that accepted my research.

I began by recruiting the principal. After contacting him via email, I asked the principal and gained his permission to attend one of his staff meetings where I made a presentation to the entire body of school administrators and teachers asking for prospective participants.

After I presented my research to the staff, I received two self-selected teachers to participate. Once I have the names of the teachers, I purposefully asked them if they knew of other teachers who were willing to participate. I was able to get two other teachers through the purposeful sampling method.

After developing a list of four teachers who agreed to participate in the study, I conveniently asked the teachers for names of prospective parents who might want to participate in the study. This strategy ensured that the parents invited to participate in the study had some knowledge of what happens at the school. Another method that worked well was through the help of the principal, who conveniently approached the parents when they brought their children to school or came to pick up their children, and 
introduced me to the prospective parents. The principal merely introduced me to the parents; he did not specifically arrange or select the participants for my study. Thus, after a brief introduction, I asked the parents whether they would agree to participate in the study; if so, I gathered their information for further contact.

In the initial plan, once the group of six parent volunteers was recruited, I planned to ask these parents' permission to allow me to speak with their children about participating in the study. However, this strategy was not used because the school principal recommended that I contact the school team leaders or student government for my study. The principal's justification was that these students were more involved in school activities and would be more likely to have more insights on what was actually happening at the school in relationship to parental involvement.

Therefore, I switched my recruitment plan and followed the principal's advice by working with the school team leaders to develop a list of potential student participants. After I was provided with a list of students' names and their parents' contact information, I contacted each parents of these students asking them for permission to participate in the study. Upon gaining parental permission, I then spoke with the parents and children to schedule a time to conduct the interview.

Despite the approaches used to recruit the participants, given the fact that the school is a Hmong charter school, which seem to attract entire families into its fold, many of the members of the school are directly related to one another. Therefore, it was not surprising to find that with exception of one parent and one student, all of the individuals who agreed to participate in the study are known to each other in some manner. 
In accordance to Human Subjects Research protocol, I let the research participants know that all of their responses would be kept confidential and that their identity would not be shared with others. I also assured them that their participation in this study was strictly voluntary and that they could withdraw from the research at any time if they became uncomfortable and did not wish to continue. However, none of the parents or students who initially agreed to participate backed out from the interviews.

\section{Procedures}

Once the dissertation research committee approved the dissertation proposal in November 2015, I submitted an application to Portland State University's Institutional Review Board (IRB). After making two revisions, the application was approved by the PSU, IRB committee on December 18, 2015.

In addition to the protections for human subjects required by the institution, I was also sensitive to the school's environment and culture. I followed the school's protocols and made sure not to disturb school functions or create any activity that would be perceived as being harmful or distasteful to the administrators, teachers, or students.

However, despite my best efforts to ensure the students' comfort, it was difficult to maintain the same protocol when interviewing children participants given the lack of time to establish a positive rapport with the students. I found the student participants to be tentative and shy during the interviewing sessions. The children clearly found the experience to be a somewhat uncomfortable experience, especially because they were not used to being asked the type of questions posed during the interview. That said, the 
experience was certainly not one that could have been viewed as harmful to the children other than being slightly uncomfortable.

Throughout the data collection phase, I reminded the participants that all interview responses would be kept confidential. The participants were told that, in accordance with IRB protocols, recordings, transcriptions, and notes would be stored in a lock cabinet at my residence for a period of three years. Participant names and the name of the school would be assigned pseudonyms recorded in a confidential codebook that would also be locked up in the file cabinet. After the three years, all identifying information, my research notes, audio recordings, interview transcripts, and school artifacts are destroyed.

\section{Research Instruments and Measures}

In this section, I describe the two instruments used in my case study: interviews and school artifacts. I begin with a description of the interview protocol.

Interview protocols. I drafted a set of initial and follow-up interview questions inspired by examples from other studies (e.g., Valdés, 1996; Vogt et al., 2012). These questions were designed to inform each of the research questions; they were framed in a manner to elicit the perspectives of each of the four stakeholder groups including parents, students, teachers, and administrators.

The first set of interview questions presented here was designed for the school administrators and teachers:

1. In what ways does this school support parents?

2. Tell me why this school is different from other schools. 
3. Why do you think parents send their children to this school?

4. Tell me some of the before- or after-school activities this school offers?

5. What school functions do you use to attract more parents or encourage parental involvement?

6. How would you recommend this school to other parents or students?

The second set of questions was designed for the parents. Note that three of the interviews with parents were conducted in English and Hmong and three were conducted in Hmong with parents who possess low levels of English literacy.

1. In what ways does this school support your involvement? (Lub tsev kawm ntawv no txoj kev pab txhawb koj txoj kev koom zoo licas?)

2. Tell why this school is different from other schools. (Qhia kuv ib yam seb lub tsev kawm ntawv no ho txawv lwm lub tsev kawm ntawv zoo mus licas).

3. Why do you send your children to this school? (Yog vim licas koj ho coj koj cov menyuam tuaj kawm lub tsev kawm ntawv no?)

4. Tell me some of the before or after-school activities this school offers. (Qhia kuv tej yam uas lub tsev kawm ntawv no muaj pab rau cov niam/txiv thiab menyuam ua ntej thaum tsis tau nkag chav kawm ntawv kawm thiab thaum twb lawb lawm?)

5. How are you treated at this school compared to other schools? (Lub tsev kawm ntawv no tos txais koj licas muab piv rau lwm lub?)

6. Would you recommend this school to other parents or students? (Koj puas pom zoo txhawb thiab qhuas txog lub tsev kawm ntawv no rau lwm tus niam/txiv los yog tub kawm ntawv?) 
Finally, the third sets of questions presented here were designed for the student. Again, the interviews were conducted in English and Hmong, therefore the Hmong translation is provided here.

1. In what ways does this school support your parents' involvement? (Lub tsev kawm ntawv no txoj kev pab txhawb koj niam/txiv zoo txoj koom licas?)

2. Tell me what is different (unique) about this school. (Qhia kuv ib yam seb lub tsev kawm ntawv no ho txawv licas?)

3. Why and how do you like this school? (Vim licas thiab ua licas koj ho nyiam lub tsev kawm ntawv no?)

4. Tell me some of the before or after-school activities this school offers. (Qhia kuv tej yam uas lub tsev kawm ntawv no muaj pab rau cov niam/txiv thiab menyuam ua ntej thaum tsis tau nkag chav kawm ntawv kawm thiab thaum twb lawb lawm).

5. How are you treated at this school? (Lub tsev kawm ntawv no tos txais koj licas?)

6. Would you recommend this school to other students? (Koj puas pom zoo txhawb thiab qhuas txog lub tsev kawm ntawv no rau lwm tus tub kawm ntawv?)

The protocol was designed as a semi-structured, open-ended interview conducted one-on-one with each participant. The goal was not to get through the list of questions quickly or to maintain absolute fidelity by marching through the sets of pre-designed 
questions. Instead, the questions were designed to evince reflection, stimulate conversation, and gradually elicit perceptions related to parental involvement.

My role as a researcher during the interview was to explain the purpose of the research, what the interview would involve, ask the questions, audio record what each participant had to say during this conversation, and to ask follow-up questions for clarification.

Before beginning of each interview, I introduced the Consent to Participate in Research form (see Appendix A) for the adult participants. I read and explained each paragraph to the participant, checking frequently to ensure understanding and clarifying any points as necessary throughout.

In the case of children participants, I repeated the process with the Permission Form (Appendix B) and Child's Name (Appendix C). Each interview took place only after each participant clearly understood the forms and signed them.

During this process, I also asked each of the participant's permission to tape record the conversation. I realized that using an audio recorder could potentially be viewed as being intrusive and potentially make participants feel uncomfortable. In light of these possibilities, I worked to assure the interviewees that the recording allowed me to capture every audio nuance of the interview, would help me to avoid misinterpretations of their meaning, and that no one except for me would have access to listening to the audio recordings. Furthermore, participants were ensured that their identities would be kept confidential and that given that the recordings would not be shared, there would be no way that someone would recognize their voice on the recordings. The interview 
questions were provided orally and in writing and, as mentioned above, in the case of the questions designed for the parents and students, the questions were written in English and translated to Hmong. Each question was read to the participants during the interview one-by-one as the conversation progressed.

The interviews with the administrators and teachers took place in their office or classrooms, whereas the interviews of parents were done in various places, such as in their home and at school. The interviews of the students also were done in their home or at the school, depending on the parents and children's preferences (Vogt et al., 2012). During each interview, I sat across from or next to the participant at a table upon which I set the audio recorder. Each interview lasted approximately 30 minutes.

During the interviews, I collected field notes and made sketches to record significant observations. These field notes and sketches were later used as part of the data analysis process to ensure that I understood the context of the discussions and the nature of participants' responses. Notes about observations of each participant's movements, eye contact, and facial expression were recorded and later analyzed side-byside with the interview transcripts with the goal of gaining deeper insights into any available sub text involved in each of the conversations (Vogt et al., 2012).

School artifacts. During the interview with the principal, I inquired about printed artifacts. The interviewee emphasized that information about the school can be access online, but he provided a PowerPoint presentation and wristband as samples of artifacts. I collected the artifacts, as informational materials to understand the supports available through the school to promote parental involvement. I collected a 14-page PowerPoint 
presentation prepared by the principal to present to the school board for the school's petition for the renewal of the school charter. The slide presentation contained valuable information on the school's mission, standardized test patterns, geographical data related to the students, and various programs available at the school. I modified an illustration from the PowerPoint presentation on Figure 1 in Chapter 2.

I accessed the school website for other information, but preferred to focus data collection through "live" conversation rather than relying too heavily on printed materials. I did not observe any school newsletter; however, I did observe a large bulletin board (kiosk) in the front schoolyard with dates of upcoming events, such as testing, registration for new students, and performances.

\section{Role of the Researcher}

I worked to maintain impartiality with all participants (Vogt et al., 2012). In advance of conducting this study, I realized that maintaining impartiality would potentially be difficult because of my ethnicity as Hmong, my role in the community, or acquaintance through relatives with some participants due to extended kinship ties and shared culture. Although my contact with each person was limited, over the course of this study, I actively worked to build positive rapport with participants during our brief interactions. For the most part, this rapport enabled a free flowing conversation with the adult participants so that the respondents felt less intimidated to answer each questions. That said, the students were a bit uncomfortable speaking with a strange man, albeit in the safety of their own home or school. Nonetheless, I was able to establish a reasonably friendly rapport with the children and have productive conversations. 
Throughout the interviews, I maintained my impartiality primarily by refraining from asking leading questions and talking about my own experiences as a Hmong refugee and parent. I also maintained the use of formal, respectful language and demeanor rather than using informal language during the conversations.

My personal experiences as a Hmong student, parent, and educator may have brought up biases. However, as Creswell (2013) stated, having shared the participants' view as an insider, I argue that my emic perspectives serve as a benefit to the study. If I had brought to the situation an outsider's (etic) view of the Hmong culture and school environment, the shortcoming might have been a hindrance. Instead, the careful use of well-designed research questions, interview questions, the multi-staged coding protocol and use my notes served to control for potential threats to validity and raised my awareness of potential bias. These considerations served to ensure a level of neutrality necessary to accurately identify the themes that were actually present in the data.

\section{Data Collection and Analysis}

The interviews took place at the school, participants' homes, and/or a public place, so long as the locations were convenient and comfortable for the participants as recommended by Vogt et al. (2012). Each interview lasted approximately 30 minutes.

The principal emailed the PowerPoint presentation intended for the school board to me. Observational field notes, sketches, and interview notes were recorded by hand in a research journal during visits to the school and the homes where some of the interviews were conducted. 
After interviewing each of the English-speaking participants, I immediately listened to the recordings and then transcribed the responses of each participant using a visual coding model (Plano-Clark, \& Creswell, 2010). According to Plano-Clark and Creswell (2010), the coding process involved "segmenting and labeling [the] text to form descriptions and broad themes in the data" (p. 281). For the most part, I followed the work of Valdés (1996), whose work with the Mexican parents in Texas guided me in my study. In my visual coding model, following the interviews conducted in English, I transcribed the words from the open-ended question on the data collection form (see Appendix H). For the responses to the follow-up questions, I input the data in another data collection form (see Appendix I).

In the case of Hmong speaking participants, I translated each of the participants' responses into English as I transcribed their words. I also input their responses on the data collection forms. I did not transcribe the interviews verbatim throughout. Instead, I decided to summarize the participants' responses whenever their utterances strayed off topic rather than transcribing irrelevant conversation word-for-word. My visual coding model provided me with a clear view of my data.

Dialogical coding. To analyze the interview transcripts, I examined the participants' responses and created sets of thematic categories. To do this, after each of the interviews, I first listened to each of the conversations in their entirety to refresh my memory and focus my attention. Then, I read the transcriptions to prepare for the coding process. 
Each participant was assigned a set of initials identifiable only to me. Then, each response was recorded onto a data collection tables (see Appendices $\mathrm{H}$ and I) according to the related research question. Next, in the first stage of coding, I coded the entire responses per each question, and I assigned initial codes to each utterance. The codes were not predetermined rather they were based on the patterns derived from the data (Plano-Clark, \& Creswell, 2010, p. 282).

I developed an initial set of thematic categories by paying close attention to the repeated words found within the text and common themes. Each time a response appeared on the collection table that closely matched the meaning of a term or phrase already used, it was tallied on a table as part of a frequency count. This frequency count was not used to indicate a higher or lower level of importance of each utterance, but rather to identify similar comments among the interviewees and identify common themes to groups under particular codes to reduce the data to a set of themes useful to understanding the participants' various perspectives related to parental involvement.

After each interview was assigned sets of initial codes, all the coded responses were added to one table. Codes with the same meaning were counted and totaled. Thus, by preserving the frequency count of particular words that were used, I was able to contextualize these responses and analyze the importance of these words from a relative perspective. Furthermore, by comparing my field notes that captured nuances like facial expressions, body postures and eye contact, I was further able to note the context of the utterances. 
Then, in the final coding stage, words with the same meaning were combined to further reduce the data to a set of nine final codes or themes. I describe the nine resulting themes in chapters four and five of my manuscript.

Analysis of school artifacts. Next, I analyzed the school artifacts, the PowerPoint presentation, and the wristband. I found that the two artifacts collected from the charter school had little value in relation to understanding perspectives of parental involvement found within the school. That said, the PowerPoint presentation yielded useful background information related to changes in student academic achievement in the school as measured by statewide standardized tests and some information related to the enrichment programs, which provided a sense of context when the interviewees mentioned these programs.

\section{Research Timeline}

The timeline of activities for this research is described in Table 4. Overall, my study lasted approximately six months. I successfully defended the dissertation research proposal in the fall of 2015, acquired IRB approval in December 2015, collected and analyzed the data in the winter of 2016, completed the manuscript, and planned to defend the dissertation in the spring. 
Table 4

Research Timeline

\begin{tabular}{ll}
\hline $4 / 13 / 15$ & Defend proposal \\
$4 / 13 / 15$ to $10 / 12 / 15$ & Revise proposal \\
$11 / 2 / 15$ & Complete proposal revision \\
$11 / 2 / 15$ & Submit proposal to IRB \\
$12 / 3 / 15$ & Return proposal from IRB for revision \\
$12 / 17 / 15$ & Resubmit proposal to IRB \\
$12 / 18 / 15$ & IRB approve proposal and advance to candidacy \\
$1 / 5 / 16$ to $1 / 10 / 16$ & Visit school and recruitment of participants \\
$1 / 11 / 16$ to $1 / 16 / 16$ & Contact participants and conduct interviews \\
$1 / 20 / 16$ to $1 / 25 / 16$ & Transcribe and analyze data \\
$2 / 5 / 16$ to $2 / 29 / 16$ & Revise and write results \\
$3 / 1 / 16$ to $4 / 20 / 16$ & Edit and format dissertation \\
$4 / 26 / 16$ & Submit final draft to committee members \\
$5 / 10 / 16$ & Defend dissertation
\end{tabular}

\section{Validity}

There are several validity threats related to the methods used in this study. I begin by addressing how I controlled internal threats to validity.

In an effort to address threats to internal validity related to instrumentation, the interviews with the participants were conducted in a mixture of both English and Hmong, or whichever language they feel most comfortable with using now. I provided translations of the questions from English to Hmong. The interview questions were provided in writing and spoken aloud one-by-one throughout the interviews. Respondent were given opportunities to ask clarifying questions throughout each interview to ensure that they understood the meaning of each question. Furthermore, I asked clarifying 
questions throughout each interview to ensure that the participant understood each question and to ensure that I understood the meaning of their responses.

A second measure I took to address internal threats of validity was the approach I took to select the interview participants. By asking the entire body of teachers and administrators to self-select to participate in the study, I avoided potential bias in the selection process. Furthermore, by asking the principal to assist with approaching parents by having him randomly approach whomever appeared at pick-up and drop-off time, I controlled for potential selection bias. Finally, by asking the principal to provide me with a list of students to approach and then purposeful and conveniently selecting the names of the students I actually contacted, I further reduced the potential threat to internal validity. These approaches also controlled for external threats of validity related to the interaction of selection bias and the experimental variable.

My culturally influenced set of values and expectations as a Hmong refugee may have influenced the conduct and conclusions of the study. To control for external threats to validity posed by reactive or interactive effects, I limited the data collection process to only one, one-on-one interview with each participant rather than imposing a battery of multiple tools used to gather data. Thus, avoiding problems caused by the increase or decrease of the subjects' interaction with the experimental variable and to maintain my distance from the participants as a non-participatory researcher.

To further strengthen the validity of this study, I performed a member check on five individuals for clarifications; in other words, I asked that participants check the descriptions of their responses and perceptions to ensure correct interpretation of their 
meanings. I emailed both administrators to clarify the PowerPoint slides and asked permission to use the data, in which they approved. I called one teacher to provide clarification on the enrichment program some teachers used, which he happily obliged and gave me the information. The two other members were parents, who I called to get clarification on when they arrived in the U.S.

Relying on inferences from realist questions may lead me to draw "unwarranted conclusions, ignoring potential validity threats such as participants' deliberate or unintentional distortions of the actual effects on them" (Maxwell, 2013, p. 81) or might introduce my possible biases. The practice of checking with those interviewed to ensure correct interpretation of meaning is an important way to prevent any biases and misunderstandings, which might surface from what is recorded. Furthermore, using interviews and field notes involving self-reflection and observations made during the interviews and data analysis period reduced the risks associated with systematic biases due to using just one method.

\section{Summary}

The purpose of my qualitative descriptive case study was to describe perceptions related to Hmong parental involvement in their children's education. My study involved recruiting representatives from stakeholder groups, administrators, teachers, parents, and students, who are each involved in a Hmong American charter school. Sunny Charter School is a K-6 Hmong American charter school located in Northern California with approximately 415 students. The 16 participants interviewed for my study were purposefully selected from particular pools of potential participants. 
Two forms of data were collected in my study: interviews with representatives of the four stakeholder groups and two school artifacts. The interviews were conducted using two sets of interview questions - open-ended and follow-up - explicitly designed for the following four stakeholder groups: the administrators, teachers, parents, and students.

The interviews were transcribed and dialogically coded to describe patterns found with the utterances. As a result of my analysis, I categorized nine major themes from the data related to parental involvement in Sunny Charter School. Next, in chapter four, I describe each of the nine themes along with a description as to how each of these themes informs the research questions. 


\section{Chapter 4: Results and Analysis}

Hmong parental involvement in their children's education is typically quite low, which has been a disadvantage to Hmong children in many ways. My study contributes to a growing body of literatures that seek to understand perceptions of Hmong parents as they negotiate their roles within the U.S. system of education (Moua, 2004). Specifically, this research aims to address the lack of research related to parent involvement among Hmong communities by contributing to baseline knowledge useful to develop culturally responsive models to involve Hmong families in U.S. schools.

Recall from chapter one that the focus of my study is Sunny Charter School (pseudonym) in Northern California and the perceptions of four stakeholder groups: administrators, teachers, parents, and students associated with the school. Sunny Charter School was chosen as the context of my study because the school design provides an opportunity to examine multiple stakeholder perspectives about parent involvement within the context of a school specifically designed to accommodate the needs of Hmong refugees.

A major feature of the school design is brain-compatible learning principles that are based on biological factors related to how people learn. The school offers extensive hands-on learning opportunities through culturally relevant curricula, such as enrichment courses in Hmong language and culture that each of the four stakeholder groups involved in my study strongly identify as central features of their school design.

In this chapter, I present the approach used to derive the nine themes related to parent involvement found in the school. Next, I present the nine themes and describe each of the stakeholder groups and provide a brief description of the individuals who 
represented the stakeholder groups for interviews. Subsequently, I describe their perspectives related to the research questions.

Next, I once again present the nine themes derived from the interview data and describe how each of these themes are relevant to what motivates and sustains parental involvement at Sunny Charter School based on responses to the follow-up interview questions. Then I discuss the limitations of my study and end with a chapter summary.

\section{Analysis of Data}

After interviewing each participant, I listened to the conversation and transcribed the response using a visual coding model (Plano-Clark, \& Creswell, 2010). Plano-Clark and Creswell (2010) described the coding process as involving the "segmenting and labeling [the] text to form descriptions and broad themes in the data" (p. 281). My visual code model is different from the one Plano-Clark and Creswell illustrated, but it presents a visual organization of the data I am most familiar with (see Appendices H and I).

When analyzing the interview transcripts, I examined the participants' responses and created sets of thematic categories. The process allowed me to listen to each conversation in its entirety and identify patterns to develop thematic categories.

An initial set of thematic categories was developed by paying close attention to the repeated words found in the text and common patterns of perceptions described by the participants. Each time a response appeared on the collection table that closely matched the meaning of a term or phrase already used, it was tallied as part of a frequency count. The frequency count was not used to indicate a higher or lower level of importance of each utterance, but rather to identify similar comments among the interviewees and 
identify common themes to group under particular codes to reduce the data to a set of themes useful to understand the participants' various perspectives related to parental involvement.

After each interview was assigned sets of initial codes, all the coded responses were added to one table. Codes with the same meaning were counted and totaled. Thus, by preserving the count of the frequency that particular words were used, I was able to contextualize these responses and analyze the importance of these words from a relative perspective. In the final coding stage, I combined words with the same meaning to reduce the data to a set of nine final themes.

\section{Presentation of Results}

I identified nine themes related to Hmong parent involvement. The themes were:

- Communication with parents through email, telephone, verbal reminder, meeting, home visit, radio, or television programs: stakeholders should have an effective communication system in place

- Committee involvement such as PTA, ELAC, Fundraising, or policy: encourage parents to participate in decision making

- Flexibility of staff, open door policy, welcoming to parents, or students: flexible staff that can meet parents' needs

- Enrichment programs: dance, music, movement, Taekwondo, Hmong Language class that are culturally relevant programs that stakeholders can relate to

- School schedule or instruction: nontraditional schedule that stakeholders embraced

- Importance of field trips: all stakeholders believe in experiential learning

- Cultural events and presence of other cultures: performance of different cultures are valued 
- Recommend school to others: stakeholders likely to recommend the school to others

- Behavioral reinforcement: positive reinforcement instead of punishment is more effective

These themes were not hierarchically ordered by importance.

\section{Stakeholder Groups and Their Perspectives}

The stakeholder groups selected for interviews were the school district superintendent and the school principal, four teachers, six parents, and four students associated with Sunny Charter School. I interviewed 16 participants.

There are several reasons why these stakeholder groups were selected for the study. Rather than recruiting people in the Hmong or educational community who have only theoretical knowledge of the school design, I chose to elicit the perceptions of those who are familiar with the school itself on an on-going personal basis and who directly participate in parental involvement activities in some manner.

Recall from chapter three that I employed the use of snowball, purposeful, and convenience sampling methods to select the site and the study of participants (Maxwell, 2013; Plano-Clark \& Creswell, 2010). The 16 people who were selected to participate in the study were selected from pre-determined pools of potential participants. These pools included administrators and teachers in the first pool and parents and students in the second pool of potential participants.

What follows is a brief description of the participants who interviewed. The background data is coupled with a reminder of the interview questions posed to each stakeholder group. 
Administrators. Recall that both the superintendent and principal are Hmong males, highly educated, and fluent in the Hmong language. They were in their mid-40s respectively, both with extensive teaching, supervisory and administrative experiences. The open-ended research question posed to the administrators was: What activities do you use to promote parental involvement in your school?

Administrators' perspectives of parental involvement outreach in the school. I had an opportunity to ask the superintendent about some of the activities he used to promote parent involvement. Although his role as superintendent limited him from directly getting involved with parents at the school, he discussed what he used to overcome the challenges of recruiting parents to enroll their children at Sunny Charter School during the different phases of the development of the school. He explained,

At the initial stage of the charter school, I would walk the streets and street corners handing out brochures to parents to recruit students. I would go to the radio station and Hmong TV programs to do announcements or drop off public announcement materials for programmers to broadcast about Sunny Charter School. (Personal communication, January 11, 2016)

The superintendent shared that once the charter school was up and running, over time more parents started to get involved at the school. He explained that it is important to involve parents in their children's education. I asked him what strategies he used to involve parents. He elaborated by saying,

I would email, call, or talk to parents in the hallway asking them to volunteer, and remind parents to get students to bed early so their children could get up in time for school. It is important to communicate, encourage, and remind parents the importance of being involved in their children's education. (Personal communication, January 11, 2015)

The superintendent often participated in many of the daily routines at the school, including talking to the principal, staff, parents, or students and in some cases, taking part 
in activities with the children. For example, during one morning before school started, I observed the superintendent dressed in a suit and tie standing in line with the students in the concrete playground. As music played in the background and an instructor directed each movement, the superintendent joined the morning exercise routine and danced along with the teachers and students. I observed that the superintendent's unique character, and the fact that he sees himself as a student, teacher, parent, and an administrator seemed to bring great joy to everyone.

When it came to interview the principal, I asked him the same question. Instead of describing the activities he used to promote parental involvement, he discussed what he did to encourage teachers to get parents to involve. For example, he stated that before each school year begins, he encouraged teachers to conduct home visits. These home visits enable teachers and parents to develop a positive rapport with parents and for the teachers to be acquainted with the students. He described that,

During the home visit, the teachers would introduce him or her to the parents, inform the students of who the upcoming teacher, and invite parents and students to attend the back-to-school night and familiarize themselves with the school and classroom. These activities serve as icebreakers for teachers, parents, and students. (Personal communication, January 11, 2016)

In keeping with the spirit of my comment made by the principal, according to the superintendent, one of the main approaches the school uses to get parent involved is to show the parents that the staff care about their children's future success. He emphasized that once parents saw that and the staff gained their trust as educational partners interested in the same essential goals, parents will want to get involve.

The principal also stated that he strongly believed in the importance of establishing trust and then maintaining the families' confidence by following through 
with his words. He shared that if he modeled his ideas and follows through each time, then parents and students seemed to imitate the behavior as well.

The principal described various ways that he works to maintain positive relations with families such as making sure to acknowledge and praise parents for their contributions to the school and their own children's education. For example, he emphasized that when he regularly attends the Parent Teacher Association meetings, parents see the value of their involvement as well.

Teachers. Recall that two of the teachers are female and two are males. The teachers are relatively young, all ranging in their mid-30s and 40s. One of the teachers was in his late-20s. One of the male teachers teaches math and the other teaches physical education, while one of the female teachers teaches the Hmong language class and one teaches kindergarten respectively. The open-ended research question I posed to the teachers was:

What activities have you used to promote parental involvement in your school?

Teacher perspectives of parental involvement outreach in the school. According to all the teachers, there were many different reasons for the parents to get involved at Sunny Charter School. For example, parents can volunteer in the classroom, tell stories, chaperone during field trips, help organizing school events, perform traditional musical instruments, and participate in other cultural performances. The Hmong language teacher explained the school parental involvement policy:

This requirement is clearly stated in the brochure so parents feel they are accountable to meet the hours. Since the teachers and parents agreed to this requirement at the beginning of the school year, many parents felt obligated to do what is in the agreement. (Personal communication, January 12, 2016) 
However, two of the teachers indicated that the volunteer policy alone is not sufficient to recruit parental involvement in the school. According to these two teachers, throughout the school year, the school works to actively communicate the many different events happening at Sunny Charter School to involve parents so that parents will have a variety of choices for how to involve themselves in the school. One parent said parents often work to organize, communicate, and collaborate with teachers and staff members about volunteering opportunities at the school. For example, teachers regularly organize events through the support of the parents. They engage student involvement in these events by having the children perform a variety of different demonstrations of skills they are learning in school such as dance, exercise, or Taekwondo.

The two female teachers shared that they often ask parents to help them organize activities at school such as performing dance, music, or demonstrating Taekwondo. One special kind of performance for parents was to show and perform their traditional qeej instrument and showed students how to play the traditional spin tops or play the ximxau instrument (a two string instrument, similar to a banjo). Parents are also invited to do Zumba dance with students and grow vegetables in the school's community garden.

These two female teachers shared that they encourage parents to be involved in their children's education by asking them to go on field (study) trips with students. The teachers said all the field trips have been successful because of the parents' involvement.

In addition to serving student learning outcome goals, a key purpose of the school events and activities such as school garden projects and fieldtrips are to bring the parents into the fold of the school community, encourage a welcoming school environment, and 
increase their understanding of the school system. One outcome goal in developing a sense of community, teachers hope that parents will find their places within the school such as seeking opportunities to become involved in their children's classrooms by supporting enrichment programs.

Last year, the kindergarten teachers organized an event around mother's and father's day wherein the parents came to the school and participated in specially organized activities with their children. The kindergarten teacher described:

For mother's day, I invite every parent to come. If a parent cannot come, she must find an aunt, grandma, or someone to represent the mom for that day. Last year every mom came. For the day, I have an activity for the child and mom to do together as 'mother's day'. The children and moms get to sing 'Happy Mother's Day' together. Last year I also organized a 'Father's Day' for all the dads to come. Again, if a dad cannot come, he must also find an uncle, grandpa, or someone to represent him. The child and dad get to do activities together for the day. For this activity, I see that it brings the parents over when we ask them to come. It was our hope that parents would come, and they did. Overall, this event brings parents over and allows the scholars to participate in the activity with the scholars. (Personal communication, January 12, 2016)

The teachers added that it is important to ask the parents to help in classroom.

Teachers said that they sense that parents want to help, but unless the teachers ask, parents will not necessarily volunteer. However, teachers have found that when they delegate parents to do something in the classroom or in another part of the school, parents will often respond positively.

Parents. Again, six parents were interviewed, four females and two males. All of the parents are Hmong and about half of the parents are fluent in English, whereas the other half came to the U.S. during the last wave of refugees in 2004 and able to communicate in basic English. Three parents held full-time employment. Three parents were in their mid-40s and all had fled Laos at an early age with their parents and spent 
the majority of their youth and teenage years in Thailand as refugees before coming to the U.S. as parents in the last wave. The other three parents were also in their mid-40s and came to the U.S. during the second wave.

The open-ended research question I posed to the parents was: What activities has this school offered you to get involved in your children's education? Translation: Lub tsev kawmntawv no tau ua tejyam abtsi los pab rau koj paub txoj kev txhawb koj tus menyuam txoj kev kawm?

Parents' perceptions of parental involvement. As I related the interview questions to the parents, about one-third of them reported knowing the school's parental involvement requirement. One of the female parents who came to the U.S. in 2004 reported, "The school encourages me to volunteer 40 hours during the year so I come to the school as often as I can." Other parents said the school has asked them to go on field trip and chaperone the children with the teachers, while others stated the teachers also have many volunteers in the classroom

Students. I interviewed four students; three are females and one male, and their class ranged from third to sixth grade. These four students served on the student government. Because of their role, they were highly involved in the school activities.

I posed the open-ended research question to the students: What school activities have you seen that influence your parents' involvement in your education? Translation: Lub tsev kawmntawv no tau ua tejyam abtsi rau koj pom ua rau koj niam/txiv muaj siab koom koj txoj kevkawm? 
Student perceptions of parental involvement at their school. The students I

interviewed were not clear on the types of activities the school used to influence parental involvement during the school day; perhaps the wording of the question was too ambiguous or too difficult for them to understand. However, every student said the enrichment programs offered during the school day and after school are important to bring their parents to school because teachers asked parents to support these programs. As a result, parents often volunteered to help monitor and support the students. Students reported the school's cultural events, such as Hmong culture day, Chinese New Year, or Black History month bring many parents to the school because teachers often need parents to help organize and run the events.

All of the students shared that they enjoy the extracurricular activities provided by the school. The sixth grade female student related:

The Hmong language class is very important at Sunny Charter School. Having the Hmong language [at school] is great because my parents want me to learn to speak in Hmong so I can interact with other Hmong. Being able to read, write, and interact in Hmong is important to me. I also like the movement time/exercise, dances, Taekwondo, and the different cultures at the school. (Personal communication, January 15, 2016)

\section{Culturally Relevant Approaches to Parental Involvement}

I realized something special about the school in terms of culturally relevant approaches to parental involvement. For example, the superintendent used different forms of strategies in the recruitment of parents to the school, which included personal interactions, Hmong language flyers, or going on Hmong TV and radio programs to deliver the message. 
Additionally, the principal supported the activities teachers used to recruit, prepare, and support parent involvement. In turn, the teachers have responded positively to parental involvement and asserted their role in the school's parent involvement program, such as home visits and other activities that take up significant amounts of the teachers' time.

Overall, in contrast to the experiences of other schools involving large populations of Hmong families, Hmong parents at Sunny Charter School appeared to be highly receptive to getting involved in certain types of educational activities. That said, as is the case in many schools (Smith et al., 2011), the students seemed to be oblivious to what is required of their parents. Nonetheless, the following section shows that parent involvement is an emerging phenomenon within the Hmong community in general, the Hmong charter school is providing a variety of opportunities for parental involvement and indeed, parents are actively involved in a number of ways.

\section{Interpretation of Findings}

In this section, I interpret the nine themes from the data analysis. I derived the themes from the participants' responses to illustrate how each of the four stakeholder groups perceived parent involvement at the Hmong American Sunny Charter School charter school.

Table 5 indicates the numbers of response and perceptions related to each thematic code mentioned by members of each stakeholder groups during the interviews. As mentioned in chapter three, the purpose of the frequency count is not to rank order the 
participants' responses by order of importance, but rather to provide a description of the stakeholders' perceptions related to the themes.

\section{Table 5}

Frequency of Responses Related to the Nine Themes

\begin{tabular}{|c|c|c|c|c|c|}
\hline Themes & $\begin{array}{c}\text { Admins } \\
(2)\end{array}$ & $\begin{array}{l}\text { Teachers } \\
(4)\end{array}$ & $\begin{array}{l}\text { Parents } \\
(6)\end{array}$ & $\begin{array}{l}\text { Students } \\
\text { (4) }\end{array}$ & $\begin{array}{l}\text { Total } \\
\text { Response }\end{array}$ \\
\hline $\begin{array}{l}\text { Communication with parents through } \\
\text { email, telephone, verbal reminder, } \\
\text { meeting, home visit, radio, or television } \\
\text { program }\end{array}$ & 2 & 4 & 4 & 0 & 10 \\
\hline $\begin{array}{l}\text { Enrichment programs: dance, music, } \\
\text { movement, Taekwondo, Hmong Language }\end{array}$ & 0 & 0 & 3 & 3 & 6 \\
\hline School schedule or instruction & 1 & 1 & 2 & 2 & 6 \\
\hline PTA, ELAC, Fundraising, or policy & 1 & 1 & 3 & 0 & 5 \\
\hline Importance of field or study trips & 0 & 1 & 3 & 1 & 5 \\
\hline $\begin{array}{l}\text { Cultural events or presence of other } \\
\text { cultures }\end{array}$ & 1 & 0 & 2 & 1 & 4 \\
\hline $\begin{array}{l}\text { Flexibility of staff/open door policy, } \\
\text { welcoming to parents, or students }\end{array}$ & 0 & 0 & 2 & 1 & 3 \\
\hline Recommend school to others & 0 & 1 & 1 & 0 & 2 \\
\hline Other: behavioral reinforcement & 1 & 0 & 0 & 1 & 2 \\
\hline
\end{tabular}

The Four Stakeholder Groups' Perceptions Related to Parent Involvement

The four stakeholder groups included 16 participants. Of the 16 participants, two were administrators, four teachers, six parents, and four students. Again, the frequency of responses related to a particular theme does not necessarily indicate the weight of importance that the stakeholders placed on the themes that derived from their utterances. That said, the following descriptions begin with the themes that occurred up most 
frequently in the data and are the presented in descending order based on the frequency of responses related to each particular theme. Please refer to Table 5 for the frequency of responses related to each theme.

Communication and importance of bilingual staff. Of these 16 individuals, communication was considered an important component in promoting parental involvement among the responses from the stakeholder groups. Ten responses reported that communication were an important part of collaboration between staff and parents. The participants emphasized that the availability of bilingual staff as being essential in being able to communicate effectively between parents and staff.

The majority of parents praised the school's bilingual staff. They said that having staff members who speak their language was an important factor in their decision to enroll their children at Sunny Charter School. One parent explained her feelings about having bilingual staff members,

We can come to the school any time and would feel welcome. The school staff is Hmong and they help students learn to read, write, and speak Hmong. They are able to support students and parents in learning the Hmong language. The school [staff] helps me to plan what I need to do to help my child. The teachers tell me what I need to do. I did not get this help from the previous school. (Personal communication, January 14, 2016)

Two of six parents specifically stated that they felt welcomed by the school and staff members. These parents said having bilingual staff at the school allowed them to interact with the teachers and enable them to understand their children's progress easily during parent conferences and when they were helping teachers or staff to organize school events or go on field trips. These parents said the teachers were also flexible and made time available for parents to talk to them. These parents added that having 
bilingual staff at school made the parents feel comfortable discussing with teachers about their children's educational progress and goal.

Enrichment programs. Three of six parents and three of four students responded that the enrichment programs play a vital role in the children's education. The programs specifically mentioned include the Achievement Through Technology (ATT) program, dance, music, physical education, Taekwondo, and the Hmong language class. The three parents reported that without the enrichment programs at Sunny charter School, they would not be able to afford these classes elsewhere, and their children would not get the opportunity to experience them. Given that these culturally appropriate enrichment programs paired with programs that assist their children in learning $21^{\text {st }}$ century skills, the enrichment programs proved to be a significant draw to parent volunteers who wished to ensure the sustained existence of these programs that drew them to enroll their children at the Sunny Charter School.

Three of four students said they enjoy learning and participating in the enrichment programs at Sunny Charter School. These students agreed that these extracurricular programs are important to their education. These students also shared that they did not have the opportunity to learn Hmong language or about their native culture at other schools.

All four students said they especially enjoy taking the Hmong language class-a requirement for all students in Grades 1-6 - to learn to read, write, and speak Hmong. After taking the Hmong class, students reported feeling more confident interacting with 
others in Hmong and seemed to help them to realize the importance to be a Hmong and to preserve their cultural heritage.

Three of four students said the enrichment programs are important to promote parental involvement in their education. One student shared that,

I like the movement time/exercise, dances, Taekwondo, and the different cultures at the school. Many of these movement helps keep me in shape. I also like the Hmong language class. I think it is very important we have it at school. Having the Hmong language class [at school] is great because my parents want me to learn to speak in Hmong so I can interact with other Hmong. Being able to read, write, and interact in Hmong is important to me. (Personal communication, January 15, 2016)

Impact of the non-traditional school schedule. One of two staff

(administrators), one of three teachers, two of six parents, and two of four students preferred the nontraditional school schedule. Two of four students cited the school schedule as central to promoting parental participation. These staff, parents, and students said they embrace the school's 4-day classroom schedule, which runs from MondayThursday, from 8:00 a.m. to 5:00 p.m. The schedule gives students Fridays off and allows teachers to do planning or be caught up. Fridays are optional for teachers if they are all caught up.

In addition to promoting the four-day school week, the superintendent endorsed the short summer break as being beneficial to families. He shared that, Staff, parents, and students have embraced the month-long summer vacation. Everyone likes the shorter vacation because it allows scholars to retain more of what they acquired or learned. I have not heard any complaints from staff, parents, and students about the long days or short vacation. (Personal communication, January 11, 2016)

When I first interviewed the superintendent and principal, they reported that parents and students embraced the school's nontraditional school schedule. I was 
skeptical of their assertions, but as I spoke with the teachers, parents and students, they all seemed to agree with the assertion.

The non-traditional schedule allowed parents more freedom to tend to their daily schedule. For example, parents are able to work the full day schedule and have time to pick up their children after school. Every parent said the schedule does not distract them from their daily routine and still gives them more time to spend time with the children when they are away from work.

Committee involvement. Three of six parents stated they joined the Parent Teacher Association, English Learners Advisory Council, and Academic Council, Parents on the Move, and School Site Council or have participated on sub committees dedicated to goals such as fundraising activities because they viewed involvement as part of their responsibilities as parents at the school. The parents reported that seeing administrators and teachers at the meetings made them feel empowered and confident that the staff cared, not only about their children, but also about the fact that parents were involved.

Three parents also mentioned that they felt proud attending these meetings because they understood that their participation contributes to important decisions for the school. One parent explained the importance of her involvement:

I attend Parent-Teacher Association (PTA) meeting monthly to [decide on PTA funding priorities] and fundraise for field trips and culture nights. I also attend and can vote in English Learner Advisory Council. [I feel that] I can help the school in other ways too, besides helping my children at home. Joining the Parent-Teacher Association, taking part in fundraising, and volunteering had boosted my self-esteem. The principal and teachers encourage me to volunteer 40 hours during the [academic] year and I enjoyed volunteering in the classroom. (Personal communication, January 13, 2016) 
Importance of field trips. Three of six parents felt that field trips are an important part of their children's education. These parents said they are drawn to volunteering to support field trips because the teachers explained that such experiences enable the students to apply what they learn in the classroom out in the field.

Some parents reported they enjoy volunteering in the school building while others said they prefer going on field trips. One parent shared her involvement in field trips and the impact of having a welcoming school and staff:

[The] teachers encourage me to chaperone students during field trips. Teachers ask me to help at the school during other events. I can come to the school and speak to any staff any time during the day. The teachers are very welcoming and encourage me to come and volunteer in the classroom. Teachers talk to my child about colleges and career opportunities. (Personal communication, January 12, 2016)

Cultural events or presence of other cultures. Two of six parents felt that the multicultural events at Sunny Charter School offer great learning experiences for children to learn about Hmong traditions and about other cultures and ethnicities. These parents said the teaching and learning about different cultures through cultural performances are great examples of ways of introducing their children to other cultures. The parents who attended and watched these performances stated that they believed that having high-level cultural competency skills is important for every student. They said that they value the idea that with preparation, children will grow to appreciate people with different cultural values and maintain a strong identity themselves.

The students reinforced the idea that parents are drawn to support multicultural events at the school. Specifically, one of the students reported that the school's cultural 
events, such as Hmong culture day, Chinese New Year, and Black History month brings many parents to the school as volunteers and audience members.

Recommendation of school. It should be noted that in the open-ended questions to the stakeholder groups, the final two themes-recommendation of school and behavior reinforcement— did not get many responses because the initial question did not specifically address them. With that said, I should add that, every participant said that they highly recommended Sunny Charter School to other parents or students. The administrators and teachers indicated that Sunny Charter School's popularity has been pervasive and has resulted in a long waiting list of parents wanting to enroll their children there. The waiting list has led the school to establish a lottery system to randomly draw names of students who want to attend.

Behavioral reinforcement. During the open-ended question interview, the principal seemed to believe that positive reinforcement was more effective instead of punishment. He stated that children would sometimes misbehave, but if the teachers were taught to redirect the children, students mostly respond well and channel their energy toward something more positive. The principal indicated that the low disciplinary problems at Sunny Charter School appeared to contribute to the practice of positive reinforcement.

\section{Follow-up Questions and Responses}

I developed six additional questions as follow-up to the initial interview questions that slightly modified the open-ended research questions (see Appendices D-G). 
Table 6 presents the frequency of responses related to each of the themes. Once again, the themes are not weighted according to the frequency of particular responses, but rather, are offered to provide a description of which stakeholder groups spoke about each of the themes and how many times those themes arose during the interviews.

The key difference between Tables 5 and 6 is the increased frequency of responses due to the number of follow-up questions. The patterns of responses in the open-ended and follow-up questions are very similar. Both tables show similar pattern to responses of the stakeholder groups.

\section{Table 6}

Summary of Follow-up Questions Results

\begin{tabular}{lccccc}
\hline Themes & $\begin{array}{c}\text { Admins } \\
(2)\end{array}$ & $\begin{array}{c}\text { Teachers } \\
(4)\end{array}$ & $\begin{array}{c}\text { Parents } \\
(6)\end{array}$ & $\begin{array}{c}\text { Students } \\
(4)\end{array}$ & $\begin{array}{c}\text { Total } \\
\text { Response }\end{array}$ \\
\hline $\begin{array}{l}\text { Enrichment programs: dance, music, } \\
\text { movement, Taekwondo, Hmong Language } \\
\text { class }\end{array}$ & 4 & 11 & 12 & 9 & 36 \\
$\begin{array}{l}\text { School schedule or instruction } \\
\begin{array}{l}\text { Communication with parents through email, } \\
\text { telephone, verbal reminder, meeting, home } \\
\text { visit, radio, or television programs }\end{array}\end{array}$ & 5 & 5 & 3 & 2 & 15 \\
$\begin{array}{l}\text { Flexibility of staff/open door policy, } \\
\text { welcoming to parents, or students }\end{array}$ & 2 & 4 & 5 & 3 & 14 \\
$\begin{array}{l}\text { Recommend school to others } \\
\begin{array}{l}\text { Other: behavioral reinforcement } \\
\text { Importance of field or study trips }\end{array}\end{array}$ & 3 & 1 & 3 & 3 & 10 \\
$\begin{array}{l}\text { Cultural events or presence of other cultures } \\
\text { PTA, ELAC, Fundraising, or policy }\end{array}$ & 1 & 1 & 3 & 4 & 10 \\
& 2 & 1 & 3 & 3 & 9 \\
\hline
\end{tabular}


Because the responses for six of the nine themes were closely aligned with the feedback described above, I will only describe the perceptions here that were spoken of in detail during the interviews in response to the follow up questions. These three themes are: enrichment programs, nontraditional schedule, and communication.

Enrichment programs. Twelve responses from the Hmong parents and nine from the students indicated the enrichment programs influenced their decision to choose Sunny Charter School over other schools. Both Hmong parents and students stated the enrichment programs have taught them new skills that they would not have learned through other schools. Parents and students agreed that the Hmong language class is the single most important factor in their choice of picking the school. These parents said they now realized they made the right choice to send their children to Sunny Charter School.

In addition, every Hmong parents that I interviewed reiterated the fear of their children losing their native language and knowledge of their Hmong culture. Parents expressed that retention of their native language is important to preserving the culture and identity. These parents said the Hmong language program offered through the school has brought them a sense of new hope that their children will in fact, sustain the Hmong language and knowledge of their culture. Those parents who did not read or write Hmong felt that the class has motivated them to learn with their children.

Impact of the non-traditional school schedule. Furthermore, all participants prefer the school's nontraditional schedule. Twenty-four responses indicated that teachers, parents, and students like the long daily schedule, but shorter week, and only a 
brief summer vacation. All participants shared that the schedule, which starts from 8:00 A.M. in the morning and ends at 5:00 P.M., is convenient for the working parents.

The parents elaborated that the long day allows them to work a normal schedule and still be able to pick up their children after school gets out and spend focused time with them. The students said they like the short week because of the three-day weekend and they get to get involve in other extracurricular activities.

Teachers, on the other hand, added that the short summer break enable students to retain more of what they learned from the previous year. For the majority of parents, they related that the summer schedule makes teaching easier for teachers which they support and that, because of the limited time off available in the summer, parents feel more motivated to plan special activities around their children's schedule in the summer rather than sending them off to summer school or a daycare situation.

Culturally appropriate communication and importance of bilingual staff. In the follow-up questions, communication ranked third, with 15 responses. Three of six parents agreed that the school's communication methods such as sending letters home written in English and Hmong, emailing, texting, and face-to-face interactions are very effective. Teachers and parents said it would be hard for parents to miss anything because the school has a great way of consistently communicating with parents and students.

\section{School Artifacts}

I collected a 14-page PowerPoint presentation prepared by the principal to present to the school board for the school's petition for the renewal of the school charter. I 
collected the item because it contained valuable information on the school's mission, standardized test patterns, geographical data related to the students, and various programs available at the school.

I was encouraged to access the school website for additional information, but purposely chose not to include these data as part of the dataset as I preferred to focus the analysis on conversations with stakeholders rather than relying heavily on printed or digital materials. In addition, I observed a large bulletin board (kiosk) in the front schoolyard with dates of upcoming events, such as testing, registration for new students, and performances. Although materials such as these and the school website provided a sense of context used to better understand the interviewees' comments, these artifacts turned out not to be useful to my study as was originally conceived in the proposal.

\section{Limitations}

My study was limited to one K-6 Hmong American charter school in Northern California with approximately 415 students. More than $90 \%$ of the students enrolled in the school are Hmong. When compared to other schools, Sunny Charter School is a relatively small school with a very narrow distribution of ELLs in the sense that most of the children either speak Hmong as their first language and all of the students are actively learning Hmong as part of a school requirement, but no other foreign languages are offered.

The 16 participants I interviewed were all Hmong, with the exception of one student. Three of the six parents possess very limited English language skills. Despite having the questions translated from English to Hmong, the participants' level of 
understanding was questionable since the interview experience was in many ways, foreign to them and the questions themselves may have been misinterpreted. When the questions were asked in Hmong, some words could not be translated directly into Hmong, which could have distorted understanding and altered their responses.

Furthermore, the student participants were young elementary level children, which decreased the number of responses they provide and the depth of consideration given to each question. Given their age, they may have never seriously considered parent participation in their education and thus, their responses may have been affected by their limited reflections in the sphere of inquiry.

Although my research highlighted several successful activities employed by the community at Sunny Charter School to attract parent involvement in the school in a manner that can be replicated by people in other communities, there are some important limitations to consider, especially related to the generalizability of the findings.

Myers (2000) defined generalizability as "the degree to which the findings can be generalized from the study sample to the entire population" (p. 2). Given that my study did not use an experimental design approach but rather, used a descriptive case study approach to elicit the perspectives of 16 participants found within just one school, the finding from my study cannot be generalized to the greater population of Hmong charter schools or indeed any school involving a significant Hmong population. Rather, the purpose of my study was to contribute towards the development of a baseline description of perceptions from four stakeholder groups that researchers, educators and parents may draw upon to inform their own perspective in the ways that they see fit. 
Another limitation to my study relates to internal generalizability (Maxwell, 2013). Maxwell (2013) stated, "A key issue for internal generalizability is to adequately understand the variation in the phenomena of interest in the setting or group of the people studied" (p. 137). Although my study did employ a purposeful sampling approach to recruit representatives for each of four stakeholder groups, the responses of the 16 people interviewed cannot be said to represent the perspectives of everyone in the entire school community. Rather, the insights provided by the respondents provide a window into understanding some aspects of parental involvement in the school, not the entire spectrum of perspectives found within the Sunny Charter School.

The fact that I conveniently chose the students referred by the principal to interview might have skewed the outcome. However, due to school protocols, I took the names of the students given rather than seek to obtain other students. This seemed to be my chance to get the student participants after I unsuccessfully tried to get the names of other students through the attendance office.

\section{Summary}

In summary, I presented data and analysis from the interviews in this chapter. The responses were derived from interviews that were transcribed and coded using a dialogical coding strategy and a modified a visual coding model (Plano-Clark, \& Creswell, 2010). The frequency of the responses that match each of the themes were tallied for each of the four stakeholder groups (administrators, teachers, parents, and students) and recorded on Table 5 and Table 6 as a means to provide data on who said what. 
The analysis of the interview responses yielded nine major themes. Each of these nine themes informed the research questions related to the stakeholder groups' perceptions on parent involvement. Recall that the themes related to patterns such as the importance of two-way, culturally sensitive communication among the stakeholder groups, the effects of parental involvement in decision-making committees such as Parent Teacher Association or English Language Advisory Council, the benefits of the flexibility of staff, and the draw of enrichment programs offered the school.

Furthermore, the nontraditional schedule, fieldtrips, and cultural events were also vital to draw and sustain parents' involvement. The stakeholder groups would recommend the school to others in part because of the positive behavioral reinforcement strategies put in place by the staff members that are consistently maintained at home by parents. Each of these themes revealed important data related to what motivates Hmong parents to be involve in the school and in their children's education.

Finally, elements of the Hmong charter school design such as the enrichment programs and presence of a bilingual and bicultural staff were shown to be important avenues for communication and promoting a sense of feeling part of a community effort to educate Hmong children. The school design also provides motivation for parental involvement because of the school's curricula design around culturally relevant ideas and clear articulation of various pathways for parental involvement that may appeal to different types of temperaments and skills levels.

In the next chapter, I discuss the implications of my research and provide interpretation to communications, PTA, flexible staff, enrichment programs, 
nontraditional schedule, fieldtrips, cultural events, recommendation of school, and the behavior component. Further, I touch on the artifacts, provide the implication to my findings, a discussion, list the recommendations, and a conclusion. 


\section{Chapter 5: Discussion and Conclusion}

The purpose of my case study research is to examine what influences Hmong parents to be involved in supporting their children's education. The reason that my study was conducted is that parent involvement in education among Hmong communities is typically quite low, a situation that disadvantages Hmong children in a number of ways. Parent involvement models in the U.S. are typically informed by a number of assumptions that do not hold true for Hmong refugees. Thus, parent outreach mechanisms and other forms of support offered through formal educational venues tend to be culturally irrelevant to Hmong parents, even in the case of second generation parents who spent a portion of their childhood in U.S. school (Arias \& Morillo-Campbell, 2008).

For example, teachers and other school staff frequently assume a basic level of foundational knowledge of formal education systems in the U.S. and basic literacy skills that many Hmong parents are simply lack (P. Xiong, 2000). At the same time, according to T.P. Bliatout (personal communication, January 25, 2016), based on strict cultural hierarchies found in Laos, many Hmong parents assume that it is disrespectful to professional educators to intervene in their children's education (Sy, 2006). Thus, as a result of noticing that Hmong parents rarely get involved in their children's education, teachers often mistakenly believe that Hmong parents are uninterested in being involved in their children's education. In reality, that is not actually the case. Hmong parents often feel that they are simply not invited to participate or that they lack skills necessary to contribute to their children's education (Ngo \& Lee, 2007). 
In an effort to increase the level of equitable access to education, culturally specific charter schools have been developed throughout the U.S. since the 1990s (Kahlenberg \& Potter, 2014/2015). Examples of schools that have been developed through the movement are Hmong charter schools (Bailey \& Cooper, 2009).

Hmong charter schools involve culturally relevant curricula and instruction specifically adapted to the needs of Hmong families through collaborative efforts involving significant numbers of people who themselves are part of the Hmong refugee population. Because these schools are explicitly designed to support Hmong children, the stakeholder groups involved in the schools bring unique perspectives about parent involvement in education within their particular context. Therefore, Hmong charter schools provide an excellent opportunity to examine community members' perceptions with an eye towards understanding what motivates parental involvement for Hmong families.

Taking advantage of the opportunity to elicit the perceptions of key stakeholder groups found within a Hmong school community, my study focused on perceptions of parental involvement among parents, students, teachers and administrators associated within a Hmong charter school located on the west coast of the U.S. The research involved four open-ended research questions, where each question was specifically focused on each stakeholder groups (see Appendices D-G).

Chapter 5 presents interpretation of each of the nine key themes derived from the one-on-one interviews. I include a discussion of what is to be learned from my research study and the implications of the nine key findings related to parental involvement among 
Hmong families. I briefly describe how my study relates to earlier research and provides recommendations for research that could build upon the foundational descriptions provided in my case study that have the potential to inform the design of policies coupled with implementation strategies to improve parental involvement in education. The chapter offers recommendations for specific public policies designed to effectively integrate culturally sensitive approaches in school for Hmong families. Finally, I conclude with a summary of why the findings in my dissertation research matter and to whom and how my study provides an excellent foundational knowledge for designing culturally relevant parent involvement models for schools involving the families of refugee and immigrant families who speak English as a second language.

\section{Follow-up Questions and Responses}

Recall that nine themes came from the transcription of responses to the interview questions and analysis of the data. In chapter four, the sets of questions were designed for each stakeholder group beginning with the open-ended research questions. Refer to Appendices D, E, F, and G for the open-ended and follow-up questions for each stakeholder groups.

The data analysis derived nine themes that are relevant to parental involvement that inform each of the four research questions. The nine themes derived in my study are:

- Communication with parents through email, telephone, verbal reminder, meeting, home visit, radio, or television programs: stakeholders should have an effective communication system in place

- Committee involvement such as PTA, ELAC, Fundraising, or policy: encourage parents to participate in decision making 
- Flexibility of staff, open door policy, welcoming to parents, or students: flexible staff that can meet parents' needs

- Enrichment programs: dance, music, movement, Taekwondo, Hmong Language class that are culturally relevant programs that stakeholders can relate to

- School schedule or instruction: nontraditional schedule that stakeholders embraced

- Importance of field trips: all stakeholders believe in experiential learning

- Cultural events and presence of other cultures: performance of different cultures are valued

- Recommend school to others: stakeholders likely to recommend the school to others

- Behavioral reinforcement: positive reinforcement instead of punishment is more effective

\section{Synthesis of the Findings}

The following presents the each of the themes from the interviews and the implications of each in terms of parental involvement. Refer to Appendices D, E, F, and $\mathrm{G}$ for the interview questions.

\section{Enrichment Programs}

Every interview participant touted the importance of the enrichment programs offered through Sunny Charter School. A theme that derived from the data is that the parents shared that the Hmong language and cultural enrichment courses were key motivations for them to enroll their children at Sunny Charter School. Parents elaborated on the idea by saying that enrich programs are critical to helping their children to develop and maintain their native language. One parent said,

I am glad that we have the Hmong language class at Sunny Charter School. Having this class is great because it is important that my child learn to speak in Hmong so my child can interact with other Hmong in the community. Because if 
my child does not learn to read, write, and interact in other Hmong then he will lose the language and our culture. (Personal communication, January 15, 2016)

Parents emphasized that the importance that culturally relevant classes had to them was based on the fact that such learning opportunities enabled their children to learn and respect their native language and cultural traditions such as songs, chants and stories passed down through the oral tradition. Parents expressed relief in not having to pay for these programs outside of school, since such classes were generally opportunities that they could not otherwise afford regardless of how highly they valued such offerings.

Just as these students have shared in their perspectives, it appeared that without the enrichment programs related to the Hmong culture or other extracurricular courses, students would not be able to participate in the different activities the school has offered, such as the ATT program, dance, exercise and movements, and Taekwondo. As a parent, I share the students' energy and motivation because knowing that taking part in these activities would benefit them to improve their math skills, build their vocabularies, and reading skills, while the different types of movement and Taekwondo, which often help students to stay fit.

One teacher spoke of the dance and community garden that attracts parental involvement. She stated:

We have Zumba here every Thursday. Our parents come to the cafeteria and we have an instructor lead the group of parents. Would you like to come and join us? We also have a community garden that our parents can grow their own vegetables. Our parents often teach their children how to grow too. (Personal communication, January 15, 2016)

Thus, respondents emphasized not only enrichment programs involving the Hmong culture, but other types of skill building experiences such as gardening and academic skill 
development draws for parent involvement. In this case, parental involvement appeared in the form of volunteering to support activities, careful selection of extracurricular and special in school programs that parents view as beneficial to their children and serving on committees that support the enrichment offerings.

\section{Impact of the Non-Traditional School Schedule}

Administrators, teachers, parents, and students embraced the school's nontraditional school schedule as a means of encouraging more family time, and thus opportunities for involvement with children's learning.

The non-traditional schedule gives parents time to work, pick up their children afterward, or spend time with them. Parents shared that the staff's flexibility to stay after hours when some parents are late to pick up their children is extremely helpful because that gives parents a sense of a collective community. Parents were appreciative of the schedule because it enabled them to focus on their work during the day and still be able to spend valuable time with their children in the evening or during the weekend.

The short summer vacation is also advantageous to the teachers and students. According to teachers, the short summer break allows students to retain more of what they learn from the previous year. Furthermore, teachers stated that students could recall the previous lessons more quickly and they did not have to spend as much time to reteach the students on the materials.

\section{Culturally Appropriate Communication}

Clear communication plays a vital role in facilitating smooth, productive collaborations between administrators, teachers, parents, and students at any schools. 
However, an important point surfaced by the parents about what make Sunny Charter School unique and attractive to Hmong parents and students are its bilingual administrators, office staff, and teachers, which makes communication simpler for everyone. One parent explained her feelings about having bilingual staff members:

We can come to the school any time and would feel welcomed. The school staff is Hmong and they help students learn and speak Hmong. They are able to support students and parents in learning the Hmong language. The school [staff] helps me to plan what I need to do to help my child. The teachers tell me what I need to do. I did not get this help from the previous school. (Personal communication, January 14, 2016)

Parents said that they appreciate that the schools keep them updated on what is happening at school so that they can get involved with things such as finding supplemental supports for their children when they are struggling in some manner and volunteering for events. The administrators and teachers have established a communication strategy, wherein information pertaining to the school, parents, and students is quickly and efficiently disseminated. Administrators and teachers elaborated that when they have important messages to give to the parents about events they frequently put the notes in the students' backpack. Knowing that notes in the backpack sometimes do not reach their intended destination, teachers also said they often call or email parents about other activities to ensure that messages successfully reach them directly. The communication strategy keeps parents well informed about what is happening at the school, or in the community.

According to the staff, timely and systematic communication that provides information using multiple modalities that appeal to different types of learners, have increased the level of parent involvement at the school. As a result, teachers claim that 
parental involvement in the school has improved the overall student achievement in class, increased overall standardized testing results, and improved students' behavior in school. My finding is consistent with that of Epstein's (2005) research that found that clear and timely two-way communication between schools and parents improved academic and social outcomes for students.

\section{In-School Volunteering Activities}

Next, four themes derived from my study appeared to provide added motivations for parental involvement in school. These themes were field trips, flexibility, committee involvement, and cultural events.

Field trips. Going on field trip is a recurrent theme parents said they enjoy doing with their children. Five parents said the teachers often ask them to chaperone children on trips and they normally will go when their schedule allows them. These five parents indicated they would often learn to do different activities with their children.

Flexibility of staff. A theme equally vital is the flexibility of staff members. Parents felt the bilingual staff at school eased many of their fear of talking to teachers and staff because of their shared Hmong language. In the event they have a conference with an English-speaking teacher, Hmong speaking teachers are often available to interpret. Thus, the language barrier preventing volunteering to help out with activities such as fieldtrips and preparing for cultural events was not significant and the fact that the staff was flexible enough to understand and support parents' learning curves was appreciated by parents. 
Committee involvement. In addition, staff mentioned that they often encourage parents to participate in the school Parent Teacher Association or other decision-making committees that affect other parents and students. One of these decision-making mechanisms mentioned involved fundraising activities, where parents occasionally raise funds to cover field trip expenses. Without the collaborative effort and participation of parents, funding for student field trips are limited, thus preventing parents to go along with students and take part in hands-on, experiential learning experience. By emphasizing the impacts of parental contributions on programming, parents understand the importance of the role as partners in education.

As reported in chapter four, the sense of appreciation related to committee involvement is a two-way street. Parents stated that they appreciated the opportunity to be involved in decision making and one parent emphasized that involvement with the PTA had enhanced her own sense of self-esteem. Thus, the implications of parental involvement were not only to view in terms of benefiting the children and teachers, parental involvement also enriches the lives of the parents themselves.

Cultural events. Parents and students emphasized that they frequently attend and participate in cultural events, such as Hmong New Year, Chinese New Year, and Black History Month. Parents reported that they appreciated the sense of feeling that they are a part of the school community when teachers asked them help organize such events. Both parents and students agreed that it is a great opportunity being able to participate and experience both cultural events focused on Hmong traditions as well as other cultural 
events wherein children and their families are able to learn about and celebrate the traditions of other cultures.

\section{Relevance of School in the Community}

Next are two themes that derived from the interviews that were expressed as being essential to the school's future sustainability. These two themes are recommendation of school to other Hmong community members and positive behavioral reinforcement.

Recommendation of school. Every stakeholder groups responded positively that they would recommend the school to other parents and students. Specifically, each and every participant said they would recommend their friends or relatives to the charter school because of the great programs the school offers to the students and opportunities for families to support these programs.

The superintendent admitted that at the beginning of the charter process, enrollment was low because the community did not know too much about the school and was still skeptical of the school and its programs. However, as people begin to learn more about the charter school, they began to become interested. After four years in operation, the school has become very popular in the community and in fact, the school is currently oversubscribed. Students who wanted to attend had to put on the waiting list. He said that given the situation, in the interest of equity, the school has established a lottery system where names of students have to be drawn to get in. The fact that the Sunny Charter School is now viewed in the greater Hmong community in the area as a 
privilege to attend instills a sense of commitment on the part of the entire school community, including the parents, to continue to develop a program of excellence.

In addition, the superintendent shared that due to the success of Sunny Charter School, he plans to start a middle and high school in the near future and help students maintain their focus and retain continuity. He fears that without continuity, students may stray off and lose focus on education and career goals.

Behavioral reinforcement. Finally, the last theme involves with positive behavioral reinforcements. Students reported that the majority of students in the school are courteous and respectful toward each other and help each other to achieve their goals. The principal echoed the statement and said that the students are often courteous and respectful of each other. He reminded me that the students are encouraged to call each other 'scholar' to show their respect for one another. The principal believes that punishing students does not solve the behavioral problem, but that consistent and positive messages should deter acts of negative behavioral.

Parents reiterated their belief by stating that the administrators and teachers practice of positive behavioral reinforcements that they think teaches students to be responsible and respectful citizens. Parents said the staff serves as great role models for their children. They emphasized that because they speak a common language and share common cultural perspectives related to respectful behaviors, parents feel enabled to work with the teachers in partnership to consistently reinforce the messages about positive behavior taught at school when their children are at home. 


\section{Implications of the Findings for School Administrators and School Districts}

The findings from my study suggest several important implications for school and district level administrators. My study demonstrates a number of approaches that school administrators and districts may take to support effective parental involvement programs in schools. However, as seen in the example of the Sunny Charter School, parental involvement programs can only be successful when the District and school administrators are willing to invest resources and staff time into supporting culturally relevant programs that draw parents in and help them to feel part of the school community.

For example, at the Sunny Charter School, a commitment to language and cultural enrichment programs play an essential role in recruiting and supporting parental involvement. Indeed, without the parent's involvement, many of these enrichment programs would not exist. That said, without district financial commitments and supportive policies in place, the parents could not afford to offer similar opportunities to the children on their own and therefore would not be presented with the same opportunities to be involved in children's education.

When parents recognized what the school and school district were willing to invest in the growth of their children, the respondents in my study claimed that Hmong families were more inclined to get involved to do their part to maintain and even expand opportunities for their families.

With a huge variety of demands of teachers' time and energy, it is important that administrators verbally support teachers' work to prioritize clear communication with parents and cultivate parental involvement by collaborating with parents in the classroom, 
in committees, and in planning and organizing school events. It is important that administrators encourage teachers and other staff members to spend time cultivating relationships with parents and establishing trusting relationship, and that they do so themselves as well. One reason for that is because when the school staff can relate to the parents' needs and serve as role model for parents and students and authentic partners in education, parents will respond more positively and be willing to become more involved in supporting the school and their children's classrooms.

The importance of bilingual and bicultural school staff members. School districts and administrators ought to consider hiring bilingual staff that speaks one or more of the major foreign languages used by students and their parents. Bilingual staff enables more clear and consistent communication between the school and parents and signals to families that someone at the school understands them and that their voice as parents is highly valued as a school asset.

The importance of culturally sensitive modes of communication. It is pertinent for schools and districts to understand what is required to facilitate smooth, productive collaborations between administrators, teachers, parents, and students. Schools and districts ought to consider the unique relationship between the staff, parents and students at Sunny Charter School, which is designed by bilingual, bicultural administrators, office staff, and teachers in collaboration with the Hmong parents so that they can serve all students effectively. It is also essential for the schools and districts to have an open-door policy wherein dialogue between different stakeholders can provides 
information using multiple modalities of communication that appeal to different types of parents and learners.

Consider non-traditional school schedules. Overall, participants at Sunny Charter School favored the nontraditional school schedule. The four-day, nine-hour daily schedule ensured students a longer weekend, which meant more time to spend with parents and friends on extracurricular activities, such as going camping or fishing. Scheduling one day per week for teacher planning time also promotes opportunities for collaboration between teams of teachers, committee members, classroom parents, and others. The implication here is that non-traditional school schedules benefit not only family-time, and affords children time to access out-of-school learning opportunities, but also provides time for teachers to thoughtfully draw upon community resources to develop rich, well-designed learning opportunities for students.

\section{Implications of the Nine Themes for Teachers}

A key idea to be learned from my study is that Hmong parents are motivated to get involved in the school when provided with structural elements that encourage and support parents to take on roles in the school. Parents gain more confident about their abilities when they are wanted and appreciated in the school. Parents are empowered by joining decision-making policy committees, chaperoning children on fieldtrips, being delegated with new responsibilities as their self-confidence and sense of belonging increases within a school community.

To cultivate the development among parents, teachers should be flexible and have patience with parents as learn because contrary to what they see on the surface, some 
Hmong parents do want to participate and make a difference in their children's education and in the community, they simply need help finding their way into roles they are comfortable taking on.

Indeed, several parents in my study who serve on school committees shared that they feel empowered being trusted by the staff in making important decisions that affect the school. As is the case with these parent committee members, many Hmong parents simply need clear communication to understand what opportunities are available, support to learn skills and knowledge they can use to serve real needs in the community and to be explicitly and repeatedly invited to participate in their children's education.

\section{Situated in the Larger Context}

Again, nine themes derived from the analysis of the data. To begin, I want to point out three themes that refuted my assumptions about Hmong parental involvement. At first, based on my experiences and the literature, my belief was that Hmong parents do not participate in their children's education because of the different educational system, lack of educational knowledge, and low literacy skills. The literature suggested that these shortcomings contributed to parents' low-efficacy and barriers to participate for fear of offending the teachers (Smith et al., 2011). However, the findings here suggested otherwise.

My findings presented many voices from the administrators, teachers, parents, and students. Their voices provided different perspectives and painted another picture. The administrators and teachers collaborated that in spite of parents' education or socioeconomic, parents are more than willing to help in the classrooms, on field trips, or 
organizing activities at the school, given that schools provide the support and training to work with staff or their own children. My research concluded that when schools provide Hmong culturally rich curricula and Hmong bicultural staff, all Hmong parents would respond to participate in their children's education.

In spite of having experienced a very different educational system in Laos, the Sunny Charter School community demonstrated that Hmong parents are willing and able to be involved in their children's education when effective communication and support systems are in place at the school. When there is an understanding of the design of the communication structures that are in place at the school, and parents are able to access and understand the information shared, parents do appear to realize the benefits of getting involved and are in fact willing to participate when appropriate avenues for involvement are made apparent to them.

Vang (2005) stated that there is a correlation between parents' educational attainment and being involved in school. I found that the literature did not take into account the potentially positive effects of structural design factors such as a nontraditional school schedule on parent involvement, regardless of parents' educational background.

For instance, at the Sunny Charter School, the four-day class schedule during the academic year enabled parents to spend more time with their children on the three-day weekends and to collaborate with teachers to plan events and classroom activities. The school's long daily schedule and short summer break also positively influenced parents' involvement with their children's informal education. With the shorter summer break; 
parents see the need to spend time that is more valuable with the children in a productive manner. The sense of urgency to spend what little summer break time is available to them together appeared to stimulate parents to plan ahead and go on trips together rather than simply placing their children in camps or other daycare situations throughout the summer months. The situation appeared to be true regardless of the educational background of the parents.

On the other hand, my study did confirm studies related to parents of ELLs (e.g., Arias \& Morillo-Campbell, 2008; Moua, 2004) that found that understanding barriers and limitations to parental involvement is key to adapting the way in which parents are recruited, prepared and supported to volunteer with school events and activities.

As has been found to be the case with other ELL groups, bilingual Hmong staff members with backgrounds that are similar to the families of the students provide important entry points for parents to become involved in schools. For example, in the case of the Sunny Charter School, the community demonstrated that with people available who are well prepared to help parents negotiate the unknown, parents will become involved in their children's education in a variety of ways in the classroom and beyond.

When the curricula are culturally relevant to the Hmong parents and students, even the under-educated parents will know when to get involved. Parents also restated that having culturally relevant curriculum motivate their students to maintain the language and culture (Yang, 2015). Every parent reaffirmed the importance of the Hmong language class because it has brought new hopes and reasons to be more 
involved. In addition, parents become more involved as the retention of their native language is vital for their cultural identity. My finding aligns with that of Yang's (2015) research that found that preserving cultural identities is an important motivator for parent involvement in education.

Again, my study is among first of its kind to examine parental involvement at a Hmong charter school in California. However, in a similar study on parent involvement in an urban Hmong charter school in a Midwestern state, Smith et al. (2011) found that challenges to parental involvement were still significantly apparent, even within the context of a school specifically designed to support Hmong families. Smith et al. (2011) noted that the charter school followed Epstein's model (2001) well, but still faced many challenges shared by Hmong parents in other schools.

In addition, Smith et al.'s (2011) study indicated that the charter school that they examined needed to develop new strategies to attract more parents to become involved in school-based activities. Smith et al.'s finding suggested that when the school they studied experimented with using different services, such as wrap-around services to support vulnerable communities, putting in place volunteer incentive systems, instituting and communicating parent volunteer requirements and adopting culturally appropriate communication methods, these steps did serve to increase parental involvement.

The types of challenges experienced by Hmong communities in terms of parental involvement are not limited to the Hmong American community. Indeed, other American communities experience some of the same barriers and limitations to parental involvement. For example, in a study involving Mexican-American parents in Texas, 
Valdés (1996) found themes among first-generation Mexican parents and students similar to those among Hmong parents and students.

Mexican-American parents and students involved in Valdés' (1996) study struggled to understand the formal U.S. educational system, which in many ways, was foreign to them. Consequently, parents had trouble understanding the concept of parental involvement at school and in the home as defined in the U.S.

Valdés (1996) noted that teachers are highly revered in the Mexican community, but the parent participants involved in her study appeared to have had different educational expectations for their children than those envisioned by the school. Differences in aspirations coupled with the teaching staff and administrations' severe lack of knowledge of Mexican cultures and traditions served to severely hamper efforts to effectively recruit parental involvement (Valdés, 1996).

However, in contrast to the schools examined by Smith et al. (2011) and Valdés (1996), according to the respondents in my study, what appeared to make a big difference at the Sunny Charter School was that the administration went a step ahead of the other schools by instituting a number of afterschool enrichment programs. The school also purposely recruited and hired Hmong bilingual-bicultural staff, and developed a nontraditional school schedule, all of which served to successfully attract parental involvement and provide opportunities for families to spend more productive time together than they otherwise might have done. By providing culturally relevant hooks that were-well aligned with some of the aspirations parents' expressed for their children and the types of contributions parents said that they want to make towards the school, the 
Sunny Charter School succeeded in creating a successful a parent involvement model that works well for their community.

Teachers play vital roles as resources for students to learn and tolerate other beliefs and the broader societal norms. Sunny charter school provides a set of the foundational ground for the stakeholder groups and other schools to consider, such as bilingual and bicultural staff so that parents and students can relate and connect with one another. Despite Hmong parents' lack of educational skills, they possess the knowledge that can contribute to society. While conducting my research, I observed that Hmong parents have valuable skills that they bring to the school. Schools should acknowledge the presence of Hmong parents and the untapped resources they bring. Therefore, social, human, and cultural capital theory provides justifiable applications for Sunny charter school staff, parents, and students.

Additionally, although Vygotsky's (1978) Zone of Proximal Development does not specifically address how the concept benefit Hmong parents who do not have any formal education, it provides a basic foundation for school personnel on how to work with Hmong parents. Teachers and administrators could incorporate ZPD in their curricula when developing parental involvement programs to help Hmong parents build on their existing knowledge. I noted that the majority of Hmong parents who came from Laos and affected by political strife, geographical isolation, and different educational belief possess the basic frame of reference to the American educational system. It would be a mistake to think that Hmong parents' lack of literacy skills is a detriment to be more involved, which was what I assumed. 
Despite ZPD's shortcomings to specifically explain the process of transitioning from one learning zone to the next, the concept provides useful foundational ground for the majority of Hmong parents who came from an oral tradition and had little educational background (Thao, 2006). Even though Hmong parents had many traumatic experiences of being political refugees, many of them managed to move on to acculturate in their new environment. I argue that despite the challenges, ZPD provides a framework for Hmong parents to overcome the unfamiliar functions of schooling with help from culturally sensitive staff. With these help, Hmong parents would be more receptive to involve in their children's education.

\section{Implications}

Parental involvement is a foundational element that contributes to student success (Bjork et al., 2012). Providing clear communication and culturally relevant conduits to engage parent involvement works to assist schools to become stronger community of learning and enrich the school environment that welcomes diversity.

One of the ideas that the interviewed participants emphasized is that when a school becomes a place where parents feel welcome and comfortable to volunteer and watch their children learn, team up with teachers to organize social events, and provide their input on the selection and development of curriculum materials used in the school community, a school is likely to become increasingly more successful in terms of supporting parental involvement.

In light of these findings, I recommend that to become increasingly successful at involving parents in the school as part of their mission, schools such as Hmong American 
charter school should consider adopting an open-door policy. With an open-door policy in place, parents would feel more welcomed at the school. Regardless of their level of educational attainment or English language proficiency skills, such a policy would help parents to feel explicitly invited and empowered to become an active part of the school.

Furthermore, I recommend that adaptive strategies be put into place to help parents learn how the U.S. educational system works, such as providing parents with ample opportunities to observe instruction and receive guidance in choosing the activities they wish to volunteer to support. An open-door policy paired with learning opportunities for parents such as informational workshops and peer-mentoring is especially crucial for the Hmong parents who are not familiar enough with the U.S. educational system to become an active member of the school community without support and active encouragement provided in their own language using familiar modes of communication. In many cases, such accommodations would require an interpreter to facilitate collaborations between non-Hmong staff members and parents as each learn what the other has to offer to one another for the benefit of children.

It is important to understand that mainstream schools do not typically value the same norms and values that Hmong parents have at home. A great opportunity to bridge the gap is to introduce communal educational practices such as created opportunities wherein Hmong parents and elders are invited to serve as peer-mentors to support parents who are new to involvement in their children's education. These mentorship relationships may take many forms such as asking current parent committee members to invite other parents to observe the school's curriculum adoption and planning committee 
to first learn how decisions are made in the school and then later, inviting these parents to serve as committee members empowered as voting members to contribute to making decisions on how Hmong children should be taught in school. Such collaborations between school staff members and Hmong parents may help to deliver a well-integrated curriculum involving the best of both the Hmong and U.S. mainstream culture.

The Sunny Charter School was established based on a collection of ideas offered from local educators as a response to the community's need for a communal school designed to serve the needs of Hmong families. Besides meeting the state curricula requirements, the goal of a communal school is to educate Hmong students to achieve academic and social success, close the achievement gap, develop future leaders, and teach students to learn and respect their native' culture and history. Sunny Charter School makes learning fun, enjoyable, creative, and stimulating for students without having to lose their cultural identity. The school also reinforces learning how to appreciate different cultures and languages, a key element to engender respect for cultures other than their own. A culturally relevant parent involvement model that successfully engages parents in working collaboratively makes the school possible.

\section{Recommendations for the Stakeholders}

Based on the successes observed in Sunny Charter School related to student academic success and a successful parental involvement model, I recommend that policy makers consider integrating culturally relevant, sensitive strategies into the school design process. Below, I provide specific recommendations for connected strategies to these policies for each of four stakeholder groups to consider. 
Administrators. I recommend that administrators actively work to empower teachers to make changes to the curricula that exemplify the cultures of the parents and the community. To leverage resources to make this possible, administrators would be wise to implement parental involvement programs that include cross-cultural activities such as enrichment courses and special school events to reflect and celebrate the cultures of families found within the school community and beyond.

A further recommendation for administrators is that, if the school involves large percentages of a particular group who speaks English as a second language, staff ought to be hired who is bilingual and bicultural themselves who is able to speak one or more of the languages spoken by the parents. To take a step further, to effectively bridge the cultural and linguistic gaps to successful recruit and support parent volunteers in schools designed for particular cultural groups such as Hmong schools, administrators should commit to hire bilingual and bicultural teachers that speak the native language spoken by the families and understand the culture of the parents. In addition, to leverage the strengths of the community, administrators ought to provide training for parents about the U.S. educational system and have resources available for parents in their native language.

Teachers. Teachers are the parents' and students' role models. Teachers should be committed to work side-by-side with parents, empower parents to take on new roles in the school, and advocate for diversity. In the case of Hmong schools, optimally, at least some percentage of the teachers will need to be bicultural and/or bilingual in Hmong to effectively relate to Hmong parents' perspectives and help to facilitate collaborations between non-Hmong speaking staff and parents and Hmong families. 
Finally, teachers will need to be competent in cross-cultural pedagogies. Given the large and growing body of literature and teacher professional development resources available today, there is ample opportunity for teachers to receive intensive, sustained support to grow their knowledge and skills for how to accommodate for the diverse needs of multicultural classes of students. However, to make a difference, teachers should commit to implementing changes to their practices in an adaptive manner over time; regardless of how advanced they are in their careers. It is one thing to know the right thing to do, it is another thing altogether to choose to the do the work and make changes to practice to benefit students and families.

Parents. Parents play important roles in schools and their children's education. Parents should be willing to share and become key players in schools with the teachers and administrators and with other family members. If they value preserving their cultural heritage as Hmong, it is necessary for parents to advocate for their language and culture to be part of the teaching curricula and extra-curricular activities. They should be willing to meet teachers and administrators half-way by attending informational sessions on parent involvement, asking questions when they do not understand what is being asked of them and their children and signing up to volunteer in school as well as taking advantage of the enrichment opportunities offered through their school and community.

Students. Please be sure to bring letters and fliers home that are intended for your parents and if necessary, translate the text for your parents. Be open to having your parents volunteer in school activities and provide your parents with positive encouragement when they do show up at school rather than behaving embarrassed or shy 
about having your parents around at school. As you get older, ask your parents to help find educational opportunities that are external to the school, like internships and camps that enrich your lives.

\section{Conclusion}

The purpose of my descriptive case study research was to examine what influences Hmong parents to be involved in supporting their children's education. My study contributes foundational descriptive knowledge related to common obstacles and affordances to parental involvement in the U.S. system of education among those of Hmong descent. The research describes the perspectives of four stakeholder groups related to the topic; school administrators, teachers, parents, and students.

As mentioned at the beginning of the manuscript, I theorized that knowing the challenges to parental involvement in education is vital to the growth of culturally related models of parent involvement in the U.S. educational system. My main arguments in this study remained unchanged in that with culturally relevant forms of support for Hmong parents, schools could train themselves to support Hmong children in the classroom, support students' learning at home, and develop parents' skills to communicate with school administrators and teachers more effectively to meet students' needs. Such backings are imperative for Hmong students' academic and social success in school (Thao, 2003).

Hmong history, language, culture, and arts provide significant opportunities to enrich curriculum and a Hmong school's polycultural environment. Parental 
involvement is key to accessing these valuable cultural resources that enrich the lives of entire community.

Indeed, Hmong parental involvement is a key foundational element to a successful Hmong American charter school. Regardless of parents' educational background, parental involvement within schools helps to enrich the school environment and ensure that schools become strong communities of learning that welcome and respect diversity.

As a nation, we need to understand that conventional mainstream schools do not exhibit the norm and values that Hmong parents have at home. Nor is there necessarily the case in a Hmong school, therefore attention to support students to negotiate paradox and be able to adapt to different situations. Therefore, in a Hmong school setting, to leverage the richness of wisdom, knowledge and traditions that come from the Hmong way of life while also supporting children to take advantage of modern ways of thinking and access $21^{\text {st }}$ century skills, it is necessary to embrace a communal school practice wherein Hmong parents and elders are invited to be part of decision-making committees such as the school's curriculum adoption and planning committee to contribute to planning for how Hmong children should be taught in school. The collaboration between school and Hmong parents helps to enrich educational experiences for children by integrating authentic Hmong and mainstream cultural perspectives. Such a communal school educates Hmong students to learn and respect their native culture and history through a modern lens. Sunny Charter School makes learning fun, enjoyable, creative, and stimulating for Hmong students without losing their cultural identity. 
As mentioned above, a successful Hmong American charter should deeply consider the benefits of having an open-door policy wherein parents are welcome at school anytime. This type of policy, when clearly communicated as an earnest invitation to parental involvement is likely to empower the parents to be part of the school, and help parents learn how the U.S. educational system works through situated learning experiences. This kind of policy is especially crucial for the Hmong parents who are not familiar with the formal education system in the U.S. and do not know how to help their children at home and therefore may benefit from opportunities to observe educators model the behaviors for how to assist children in a manner that assures that children do their own thinking and grow.

When a school becomes a place where parents feel welcome and comfortable to volunteer, watch their children learn, collaborate to organize social events, and have inputs on curriculum materials, schools are able to effectively leverage resources not otherwise available to them; such affordances help to make schools more successful. This kind of school can be designed in any community with a large Hmong population, be it an inner city or rural environment, as long as the staff, teachers, and administrators set a high priority for working with and supporting parent learning progressions in developmentally appropriate ways. These approaches should, by necessity, involve culturally relevant considerations.

\section{Final Thoughts on the Themes and Contribution to Research}

Recall that the research questions and analysis resulted in nine themes. Here, I list the four themes that I feel can best be applied to enhance the work of educational 
practitioners. As mentioned above, communication in any shape is crucial to parent involvement. Communication is important to every school setting, especially where it involves the mentioned stakeholder groups. To achieve that, schools should provide the necessary staff. Flexibility of the staff is a characteristic all teachers should possess. When a parent walks into the room wanting to discuss an issue about the child, they ought to take the time to thoughtfully work with the parent in a collaborative manner. Often time parents feel frustrated when the situation is not dealt with in a timely manner. I realized that teachers have many responsibilities and deal with other parents as well, but spending several minutes with one parent goes a long way. Helping parents to understand the nature of a teachers' daily workload and helping them to understand modes of communication such as email that teachers use to balance the demands on their time is critical to nurturing a mutually respectful environment in which issues are addressed in a timely manner.

Implementing extracurricular opportunities involving multicultural elements such any of the enrichment programs described in my research is also important to encouraging parental involvement in schools. Today, in most schools around the U.S., students of multiple cultures and ethnicities are often present in the class. The curricula need to be adapted to the students.

Finally, the nontraditional schedule seems to be effective for Sunny Charter School. The long school days and shorter week is much preferred as a means to promote family time and teacher planning time, as the research here suggested. Extra planning time not only allows teachers time to reflect deeply on the particular needs of the 
students, the time also affords opportunities for teachers to work with parents to plan for ways to leverage volunteer skills and knowledge in the classroom in ways that make sense and are consistent with student learning outcome goals.

My research has affected me as a researcher and educator in many ways. I am delighted to hear the perceptions of the participants in my study, but I am disappointed to see that even as a researcher and educator at this day and age and level, I still see myself as an outsider in the schools. I often reflect on how Sunny Charter School was first started. Then I recall from my experience, first as a student, a parent, and an educator that being an ethnic minority comes with many mistaken assumptions. These assumptions are not being address and that is one of many reasons the Hmong administrators, teachers, parents, students, and I have in common. With that final thought, perhaps it is justifiable to develop more Hmong charter schools. 


\section{References}

Adler, S. M. (2004). Home-school relations and the construction of racial and ethnic identity of Hmong elementary students. School Community Journal, 14(2), 5776.

Arias, M. B., \& Morillo-Campbell, M. (2008). Promoting ELL parental involvement: Challenges in contested times (Unpublished in-service paper). Vanderbilt University, Nashville, TN.

Bailey, M. J. H., \& Cooper, B. S. (2009). The introduction of religious charter schools: A cultural movement in the private school sector. Journal of Research on Christian Education, 18(3), 272-289.

Beyer, G. (1981). The political refugee: 35 years later. International Migration Review, $15(1 / 2), 26-34$.

Bjork, L. G., Lewis, W. D., Browne-Ferrigno, T., \& Donkor, A. (2012). Building social, human, and cultural capital through parental involvement. Journal of School Public Relations, 33(3), 237-256.

Bowman, L. G., \& Deal, T. E. (2008). Reframing organization: Artistry, choice, and leadership. San Francisco, CA: Jossey-Bass.

Bondioli, C. A. (2000). Hmong parent education, involvement, and its impact on children: A correlational study (Unpublished master's thesis). The Graduate College, University of Wisconsin, Stout, WI.

Bruner, J. (1984). Vygotsky's zone of proximal development: The hidden agenda. New Directions for Child Development, 1984(23), 93-97.

Chaiklin, S. (2003). The zone of proximal development in Vygotsky's analysis of learning and instruction. In A. Kozulin, B. Gindis, V. S. Ageye, \& S. M. Miller (Eds.), Vygotsky's educational theory in cultural context (pp. 39-64). New York, NY: Cambridge University Press.

Cheung, C. S. S., \& Pomerantz, E. M. (2012). Why does parents' involvement enhance children's achievement? The role of parent-oriented motivation. Journal of Educational Psychology, 104(3), 820.

Creswell, J. W. (2009). Research design: Qualitative, quantitative, and mixed methods approaches. Thousand Oaks, CA: Sage.

Creswell, J. W. (2013). Qualitative inquiry and research design: Choosing among five approaches $\left(3^{\text {rd }}\right.$ ed.). Thousand Oaks, CA: Sage. 
Creswell, J. W., Plano Clark, V. L., Gutmann, M. L., \& Hanson, W. E. (2003). Advanced mixed methods research designs. In A. Tashakkori \& C. Teddlie (Eds.), Handbook of mixed methods in social and behavioral research (pp. 209240). Thousand Oaks, CA: Sage.

Duffy, J. (2000). Never hold a pencil rhetoric and relations in the concept of "preliteracy." Written Communication, 17(2), 224-257.

Elementary and Secondary School Act of 1965, Pub. L. No. 89-10, Stat. 79 (1965).

Epstein, J. L. (1988). Parent involvement. Baltimore, MD: Johns Hopkins University Center for Research on Elementary and Middle Schools.

Epstein, J. L. (1995). School/family/community partnerships. Phi Delta Kappan, 76(9), 701.

Epstein, J. L. (2005). Attainable goals? The spirit and letter of the No Child Left Behind Act on parental involvement. Sociology of Education, 78(2), 179-182.

Epstein, J. L., Sanders, M. G., \& Sheldon, S. B. (2007). Family and community involvement: Achievement effects. Retrieved December 10, 2014. doi: 10.1057/9781137030931.0011

Every Student Succeeds Act (ESSA) of 2015, Pub. L. No. 195, § 4501, Stat 1177. (2015).Ferdig B. (2015, October 9). Community school of excellence celebrates the Hmong New Year. Hmong Times. Retrieved from http:/hmongtimes.com

Gonzalez-DeHass, A. R., Williams, P. P., \& Doan-Holbein, M. F. (2005). Examining the relationship between parental involvement and student motivation. Educational Psychology Review, 17(2), 99-123.

Guba, E. G., \& Lincoln, Y. S. (1985). Naturalistic inquiry. Beverly Hills, CA: Sage.

Guba, E. G., \& Lincoln, Y. S. (2005). Paradigmatic controversies, contradictions, and emerging confluences. In N. K. Denzin \& Y. S. Lincoln (Eds.), The Sage handbook of qualitative research ( $3^{\text {rd }}$ ed., pp. 191-215). Thousand Oaks, CA: Sage.

Hamilton-Merritt, J. (1993). Tragic mountains: The Hmong, the Americans, and the secret wars for Laos, 1942-1992. Bloomington, IN: Indiana University Press.

Hernandez, G. M. (2011). Parent involvement: Perceptions of parents and teachers (Doctoral dissertation). California State University, Sacramento, CA. 
Hoover-Dempsey, K. V., Bassler, O. C., \& Brissie, J. S. (1987). Parent involvement: Contributions of teacher efficacy, school socioeconomic status, and other school characteristics. American Educational Research Journal, 24(3), 417-435.

Hoover-Dempsey, K. V., Walker, J. M., Jones, K. P., \& Reed, R. P. (2002). Teachers involving parents (TIP): An in-service teacher education program for enhancing parental involvement. Teaching and Teacher Education, 18(7), 843-867.

Kahlenberg, R. D., \& Potter, H. (2014/2015). Restoring Shanker's vision for charter schools. American Educator, 38(4), 4-13.

Knowles, M. S. (1970). The modern practice of adult education: From pedagogy to andragogy. Englewood Cliffs, NJ: Prentice Hall

Kroll, L. R. (2004). Constructing constructivism: How student-teachers construct ideas of development, knowledge, learning, and teaching. Teachers and Teaching: Theory and Practice, 10(2), 199-221.

Ladson-Billings, G. (1995). But that's just good teaching! The case for culturally relevant pedagogy. Theory into Practice, 34(3), 159-165.

Larocque, M., Kleiman, I., \& Darling, S. M. (2011). Parental involvement: The missing link in school achievement. Preventing School Failure, 55(3), 115-122.

Lee, K. L., \& Green, K. (2008). Hmong parental involvement and support: A comparison between families of high and low achieving high school seniors. Hmong Studies Journal, 9, 1-27.

Lee, M. (1998). Hmong parent involvement in education. Doctoral dissertation, St. Cloud State University, St. Cloud, MN.

Mackenzie, N., \& Knipe, S. (2006). Research dilemmas: Paradigms, methods, and methodology. Issues in Educational Research, 16(2), 193-205.

Maxwell, J. A. (2013). Qualitative research design: An interactive approach (3rd ed.). Thousand Oaks, CA: Sage.

McGeehan, J. (2001). Brain-compatible learning. Green Teacher, (64), 7-13.

MobyMax, online curriculum program. Retrieved from http://www.mobymax.com/

Mote, S. M. (2004). Hmong and American: Stories of transition to a strange land. Jefferson, NC: McFarland. 
Moua, R. F. (2004). Hmong parental involvement in school and its effect on the academic achievement of their children. (Master's thesis). Retrieved from https://scholarworks.csustan.edu

Myers, M. (2000). Qualitative research and the generalizability question: Standing firm with Proteus. The Qualitative Report, 4(3/4). 1-9.

Ngo, B., \& Lee, S. J. (2007). Complicating the image of model minority success: A review of Southeast Asian American education. Review of Educational Research, 77(4), 415-453.

No Child Left Behind Act of 2001, Pub. L. No. 107-110, § 115, Stat. 1425 (2002).

Ogbu, J. U. (1998). Voluntary and involuntary minorities: A cultural-ecological theory of school performance with some implications for education. Anthropology \& Education Quarterly, 29(2), 155-188.

Pfeifer, M. E., \& Thao, B. K. (Eds.). (2013). The state of the Hmong American community 2013: 2010 US Census Report. Washington, DC: Hmong National Development. doi: 10.1057/9781137030931.0011

Piaget, J. (1964). Development and learning. In M. Gauvain \& M. Cole (Eds.), Readings on the development of children (2nd ed., pp. 19-28). New York, NY: Freeman.

Plano-Clark, V. L., \& Creswell, J. W. (2010). Understanding research: A consumer's guide. Upper Saddle River, NJ: Pearson.

Pomerantz, E. M., Moorman, E. A., \& Litwack, S. (2007). The how, whom, and why of parents' involvement in children's academic lives: More is not always better. Review of Educational Research, 77(27), 373- 410.

Rogosa, D. (2003). Student progress in California charter schools, 1999-2002 (Unpublished manuscript). Stanford University. Stanford, CA.

Smith, J., Wohlstetter, P., Kuzin, C. A., \& Pedro, K. D. (2011). Parent involvement in urban charter schools: New strategies for increasing participation. School Community Journal, 21(1), 71-94.

Stake, R. E. (1978). The case study method in social inquiry. Educational Researcher, $7(2), 5-8$.

Stevens, D. D., \& Cooper, J. E. (2009). Journal keeping: How to use reflective writing for learning, teaching, professional insight, and positive change. Sterling, VA: Stylus. 
Sy, S. R. (2006). Rethinking parent involvement during the transition to first grade: A focus on Asian American families. School Community Journal, 16(1), 107-126.

Taylor, E. L., \& Christ, T. J. (2010). Elementary and Secondary Education Act (ESEA). In C. Clauss-Ehlers (Ed.) Encyclopedia of cross-cultural school psychology, pp. 420-421. Springer. doi: 10.1007/978-0-387-71799-9_157

Thao, P., Conquergood, L. D., \& Thao, X. (1989). I am a shaman: A Hmong life story with ethnographic commentary 8. Southeast Asian Refugee Studies Project, Center for Urban and Regional Affairs.

Thao, Y. J. (2003). Empowering Mong students: Home and school factors. Urban Review, 35(1), 25-41.

Thao, Y. J. (2006). The Mong oral tradition: Cultural memory in the absence of written language. Jefferson, NC: McFarland.

Trotter, Y. D. (2006). Adult learning theories: Impacting professional development programs. Delta Kappa Gamma Bulletin, 72(2), 8-13.

Trueba, H. T., Jacobs, L., \& Kirton, E. (1990). Cultural conflict and adaptation: The case of Hmong children in American society. New York, NY: Falmer Press.

Trueba, H. T., Jacobs, L., \& Kirton, E. (2014). Cultural conflict \& adaptation. New York, NY: Routledge.

Trumbull, E., Rothstein-Fisch, C., Greenfield, P. M., \& Quiroz, B. (2001). Bridging cultures between home and school: A guide for teachers. Routledge.

Valdés, G. (1996). Con respeto: Bridging the distances between culturally diverse families and schools. New York, NY: Teachers College Press.

Vang, C. T. (2005). Hmong-American students still face multiple challenges in public schools. Multicultural Education, 13(1), 27.

Veresov, N. (2004). Zone of proximal development (ZPD): The hidden dimension? In A. L. Østern, R. Heilä-Ylikallio, \& A. Åbo (Eds.), Språk som kultur: Brytningar $i$ tid och rum = Language as Culture (Vol. 1; pp. 13-30). Vasa: Åbo Akademi, Pedagogiska fakulteten.

Vogt, W. P., Gardner, D. C., \& Haeffele, L. M. (2012). When to use what research design. New York, NY: Guilford Press. 
Vygotsky, L. S. (1978). Interaction between learning and development. In M. Gauvain \& M. Cole (Eds.), Readings on the development of children (2nd ed.; pp. 29-36). New York, NY: Freeman.

Xiong, P. (2000). A study of Hmong parental involvement in school (Master's thesis). Retrieved from http://millennium.csustan.edu

Xiong, V. (2015). Yav pem suab academy: Independent charter. Prepared for SCUSD Board. (Unpublished document), Sacramento, CA.

Xiong, Y. S. (2012). Hmong Americans' educational attainment: Recent changes and remaining challenges. Hmong Studies Journal, 13(2), 1-18.

Yang, T. (2015). Hmong parents critical reflections on their children's heritage language maintenance. Journal of Southeast Asian American Education and Advancement, 3(1), 17.

Yin, R. K. (1981). The case study as a serious research strategy. Science Communication, 3(1), 97-114.

Zimmer, R., Buddin, R. J., Chau, D., Gill, B., Guarino, C., Hamilton, L., \& Brewer, D. (1999). Charter school operations and performance: New evidence from California. Santa Monica, CA: Rand.

Zimmerman, B. J. (1990). Self-regulated learning and academic achievement: An overview. Educational Psychologist, 25(1), 3-17. 


\section{Appendix A \\ Consent to Participate in Research}

\section{Perceptions of Hmong Parents in a Hmong American Charter School: A Qualitative Descriptive Case Study on Hmong Parent Involvement}

Date:

Introduction,

You are being asked to participate in a research study that is being done by Yer J. Thao, who is the principal investigator, and the co-principal investigator, Kirk T. Lee, from the Department of Education at Portland State University in Portland, Oregon. This research focuses on parental involvement at a Hmong American charter in Northern California. You are being asked to participate in this study because we want to hear your perspectives on parental involvement programs at Sunny charter school (pseudonym) and how Hmong American parents could better assist your children in school.

This form will explain the research study, and will explain the possible risks as well as the possible benefits to you. We encourage you to talk with your family and friends before you decide to take part in this research study. If you have any questions, please ask one of the study investigators.

What will happen if I decide to participate?

If you agree to participate, the following things will happen:

First, the researcher from this study will contact you. Once you are identified and selected, the researcher will set a time to meet with you to explain the research protocol, review consent and permission forms, and sign the required forms. After all the forms are signed, the researcher will ask you a series of questions. You are to answer them from your experience as it pertains to parental involvement at Sunny charter school. There are no right or wrong answers.

How long will I be in this study?

Participation in this study will take a total of 30 minutes to 1 hour over a period of one week.

What are the risks or side effects of being in this study?

There are risks of stress, emotional distress, inconvenience, and possible loss of privacy and confidentiality associated with participating in a research study.

The researcher will use all due diligence to protect your identity by assigning you a pseudonym. After the interview and research, all notes or audio recordings will be placed 
in a locked box for safekeeping for 3 years. After such time, any notes or recordings will be destroyed.

For more information about risks and discomforts, ask the investigator.

What are the benefits to being in this study?

There will be no financial benefits for participation in this study. However, the investigator may provide snacks or refreshment during the interview.

How will my information be kept confidential?

You will be assigned a pseudonym so that you are not easily identifiable. Your personal information and anything you reveal will be kept confidential and in a locked box for three years and then destroyed.

We will take measures to protect the security of all your personal information, but we cannot guarantee confidentiality of all study data.

The researcher will not reveal any information in regards to your identity or any notes taken during the interview. All recordings will be kept in a locked box.

Information contained in your study records is used by study staff and in some cases it will be shared with the sponsor of the study. The Portland State University Institutional Review Board (IRB) that oversees human subject research and/or other entities may be permitted to access your records, and there may be times when we are required by law to share your information. It is the investigator's legal obligation to report child abuse, child neglect, elder abuse, harm to self or others, or any life-threatening situation to the appropriate authorities; in such cases, your confidentiality cannot be maintained.

Your name will not be used in any published reports about this study.

Will I be paid for taking part in this study?

No, you will not be compensated for taking part in this study.

Can I stop being in the study once I begin?

Yes, this study is strictly voluntary and you may leave or stop participating in the study at any time during the study once you begin.

Your participation in this study is voluntary. You have the right to choose not to participate or to withdraw your participation at any point in this study without penalty or loss of benefits to which you are otherwise entitled.

Who can I call with questions or complaints about this study?

If you have any questions, concerns, or complaints at any time about the research study, Yer J. Thao or his associates will be glad to answer them at 503-725-8267. 
If you need to contact someone after business hours or on weekends, please call 503-7258267 and ask for Yer J. Thao.

Who can I call with questions about my rights as a research participant?

If you have questions regarding your rights as a research participant, you may call the PSU Office for Research Integrity at (503) 725-2227 or 1(877) 480-4400. The ORI is the office that supports the PSU Institutional Review Board (IRB). The IRB is a group of people from PSU and the community who provide independent oversight of safety and ethical issues related to research involving human participants. For more information, you may also access the IRB website at https://sites.google.com/a/pdx.edu/research/integrity.

\section{CONSENT}

You are making a decision whether to participate in this study. Your signature below indicates that you have read the information provided (or the information was read to you). By signing this consent form, you are not waiving any of your legal rights as a research participant.

You have had an opportunity to ask questions and all questions have been answered to your satisfaction. By signing this consent form, you agree to participate in this study. A copy of this consent form will be provided to you.

Name of Adult Subject (print) Signature of Adult Subject Date

$\overline{\text { INVESTIGATOR SIGNATURE }}$

This research study has been explained to the participant and all of his/her questions have been answered. The participant understands the information described in this consent form and freely consents to participate.

Name of Investigator/ Research Team Member (type or print)

$\overline{\text { (Signature of Investigator/Research Team Member) }} \quad$ Date 


\section{Appendix B Parental Permission}

\section{Perceptions of Hmong Parents in a Hmong American Charter School: A Qualitative Descriptive Case Study on Hmong Parent Involvement}

Your child is invited to participate in a research study conducted by Kirk T. Lee from Portland State University Graduate School of Education. The researcher hopes to learn participants' perspectives on parental involvement at a Hmong American charter school and how this concept contributes to children's schooling. Kirk T. Lee is a graduate student in the Graduate School of Education at Portland State University conducting this study under the supervision of Dr. Yer J. Thao in partial fulfillment of the requirements for a doctoral degree. Your child was selected as a possible participant in this study because of his age, interest in school, and potential ability to provide details about parental involvement.

If you decide to let your child participate, he/she will be asked to describe how parental involvement programs at Sunny charter school (pseudonym) and activities at this school has benefitted him/her. The purpose is to learn from the students' perspectives how parental involvement has benefitted him/her. The duration of this study is one week. The researcher will meet with the participant one time for about 30 minutes at his/her preferred location. During the interview, the researcher will use notepads to take notes and an audio recording device to record the conversation. While participating in this study, it is possible your child's identity will be exposed. I will use due diligence to protect the identity of your child by assigning a pseudonym. Additionally, your child may feel some level of discomforts and inconvenience. I encourage you as his/her parent to sit in during the interview so that he/she feels comfortable. I will set a time and location he/she attends regularly so he/she is comfortable. If your child feels he/she cannot continue and wishes not to participate, he/she can leave any time without consequences. Your child may not receive any direct benefit from taking part in this study, but the study may help to increase knowledge, which may help others in the future. This study may provide information on how charter and non-charter schools can better serve Hmong American parents and students.

Your child will receive a school related supply for participating in this study.

Any information that is obtained in connection with this study and that can be linked to your child or identify your child will be kept confidential. This information will be kept confidential by storage of any related notes and audio recordings in a locked box for a period of 3 years and then destroyed.

Your child's participation is voluntary. He/she does not have to take part in this study and it will not affect his/her class standing, classmates, or relationship with teachers at Sunny charter school (pseudonym). You may withdraw your permission for your child to 
participate from this study at any time without affecting his/her class standing, classmates, or relationship with the teacher(s) at Sunny charter school. Likewise, your child may withdraw his/her consent at any time without affecting his/her class standing, classmates, or relationship with teachers at Sunny charter school.

If you have questions or concerns about your child's participation in this study, contact Dr. Yer J. Thao or Kirk T. Lee at 1900 SW Fourth Ave, Portland State University, Portland, OR 97207, (503) 725-8267. If you have concerns about your child's rights as a research subject, please contact the PSU Office of Research Integrity, Market Center Building Ste. 620, Portland State University, (503) 725-2227.

Your signature indicates that you have read and understand the above information and agree to let your child take part in this study. The researcher should provide you with a copy of this form for your own records.

Participant Signature

Participant Printed Name

Investigator Signature

Investigator Printed Name
Date

\section{Date}




\section{Appendix C \\ Student Permission \\ Perceptions of Hmong Parents in Hmong American Charter School: A Qualitative Descriptive Case Study on Hmong Parent Involvement}

\section{Child's Name}

Your parents (or guardian) have said it is okay for you to take part in a project about how administrators, teachers, parents, and students respond to parental involvement activities at a Hmong American charter school. The purpose of this qualitative study is to examine how administrators, teachers, parents, and students respond to parental involvement activities at a Hmong American charter school. If you choose to do it, you will be asked to sit with the researcher for a one-time, 30-minute interview.

If you want to rest or stop completely, just tell me-you will not get into any trouble! In fact, if you do not want to do it at all, you do not have to. Just say so. Also, if you have any questions about what you will be doing, just ask me to explain.

If you do want to try it, please sign your name on the line below. Remember-you can stop to rest at any time, and if you decide not to take part anymore, let me know.

Child's Signature

Child's Printed Name

Investigator's Signature

Investigator's Printed Name
Date

Date 


\section{Appendix D \\ Open-ended and Follow-up Interview Questions for Administrators}

Open-ended Interview Question for Administrators

1. What activities have you used to promote parental involvement in your school?

Follow-up Questions for Administrators

1. In what ways does this school support parents?

2. Tell me why this school is different from other schools.

3. Why do you think parents send their children to this school?

4. Tell me some of the before- or after-school activities this school offers?

5. What school functions do you use to attract more parents?

6. How would you recommend this school to other parents or students? 


\section{Appendix E \\ Open-Ended and Follow-up Interview Questions for Teachers}

Open-ended Interview Question for Teachers

1. What activities have you used to promote parental involvement in your school?

Follow-up Questions for Teachers

1. In what ways does this school support parents?

2. Tell me why this school is different from other schools.

3. Why do you think parents send their children to this school?

4. Tell me some of the before- or after-school activities this school offers?

5. What school functions do you use to encourage parental involvement?

6. Would you recommend this school to other parents or students? 


\section{Appendix F Open-ended and Follow-up Questions for Parents}

Open-ended Question for Parents

1. What activities has this school offered for you to get involved in your children's education? Translation: Lub tsev kawmntawv no tau ua tejyam abtsi los pab rau koj paub txoj kev txhawb koj tus menyuam txoj kev kawm?

Follow-up Questions for Parents

1. In what ways does this school support your involvement?

2. Tell why this school is different from other schools.

3. Why do you send your children to this school?

4. Tell me some of the before- or after-school activities this school offers?

5. How are you treated at this school compared to other schools?

6. Would you recommend this school to other parents or students?

Translation:

1. Lub tsev kawm ntawv no txoj kev pab txhawb koj txoj kev koom zoo licas?

2. Qhia kuv ib yam seb lub tsev kawm ntawv no ho txawv lwm lub tsev kawm ntawv zoo mus licas?

3. Yog vim licas koj ho coj koj cov menyuam tuaj kawm lub tsev kawm ntawv no?

4. Qhia kuv tej yam uas lub tsev kawm ntawv no muaj pab rau cov niam/txiv thiab menyuam ua ntej thaum tsis tau nkag chav kawm ntawv kawm thiab thaum twb lawb lawm.

5. Lub tsev kawm ntawv no tos txais koj licas muab piv rau lwm lub? 
6. Koj puas pom zoo txhawb thiab qhuas txog lub tsev kawm ntawv no rau lwm tus niam/txiv los yog tub kawm ntawv? 


\section{Appendix G Open-ended and Follow-up Interview Questions for Students}

Open-ended Question for Students

1. What school activities have you seen that influence your parents' involvement in your education? Translation: Lub tsev kawmntawv no tau ua tejyam abtsi rau koj pom ua rau koj niam/txiv muaj siab koom koj txoj kevkawm?

Follow-up Questions for Students

1. In what ways does this school support your parents' involvement?

2. Tell me what is different (unique) about this school.

3. Why and how do you like this school?

4. Tell me some of the before- or after-school activities this school offers?

5. How are you treated at this school?

6. Would you recommend this school to other students?

Translation:

1. Lub tsev kawm ntawv no txoj kev pab txhawb koj niam/txiv zoo txoj koom licas?

2. Qhia kuv ib yam seb lub tsev kawm ntawv no ho txawv licas?

3. Vim licas thiab ua licas koj ho nyiam lub tsev kawm ntawv no?

4. Qhia kuv tej yam uas lub tsev kawm ntawv no muaj pab rau cov niam/txiv thiab menyuam ua ntej thaum tsis tau nkag chav kawm ntawv kawm thiab thaum twb lawb lawm.

5. Lub tsev kawm ntawv no tos txais koj licas?

6. Koj puas pom zoo txhawb thiab qhuas txog lub tsev kawm ntawv no rau lwm tus tub kawm ntawv? 


\section{Appendix H \\ Individual Response to Open-ended Questions}

Individual Participant Response Analysis (open-ended question)

\begin{tabular}{|c|c|c|c|}
\hline & Q1 & Response & Theme \\
\hline $\begin{array}{l}\text { Admin1 } \\
(\mathrm{YL})\end{array}$ & $\begin{array}{l}\text { What activities } \\
\text { have you used to } \\
\text { promote parental } \\
\text { involvement in } \\
\text { your school? }\end{array}$ & $\begin{array}{l}\text { *Radio } \\
\text { announcement/commercials } \\
\text { *Hmong TV programs, } \\
\text { *school brochures, } \\
\text { *voice messages, } \\
\text { *email, } \\
\text { *letters in kids' backpack, } \\
\text { *remind parents in hallway, } \\
\text { *ask individual parents to help, } \\
\text { *remind parents to get kids to bed } \\
\text { early }\end{array}$ & $\begin{array}{l}\text { *school brochures, } \\
\text { *voice messages, } \\
\text { *letters in kids' backpack, } \\
\text { *remind parents in hallway, } \\
\text { *ask individual parents to help, } \\
\text { *remind parents to get kids to bed } \\
\text { early }\end{array}$ \\
\hline $\begin{array}{l}\text { Admin2 } \\
(\mathrm{XV})\end{array}$ & $\begin{array}{l}\text { What activities } \\
\text { have you used to } \\
\text { promote parental } \\
\text { involvement in } \\
\text { your school? }\end{array}$ & $\begin{array}{l}\text { *before school begin, teacher do } \\
\text { h/v } \\
\text { *meet \& greet } \\
\text { *back2school night } \\
\text { *introduce staff \& visit rooms } \\
\text { *dance, music, taekwondo } \\
\text { performances } \\
\text { *culture night } \\
\text { * garden for parents } \\
\text { *multicultural night } \\
\text { *field trips } \\
\text { *parent meetings } \\
\text { *awards } \\
\text { *assembly } \\
\text { *re-classification }\end{array}$ & $\begin{array}{l}\text { *before school begin, teacher do } \\
\text { h/v } \\
\text { *meet \& greet } \\
\text { *back2school night } \\
\text { * introduce staff \& visit rooms } \\
\text { *culture night } \\
\text { *multicultural night } \\
\text { * parent meetings }\end{array}$ \\
\hline $\begin{array}{l}\text { Teach1 } \\
\text { (VM) }\end{array}$ & $\begin{array}{l}\text { What activities } \\
\text { have you used to } \\
\text { promote parental } \\
\text { involvement in } \\
\text { your school? }\end{array}$ & $\begin{array}{l}\text { *mother's day in the class, moms } \\
\text { must attend/participate } \\
\text { *father's day }\end{array}$ & $\begin{array}{l}\text { mother's day in the class, moms } \\
\text { must attend/participate } \\
\text { *father's day }\end{array}$ \\
\hline $\begin{array}{l}\text { Teach2 } \\
(\mathrm{VX})\end{array}$ & $\begin{array}{l}\text { What activities } \\
\text { have you used to } \\
\text { promote parental } \\
\text { involvement in } \\
\text { your school? }\end{array}$ & $\begin{array}{l}\text { *involvement is stated in charter } \\
\text { mission ( } 40 \text { hrs per year) } \\
\text { *parents encourage to participate } \\
\text { in study trip (field trips) } \\
\text { *special meeting to engage parents } \\
\text { before trip } \\
\text { *Hmong culture day: skits, play, } \\
\text { planning, run booth, embroidery, } \\
\text { food station }\end{array}$ & $\begin{array}{l}\text { *parents encourage to participate } \\
\text { in study trip (field trips) } \\
\text { *special meeting to engage } \\
\text { parents before trip } \\
\text { *Hmong culture day: skits, play, } \\
\text { planning, run booth, embroidery, } \\
\text { food station }\end{array}$ \\
\hline $\begin{array}{l}\text { Teach3 } \\
\text { (YD) }\end{array}$ & $\begin{array}{l}\text { What activities } \\
\text { have you used to } \\
\text { promote parental } \\
\text { involvement in } \\
\text { your school? }\end{array}$ & $\begin{array}{l}\text { *PTA allows parents to come and } \\
\text { support } \\
\text { *email to parents as forms } \\
\text { communication } \\
\text { *Home visit } \\
\text { *Send letter home update parents } \\
\text { on activities }\end{array}$ & $\begin{array}{l}\text { *PTA allows parents to come and } \\
\text { support } \\
\text { *email to parents as forms } \\
\text { communication } \\
\text { *Home visit } \\
\text { *Send letter home update parents } \\
\text { on activities }\end{array}$ \\
\hline
\end{tabular}




\begin{tabular}{|c|c|c|c|}
\hline $\begin{array}{l}\text { Teach4 } \\
\text { (TLS) }\end{array}$ & $\begin{array}{l}\text { What activities } \\
\text { have you used to } \\
\text { promote parental } \\
\text { involvement in } \\
\text { your school? }\end{array}$ & $\begin{array}{l}\text { *PTA } \\
* \text { multicultural day to show support } \\
\text { *a lot of parents show up for } \\
\text { conferences to show their support } \\
\text { *parents offer to help }\end{array}$ & $\begin{array}{l}\text { *PTA } \\
\text { *multicultural day to show } \\
\text { support } \\
\text { *a lot of parents show up for } \\
\text { conferences to show their support } \\
\text { * parents offer to help }\end{array}$ \\
\hline $\begin{array}{l}\text { Parent1 } \\
\text { (YP) }\end{array}$ & $\begin{array}{l}\text { What activities } \\
\text { have this school } \\
\text { offered for you to } \\
\text { get involved in } \\
\text { your children's } \\
\text { education? }\end{array}$ & $\begin{array}{l}\text { *school encourages to volunteer } \\
\text { *parents volunteer } 40 \text { hrs during } \\
\text { the year } \\
\text { *teachers are welcoming } \\
\text { * chaperone on field trips } \\
\text { *multicultural day }\end{array}$ & $\begin{array}{l}\text { *school encourages to volunteer } \\
\text { *parents volunteer } 40 \mathrm{hrs} \text { during } \\
\text { the year } \\
\text { *teachers are welcoming } \\
\text { *chaperone on field trips } \\
\text { *multicultural day }\end{array}$ \\
\hline $\begin{array}{l}\text { Parent2 } \\
\text { (VC) }\end{array}$ & $\begin{array}{l}\text { What activities } \\
\text { have this school } \\
\text { offered for you to } \\
\text { get involved in } \\
\text { your children's } \\
\text { education? }\end{array}$ & $\begin{array}{l}\text { *staff are Hmong and help } \\
\text { students to learn and speak Hmong } \\
\text { *able to support students and } \\
\text { parents in learning Hmong } \\
\text { language }\end{array}$ & $\begin{array}{l}\text { *staff are Hmong and help } \\
\text { students to learn and speak } \\
\text { Hmong } \\
\text { *able to support students and } \\
\text { parents in learning Hmong } \\
\text { language }\end{array}$ \\
\hline $\begin{array}{l}\text { Parent3 } \\
\text { (XMY) }\end{array}$ & $\begin{array}{l}\text { What activities } \\
\text { have this school } \\
\text { offered for you to } \\
\text { get involved in } \\
\text { your children's } \\
\text { education? }\end{array}$ & $\begin{array}{l}\text { *school helps me to plan what I } \\
\text { need to do to help my child } \\
\text { *teachers tell me what I need to do } \\
\text { *I did not get this help from the } \\
\text { previous school }\end{array}$ & $\begin{array}{l}\text { *school helps me to plan what I } \\
\text { need to do to help my child } \\
\text { *teachers tell me what I need to } \\
\text { do } \\
\text { *I did not get this help from the } \\
\text { previous school }\end{array}$ \\
\hline $\begin{array}{l}\text { Parent4 } \\
\text { (LL) }\end{array}$ & $\begin{array}{l}\text { What activities } \\
\text { have this school } \\
\text { offered for you to } \\
\text { get involved in } \\
\text { your children's } \\
\text { education? }\end{array}$ & $\begin{array}{l}\text { *PTA meeting monthly to } \\
\text { fundraise for field trip } \\
\text { *culture night } \\
\text { *ELAC }\end{array}$ & $\begin{array}{l}* \text { PTA meeting monthly to } \\
\text { fundraise for field trip } \\
* \text { culture night }\end{array}$ \\
\hline $\begin{array}{l}\text { Parent5 } \\
\text { (LC) }\end{array}$ & $\begin{array}{l}\text { What activities } \\
\text { have this school } \\
\text { offered for you to } \\
\text { get involved in } \\
\text { your children's } \\
\text { education? }\end{array}$ & $\begin{array}{l}\text { *open door policy } \\
\text { *at will policy } \\
\text { *room for volunteer for any } \\
\text { classroom } \\
\text { *PTA } \\
\text { *Culture day } \\
\text { *Hmong New Year }\end{array}$ & $\begin{array}{l}\text { *room for volunteer for any } \\
\text { classroom } \\
\text { *PTA } \\
\text { *Culture day }\end{array}$ \\
\hline $\begin{array}{l}\text { Parent6 } \\
(\mathrm{XM})\end{array}$ & $\begin{array}{l}\text { What activities } \\
\text { have this school } \\
\text { offered for you to } \\
\text { get involved in } \\
\text { your children's } \\
\text { education? }\end{array}$ & $\begin{array}{l}\text { *encourage parents to help at } \\
\text { home } \\
\text { *field trips } \\
\text { *require } 40 \mathrm{hrs} / \mathrm{yr}\end{array}$ & $\begin{array}{l}\text { *encourage parents to help at } \\
\text { home } \\
\text { *field trips } \\
\text { *require } 40 \mathrm{hrs} / \mathrm{yr}\end{array}$ \\
\hline $\begin{array}{l}\text { Student1 } \\
\text { (XS) }\end{array}$ & $\begin{array}{l}\text { What school } \\
\text { activities have you } \\
\text { seen that influence } \\
\text { your parents' } \\
\text { involvement in } \\
\text { your education? }\end{array}$ & $\begin{array}{l}\text { *Hmong language (at school) } \\
\text { *parents want me to learn to speak } \\
\text { in Hmong } \\
\text { *parents want me to interact with } \\
\text { other Hmong }\end{array}$ & $\begin{array}{l}\text { *Hmong language (at school) } \\
\text { *parents want me to learn to speak } \\
\text { in Hmong } \\
\text { *parents want me to interact with } \\
\text { other Hmong }\end{array}$ \\
\hline
\end{tabular}




\begin{tabular}{|c|c|c|c|}
\hline $\begin{array}{l}\text { Student2 } \\
(\mathrm{OA})\end{array}$ & $\begin{array}{l}\text { What school } \\
\text { activities have you } \\
\text { seen that influence } \\
\text { your parents' } \\
\text { involvement in } \\
\text { your education? }\end{array}$ & $\begin{array}{l}\text { *movement time/exercise } \\
* \text { dances and taekwondo } \\
\text { *different cultures at the school } \\
\text { *PTA }\end{array}$ & $\begin{array}{l}\text { *movement time/exercise } \\
\text { *different cultures at the school } \\
\text { *PTA }\end{array}$ \\
\hline $\begin{array}{l}\text { Student3 } \\
(\mathrm{F})\end{array}$ & $\begin{array}{l}\text { What school } \\
\text { activities have you } \\
\text { seen that influence } \\
\text { your parents' } \\
\text { involvement in } \\
\text { your education? }\end{array}$ & $\begin{array}{l}* \text { movement } \\
* \text { taekwondo and dance }\end{array}$ & $\begin{array}{l}\text { *movement } \\
\text { *taekwondo and dance }\end{array}$ \\
\hline $\begin{array}{l}\text { Student4 } \\
\text { (TKF) }\end{array}$ & $\begin{array}{l}\text { What school } \\
\text { activities have you } \\
\text { seen that influence } \\
\text { your parents' } \\
\text { involvement in } \\
\text { your education? }\end{array}$ & $\begin{array}{l}\text { *performance in the cafeteria } \\
\text { *mayor at the school, write speech, } \\
\text { and do morning announcements } \\
\text { *study trips }\end{array}$ & $\begin{array}{l}\text { *performance in the cafeteria } \\
\text { *study trips }\end{array}$ \\
\hline
\end{tabular}




\section{Appendix I \\ Individual Response to Follow-up Questions}

Individual Participant Response Analysis (follow-up question)

\begin{tabular}{|c|c|c|c|c|c|c|}
\hline & Q1 & Q2 & Q3 & Q4 & Q5 & Q6 \\
\hline & $\begin{array}{l}\text { In what } \\
\text { ways does } \\
\text { this school } \\
\text { support } \\
\text { parents? }\end{array}$ & $\begin{array}{l}\text { Tell me why } \\
\text { this school } \\
\text { is different } \\
\text { from other } \\
\text { schools }\end{array}$ & $\begin{array}{l}\text { Why do you } \\
\text { think parents } \\
\text { send their } \\
\text { children to } \\
\text { this school? }\end{array}$ & $\begin{array}{l}\text { Tell me some } \\
\text { of the before- } \\
\text { or-after school } \\
\text { activities this } \\
\text { school offers. }\end{array}$ & $\begin{array}{l}\text { What school } \\
\text { functions do you } \\
\text { use to attract } \\
\text { more parents? }\end{array}$ & $\begin{array}{l}\text { How } \\
\text { would } \\
\text { you } \\
\text { recomm } \\
\text { end this }\end{array}$ \\
\hline Admin 1 & $\begin{array}{l}\text { *parent } \\
\text { meeting } \\
\text { *nurse send } \\
\text { info to } \\
\text { parents }\end{array}$ & $\begin{array}{l}\text { *body- } \\
\text { brain-based } \\
\text { model } \\
\text { *positive } \\
\text { discipline vs } \\
\text { punishment } \\
\text { *actual } \\
\text { *presentatio } \\
\mathrm{n} \text { of lesson } \\
\text { *M-Th is } \\
\text { class, Fri is } \\
\text { developmen } \\
\mathrm{t}\end{array}$ & $\begin{array}{l}\text { *Hmong } \\
\text { language } \\
\text { *Taekwondo, } \\
\text { dance } \\
* 8 \text {-2pm is } \\
\text { core } \\
\text { curriculum, 3- } \\
5 \text { pm is } \\
\text { computer } \\
\text { class prep } 1 \mathrm{hr} \\
\text { everyday } \\
\text { *12 hrs of } \\
\text { development } \\
\text { (240 mins) }\end{array}$ & $\begin{array}{l}\text { *7-8am } \\
\text { childcare in } \\
\text { cafeteria, } 7: 30 \\
\text { breakfast } \\
\text { *announcement } \\
\text { of menu, } \\
\text { activities } \\
\text { * plan to have } \\
\text { music and } \\
\text { tutoring }\end{array}$ & $\begin{array}{l}\text { *major events } \\
\text { *winter program } \\
\text { *fundraising } \\
\text { activities } \\
\text { *taekwondo } \\
\text { demo } \\
\text { *culture show } \\
\text { *black history } \\
\text { month }\end{array}$ & $\begin{array}{l}*_{\text {radio }} \\
*_{\text {word }} \\
\text { of } \\
\text { mouth } \\
*_{\text {no }} \\
\text { homew } \\
\text { ork, } \\
\text { less } \\
\text { stress } \\
\text { on } \\
\text { children } \\
\text { *build } \text { child } \\
\text { leaders } \\
\text { hip } \\
\text { *no }^{\text {no }} \\
\text { punish } \\
\text { ment } \\
\text { model }\end{array}$ \\
\hline Admin 2 & $\begin{array}{l}\text { *before } \\
\text { school } \\
\text { begin, } \\
\text { teacher do } \\
\mathrm{h} / \mathrm{v} \\
\text { *awards } \\
\text { *assembly } \\
\text { *reclassifica } \\
\text { tion }\end{array}$ & $\begin{array}{l}* \text { ELAC } \\
* \text { parent on } \\
\text { the move } \\
* \text { home visit }\end{array}$ & $\begin{array}{l}\text { *culture piece } \\
\text { in the school } \\
\text { *build } \\
\text { language and } \\
\text { culture } \\
\text { *98\% ELL } \\
\text { *being there } \\
\text { experience: } \\
\text { touch/feel } \\
\text { *see and } \\
\text { touch } \\
\text { *performing } \\
\text { art } \\
\text { *mind, body, } \\
\text { spirit } \\
\text { *schedule is } \\
\text { different- } 8- \\
5 \text { pm, M-Th } \\
\text { *technology- } \\
\text { Ipad, laptop, } \\
\text { wireless }\end{array}$ & $\begin{array}{l}\text { *dance, music, } \\
\text { taekwondo } \\
\text { performances }\end{array}$ & $\begin{array}{l}\text { *meet \& greet } \\
\text { *back2school } \\
\text { night } \\
\text { *introduce staff } \\
\text { \& visit rooms } \\
\text { *culture night } \\
\text { *garden for } \\
\text { parents } \\
\text { *multicultural } \\
\text { night } \\
\text { *field trips } \\
\text { *parent } \\
\text { meetings }\end{array}$ & $\begin{array}{l}\text { *the } \\
\text { name of } \\
\text { the } \\
\text { school } \\
\text { speaks } \\
\text { volume } \\
\text { *kids } \\
\text { talk } \\
\text { about } \\
\text { the } \\
\text { good } \\
\text { things } \\
\text { at } \\
\text { school } \\
\text { *radio } \\
\text { announ } \\
\text { cement } \\
\text { *hand } \\
\text { out } \\
\text { flyers } \\
\text { *famili } \\
\text { es take } \\
\text { owners }\end{array}$ \\
\hline
\end{tabular}




\begin{tabular}{ll}
\hline & hip of \\
the & school
\end{tabular}

\begin{tabular}{|c|c|c|c|c|c|c|}
\hline Teach1 & $\begin{array}{l}\text { *Hmong } \\
\text { speaking } \\
\text { staff helps } \\
\text { bridge } \\
\text { language } \\
\text { gap } \\
\text { *interpretati } \\
\text { on/resource } \\
\text { for non- } \\
\text { Hmong } \\
\text { speaking } \\
\text { staff }\end{array}$ & $\begin{array}{l}\text { *life skills } \\
\text { for K-6 } \\
\text { scholars } \\
\text { *behavior is } \\
\text { taught } \\
\text { throughout } \\
\text { the school } \\
\text { *all staff on } \\
\text { the same } \\
\text { page } \\
\text { *teachers } \\
\text { are } \\
\text { reminded of } \\
\text { the mission } \\
\& \text { vision of } \\
\text { the school }\end{array}$ & $\begin{array}{l}\text { *the school } \\
\text { days \& hours } \\
\text { are convenient } \\
\text { for working } \\
\text { parents } \\
\text { *students can } \\
\text { be dropped at } \\
\text { school at } 7 \text { am } \\
\text { * free } \\
\text { breakfast/lunc } \\
\text { h } \\
\text { *8-5 hrs }\end{array}$ & $\begin{array}{l}\text { *breakfast } \\
\text { *no after } \\
\text { school bc } \\
\text { incorporate } \\
\text { other activities } \\
\text { into curriculum }\end{array}$ & $\begin{array}{l}\text { *PTA } \\
\text { *zumba for } \\
\text { every parents on } \\
\text { Thursday } \\
\text { *most moms } \\
\text { attend zumba } \\
\text { *winter concert } \\
\text { * }\end{array}$ & $\begin{array}{l}{ }^{*} \text { would } \\
\text { send } \\
\text { own } \\
\text { kids } \\
\text { here } \\
\text { *Hmon } \\
\text { g } \\
\text { languag } \\
\text { e } \\
\text { is } \\
\text { require } \\
\text { d for } \\
\text { grades } \\
1-6 \\
\text { *taekw } \\
\text { ondo is } \\
\text { free for } \\
\text { all } \\
\text { students } \\
\text { *waitin } \\
\text { g list, } \\
\text { attenda } \\
\text { nce is } \\
\text { based } \\
\text { on } \\
\text { lottery } \\
* \text { turn- } \\
\text { over is } \\
\text { low }\end{array}$ \\
\hline
\end{tabular}




\begin{tabular}{|c|c|c|c|c|c|c|}
\hline Teach2 & $\begin{array}{l}\text { *PTA } \\
\text { mostly } \\
\text { Hmong } \\
\text { parents } \\
\text { *ELAC } \\
\text { *support } \\
\text { parents } \\
\text { *encourages } \\
\text { \& support } \\
\text { H/V } \\
\text { *Update } \\
\text { parents on } \\
\text { child's } \\
\text { progress } \\
\text { *Parent on } \\
\text { the move } \\
\text { *important } \\
\text { info for } \\
\text { parents }\end{array}$ & $\begin{array}{l}\text { *unique*pro } \\
\text { grams at } \\
\text { school, i.e. } \\
\text { art, drama, } \\
\text { dance, } \\
\text { taekwondo, } \\
\text { Hmong } \\
\text { class } \\
\text { *schedule is } \\
\text { 8-5 b/c } \\
\text { convenient } \\
\text { for working } \\
\text { parents } \\
\text { *many } \\
\text { study trips } \\
\text { for students } \\
\text { * fundraising } \\
\text { is used for } \\
\text { study trips } \\
\text { (trip is free) } \\
\text { *training for } \\
\text { staff (HET } \\
\text { highly ed } \\
\text { training) } \\
\text { *GLAS } \\
\text { training } \\
\text { *high } \\
\text { expectations } \\
\text { on students }\end{array}$ & $\begin{array}{l}\text { *schedule } \\
\text { works well for } \\
\text { parents } \\
\text { *programs } \\
\text { (art, music, } \\
\text { dance, } \\
\text { taekwondo) } \\
\text { are embraced } \\
\text { by parents b/c } \\
\text { free for all } \\
\text { students }\end{array}$ & $\begin{array}{l}\text { *no } \\
\text { before/after } \\
\text { school } \\
\text { programs b/c } \\
\text { core classes are } \\
\text { incorporated } \\
\text { *3-5pm } \\
\text { technology for } \\
\text { students }\end{array}$ & $\begin{array}{l}\text { *parents } \\
\text { encourage to } \\
\text { participate in } \\
\text { holiday events, } \\
\text { performances, } \\
\text { addition day, } \\
\text { multiplication } \\
\text { day }\end{array}$ & $\begin{array}{l}\text { *highly } \\
\text { recomm } \\
\text { end the } \\
\text { school } \\
\text { to } \\
\text { others } \\
\text { b/c of } \\
\text { the } \\
\text { opportu } \\
\text { nities } \\
\text { *other } \\
\text { progra } \\
\text { ms are } \\
\text { supple } \\
\text { mented } \\
\text { *offers } \\
\text { opportu } \\
\text { nities } \\
\text { for low- } \\
\text { income } \\
\text { parents } \\
\text { and } \\
\text { students } \\
\text { *only } \\
\text { four } \\
\text { weeks } \\
\text { off for } \\
\text { summer } \\
\text { vacatio } \\
\text { n } \\
\text { *studen } \\
\text { ts able } \\
\text { to retain } \\
\text { more of } \\
\text { what is } \\
\text { taught }\end{array}$ \\
\hline Teach3 & $\begin{array}{l}\text { *offer } \\
\text { additional } \\
\text { resources } \\
\text { for parents } \\
\text { * give } \\
\text { resources } \\
\text { for parents } \\
\text { to monitor } \\
\text { at home } \\
\text { *work with } \\
\text { parents to } \\
\text { address plan } \\
\text { for } \\
\text { classroom }\end{array}$ & $\begin{array}{l}\text { *unique and } \\
\text { strange } \\
\text { *a model to } \\
\text { help } \\
\text { children in } \\
\text { all } \\
\text { socioecono } \\
\text { mic } \\
\text { * focus on } \\
\text { future } \\
\text { leaders } \\
\text { *allow } \\
\text { teachers to } \\
\text { be creative } \\
\text { *body- } \\
\text { mind, } 8 \\
\text { senses }\end{array}$ & $\begin{array}{l}\text { *schedule is } \\
\text { convenient for } \\
\text { parents } \\
\text { *classes are } \\
\text { M-Th } \\
\text { *comprehensi } \\
\text { ve skills } \\
\text { *students are } \\
\text { physically fit, } \\
\text { healthy, } \\
\text { competent }\end{array}$ & $\begin{array}{l}\text { *no } \\
\text { before/after } \\
\text { school but core } \\
\text { is incorporated } \\
\text { *ATT to do } \\
\text { technology } \\
\text { *movie max } \\
\text { *dance, music, } \\
\text { art, taekwondo }\end{array}$ & $\begin{array}{l}\text { *winter } \\
\text { concert/program } \\
\text { *culture day } \\
\text { dressing in } \\
\text { traditional } \\
\text { clothes to } \\
\text { represent all } \\
\text { culture } \\
\text { *New Year } \\
\text { celebration, } \\
\text { Black history } \\
\text { *field trips } \\
\text { once/mo } \\
\text { *focus on } \\
\text { "being there" }\end{array}$ & $\begin{array}{l}\text { *Yes } \\
\mathrm{b} / \mathrm{c} \text { of } \\
\text { the } \\
\text { unique } \\
\text { progra } \\
\text { ms at } \\
\text { this } \\
\text { school } \\
\text { *Teach } \\
\text { ers are } \\
\text { compet } \\
\text { ent to } \\
\text { plan \& } \\
\text { deliver } \\
\text { the } \\
\text { material } \\
\text { s }\end{array}$ \\
\hline
\end{tabular}




\begin{tabular}{|c|c|c|c|c|c|c|}
\hline Teach4 & $\begin{array}{l}\text { *communic } \\
\text { ation, notice } \\
\text { to parents, } \\
\text { reminder, } \\
\text { engage } \\
\text { parents with } \\
\text { activities } \\
\text { *allows } \\
\text { parents to } \\
\text { chaperone } \\
\text { *allow } \\
\text { parents to } \\
\text { learn with } \\
\text { students }\end{array}$ & $\begin{array}{l}\text { *unique } \mathrm{b} / \mathrm{c} \\
\text { of mind, } \\
\text { body } \\
\text { *incorporate } \\
\text { movement, } \\
\text { i.e. dance } \\
\text { *cool down } \\
\text { moment for } \\
\text { students to } \\
\text { relax }\end{array}$ & $\begin{array}{l}\text { *the great } \\
\text { programs, } \\
\text { Hmong } \\
\text { program, } \\
\text { movement } \\
\text { programs } \\
\text { incorporate } \\
\text { into core }\end{array}$ & $\begin{array}{l}\text { *teach Hmong } \\
\text { dance, other } \\
\text { games, } \\
\text { movements } \\
\text { *zumba } \\
\text { movements } \\
\text { *sports related } \\
\text { events }\end{array}$ & $\begin{array}{l}\text { *training for } \\
\text { staff } \\
\text { *culture is } \\
\text { highly } \\
\text { encouraged } \\
\text { *collaborative } \\
\text { from principal, } \\
\text { face to face } \\
\text { interactions } \\
\text { from others }\end{array}$ & $\begin{array}{l}\text { *brain, } \\
\text { body, } \\
\text { mind } \\
\text { compon } \\
\text { ent } \\
\text { *cool } \\
\text { down } \\
\text { time for } \\
\text { students } \\
\text { to relax } \\
\text { before } \\
\text { instructi } \\
\text { on is } \\
\text { started } \\
\text { *a good } \\
\text { model } \\
\text { for the } \\
\text { future }\end{array}$ \\
\hline Parent1 & $\begin{array}{l}\text { *PTA } \\
\text { *principal } \\
\text { attends } \\
\text { monthly } \\
\text { meeting } \\
\text { makes me } \\
\text { want to } \\
\text { attend more } \\
\text { *email sent } \\
\text { out to } \\
\text { parents to } \\
\text { attend }\end{array}$ & $\begin{array}{l}\text { *Hmong } \\
\text { focus } \\
\text { school } \\
\text { *helps } \\
\text { child to } \\
\text { speak } \\
\text { native } \\
\text { language } \\
\text { *extracurri } \\
\text { cular } \\
\text { activities, } \\
\text { i.e. } \\
\text { taekwondo }\end{array}$ & $\begin{array}{l}\text { *addressed in } \\
\text { prior question }\end{array}$ & $\begin{array}{l}\text { *schedule } 8-5 \\
\text { so lesson is } \\
\text { incorporated } \\
\text { into core } \\
*\end{array}$ & $\begin{array}{l}\text { *everyone } \\
\text { knows the } \\
\text { child's name } \\
\text { *staff and } \\
\text { parents are } \\
\text { emphasize to } \\
\text { know every } \\
\text { child's name }\end{array}$ & $\begin{array}{l}\text { *yes b/c } \\
\text { school } \\
\text { reinforces } \\
\text { Hmong } \\
\text { language } \\
\text { * schedule is } \\
\text { fairly } \\
\text { convenient } \\
\text { in the } \\
\text { morning and } \\
\text { afternoon }\end{array}$ \\
\hline Parent2 & $\begin{array}{l}\text { *staff } \\
\text { mostly } \\
\text { Hmong } \\
\text { able to } \\
\text { communica } \\
\text { te with } \\
\text { student if } \\
\text { they don't } \\
\text { understand } \\
\text { English }\end{array}$ & $\begin{array}{l}\text { *founder or } \\
\text { administrat } \\
\text { or is Asian } \\
\text { and able to } \\
\text { welcome } \\
\text { every } \\
\text { student } \\
\text { from all } \\
\text { race to the } \\
\text { school } \\
\text { *Other } \\
\text { schools do } \\
\text { not have } \\
\text { Hmong } \\
\text { language }\end{array}$ & $\begin{array}{l}\text { *Hmong is } \\
\text { spoken when } \\
\text { parents } \\
\text { cannot } \\
\text { communicate } \\
\text { with staff } \\
\text { *allows } \\
\text { parents to } \\
\text { express in } \\
\text { their } \\
\text { language }\end{array}$ & $\begin{array}{l}\text { *before school } \\
\text { there is } \\
\text { crossing } \\
\text { guards to help } \\
\text { students cross } \\
\text { safely } \\
\text { *staff stay } \\
\text { after school hr } \\
\text { to help and } \\
\text { monitor } \\
\text { students until } \\
\text { parents come } \\
\text { to pick up } \\
\text { *students can } \\
\text { go at } 7: 30 \text { am, } \\
\text { but class starts } \\
\text { at } 8 \text { am } \\
\text { *students get } \\
\text { out at } 5 \mathrm{pm} \\
\text { *time is very } \\
\text { convenient for }\end{array}$ & $\begin{array}{l}\text { *very } \\
\text { welcoming to } \\
\text { all parents } \\
\text { *very receptive } \\
\text { of parents to } \\
\text { help support } \\
\text { students }\end{array}$ & $\begin{array}{l}\text { *It's a good } \\
\text { school, it } \\
\text { helps my } \\
\text { children to } \\
\text { learn, take } \\
\text { them on } \\
\text { field trips to } \\
\text { see and } \\
\text { experience } \\
\text { new and } \\
\text { different } \\
\text { things } \\
\text { *I would } \\
\text { recommend } \\
\text { the school to } \\
\text { others } \\
\text { *the waiting } \\
\text { list shows } \\
\text { that parents } \\
\text { of Hmong } \\
\text { and other }\end{array}$ \\
\hline
\end{tabular}




\begin{tabular}{lll}
\hline & groups want \\
to send their & parents & students to \\
this school & & the
\end{tabular}

\begin{tabular}{|c|c|c|c|c|c|c|}
\hline Parent3 & $\begin{array}{l}\text { *when I } \\
\text { come to } \\
\text { help my } \\
\text { child at } \\
\text { school, } \\
\text { makes my } \\
\text { child feel } \\
\text { good } \\
\text { *I don't } \\
\text { come } \\
\text { everyday } \\
\text { but } \\
\text { whenever I } \\
\text { can }\end{array}$ & $\begin{array}{l}\text { *I like the } \\
\text { Hmong } \\
\text { language } \\
\text { program } \\
\text { b/c I don't } \\
\text { want my } \\
\text { child to } \\
\text { lose the } \\
\text { language } \\
\text { *my child } \\
\text { is better at } \\
\text { reading, } \\
\text { writing and } \\
\text { speaking } \\
\text { the } \\
\text { language }\end{array}$ & $\begin{array}{l}\text { *they teach } \\
\text { Hmong and I } \\
\text { want my } \\
\text { child to learn } \\
\text { and know the } \\
\text { Hmong } \\
\text { language }\end{array}$ & $\begin{array}{l}\text { *breakfast is } \\
\text { available to } \\
\text { every child } \\
\text { * school opens } \\
\text { at } 7 \text { for any } \\
\text { parents who } \\
\text { need to bring } \\
\text { their child } \\
\text { early and staff } \\
\text { are available } \\
\text { to monitor }\end{array}$ & $\begin{array}{l}\text { * school is very } \\
\text { welcoming for } \\
\text { parents if they } \\
\text { drop in }\end{array}$ & $\begin{array}{l}\text { *Yes, I } \\
\text { would } \\
\text { recommend } \\
\text { this school } \\
\text { to other } \\
\text { parents } \\
\text { *I like the } \\
\text { field trip, } \\
\text { culture } \\
\text { night, } \\
\text { dance, } \\
\text { taekwondo } \\
\text { this school } \\
\text { offers } \\
\text { *allows my } \\
\text { child to } \\
\text { experience } \\
\text { things they } \\
\text { might not } \\
\text { get }\end{array}$ \\
\hline Parent4 & $\begin{array}{l}\text { *there are } \\
\text { many good } \\
\text { things that } \\
\text { this school } \\
\text { supports } \\
\text { my } \\
\text { involvemen } \\
\text { t }\end{array}$ & $\begin{array}{l}\text { *an } \\
\text { independen } \\
\text { t charter } \\
\text { school } \\
\text { *schedule } \\
\text { is flexible } \\
\text { for school } \\
\text { and parents } \\
\text { *instruction } \\
\text { is } \\
\text { combined } \\
\text { into } 365 \\
\text { days } \\
* 8-5\end{array}$ & $\begin{array}{l}\text { *hard for } \\
\text { young } \\
\text { parents b/c } \\
\text { most are } \\
\text { working } \\
\text { parents } \\
\text { *a Hmong } \\
\text { language } \\
\text { *flexible } \\
\text { schedule } \\
\text { *close to my } \\
\text { home }\end{array}$ & $\begin{array}{l}* 7: 15 \text { door } \\
\text { open for all } \\
\text { children in } \\
\text { cafeteria and } \\
\text { breakfast is } \\
\text { offer } \\
\text { *after school } \\
\text { programs like } \\
\text { dance, } \\
\text { taekwondo, } \\
\text { enrichment } \\
\text { class that } \\
\text { parents do not } \\
\text { have to pay }\end{array}$ & $\begin{array}{l}\text { *I see that the } \\
\text { teachers and } \\
\text { staff monitors } \\
\text { the students } \\
\text { well } \\
* \text { they also } \\
\text { welcome me as } \\
\text { parents well }\end{array}$ & $\begin{array}{l}\text { *Yes, I } \\
\text { recommend } \\
\text { this school } \\
\text { to many } \\
\text { parents } \\
\text { *the number } \\
\text { of waiting } \\
\text { list tells me } \\
\text { that this is a } \\
\text { good school }\end{array}$ \\
\hline
\end{tabular}




\begin{tabular}{|c|c|c|c|c|c|c|}
\hline & & $\begin{array}{l}\text { instruction, } \\
\text { but only } 4 \\
\text { days a wk }\end{array}$ & & & & \\
\hline Parent5 & $\begin{array}{l}\text { *PTA is } \\
\text { very active } \\
\text { *encourage } \\
\text { non- } \\
\text { English } \\
\text { speaking } \\
\text { parents to } \\
\text { participate } \\
\text { *Open } \\
\text { communica } \\
\text { tion, email, } \\
\text { text }\end{array}$ & $\begin{array}{l}\text { *schedule } \\
\text { is } 11 \text { month } \\
* \text { M-Th } \\
* 8-5 \mathrm{pm} \\
\text { *better } \\
\text { retention of } \\
\text { what's } \\
\text { taught } \\
\text { *taekwond } \\
\text { o, dance, } \\
\text { arts } \\
\text { *Hmong } \\
\text { language } \\
\text { program }\end{array}$ & $\begin{array}{l}\text { *teaches my } \\
\text { child about } \\
\text { her culture } \\
\text { *to identify } \\
\text { my child's } \\
\text { self } \\
\text { *teach child } \\
\text { of her } \\
\text { cultural } \\
\text { background }\end{array}$ & $\begin{array}{l}\text { *no real after } \\
\text { school } \\
\text { program } \\
\text { except the } \\
\text { dance } \\
\text { program, } \\
\text { zumba which } \\
\text { teaches hip } \\
\text { hop } \\
\text { *fundraise } \\
\text { goes toward } \\
\text { the trips }\end{array}$ & $\begin{array}{l}\text { *teachers are } \\
\text { very motivated } \\
\text { to teach } \\
\text { children and } \\
\text { push them to } \\
\text { succeed }\end{array}$ & $\begin{array}{l}\text { *Yes, I } \\
\text { recommend } \\
\text { ed this } \\
\text { school to } \\
\text { other } \\
\text { parents. I } \\
\text { got my } \\
\text { sisters to } \\
\text { send their } \\
\text { children to } \\
\text { this school } \\
\text { *this school } \\
\text { teaches } \\
\text { students to } \\
\text { be better } \\
\text { *teach } \\
\text { students to } \\
\text { support each } \\
\text { other } \\
\text { *prepare } \\
\text { college }\end{array}$ \\
\hline Parent6 & $\begin{array}{l}\text { *wanted } \\
\text { something } \\
\text { different } \\
\text { for our kids } \\
\text { *enrichmen } \\
\mathrm{t} \\
\text { *art, } \\
\text { drama, } \\
\text { music, } \\
\text { club, } \\
\text { taekwondo } \\
\text { *brain } \\
\text { body }\end{array}$ & $\begin{array}{l}\text { *school } \\
\text { year goes } \\
\text { from late } \\
\text { July to June } \\
\text { *study trips } \\
\text { or learning } \\
\text { trips } \\
\text { *Hmong } \\
\text { language } \\
\text { *dance, } \\
\text { music, art }\end{array}$ & & $\begin{array}{l}\text { *school open } \\
\text { at } 7 \text { a.m. when } \\
\text { parents drop } \\
\text { off kids } \\
\text { *office staff } \\
\text { watch kids in } \\
\text { the cafeteria } \\
\text { *staff also } \\
\text { flexible after } \\
\text { school, stay } \\
\text { late 'til parents } \\
\text { pick up kids }\end{array}$ & $\begin{array}{l}\text { *students are } \\
\text { call scholars } \\
\text { * greet students } \\
\text { with handshake } \\
\text { *parents are } \\
\text { comfortable } \\
\text { coming to } \\
\text { school } \\
\text { *Hmong staff } \\
\text { also available } \\
\text { for } \\
\text { communication } \\
\text { *open door } \\
\text { policy } \\
\text { *get calls from } \\
\text { staff about } \\
\text { school work }\end{array}$ & $\begin{array}{l}\text { *helped } \\
\text { students to } \\
\text { do their best } \\
\text { *other } \\
\text { parents } \\
\text { know this } \\
\text { school and } \\
\text { want to } \\
\text { bring their } \\
\text { kids here } \\
\text { *waiting list }^{\text {wing }}\end{array}$ \\
\hline
\end{tabular}




\begin{tabular}{|c|c|c|c|c|c|c|}
\hline $\begin{array}{l}\text { Student } \\
1\end{array}$ & $\begin{array}{l}\text { *doing } \\
\text { activities } \\
\text { that } \\
\text { involve } \\
\text { parents } \\
\text { *parent } \\
\text { volunteer } \\
\text { for field } \\
\text { trips } \\
\text { *special } \\
\text { events at } \\
\text { school }\end{array}$ & $\begin{array}{l}\text { *different } \\
\text { classes } \\
\text { *dance } \\
\text { *Hmong } \\
\text { language } \\
\text { class } \\
\text { *Taekwon } \\
\text { do } \\
\text { *music }\end{array}$ & $\begin{array}{l}\text { *different } \\
\text { language } \\
\text { teachers } \\
\text { (many } \\
\text { languages) } \\
\text { *I can ask } \\
\text { either } \\
\text { Hmong or } \\
\text { English } \\
\text { speaking to } \\
\text { explain } \\
\text { something if } \\
\text { I don't } \\
\text { understand }\end{array}$ & $\begin{array}{l}\text { *before: } \\
\text { principal have } \\
\text { us go outside } \\
\text { in the field } \\
\text { and do } \\
\text { exercise, } \\
\text { dance, music, } \\
\text { taekwondo } \\
\text { lead us } \\
\text { through the } \\
\text { exercise } \\
\text { *we do } \\
\text { stretches } \\
\text { to keep us } \\
\text { "awake" }\end{array}$ & $\begin{array}{l}\text { *I'm treated } \\
\text { nice } \\
\text { *we treat each } \\
\text { other nicely } \\
\text { too } \\
\text { *life skills and } \\
\text { life long } \\
\text { guidelines so } \\
\text { we have to } \\
\text { respect each } \\
\text { other and not } \\
\text { put the other } \\
\text { down } \\
\text { *we are all call } \\
\text { scholars }\end{array}$ & $\begin{array}{l}\text { *yes, bc of the } \\
\text { different } \\
\text { classes } \\
\text { *they treat you } \\
\text { very nice }\end{array}$ \\
\hline $\begin{array}{l}\text { Student } \\
2\end{array}$ & $\begin{array}{l}\text { *report } \\
\text { cards, they } \\
\text { come here } \\
\text { and they } \\
\text { tell you }\end{array}$ & $\begin{array}{l}\text { *bc school } \\
\text { teaches } \\
\text { Hmong } \\
\text { *Help me } \\
\text { learn how } \\
\text { to read } \\
\text { Hmong }\end{array}$ & $\begin{array}{l}\text { *fun } \\
\text { activities } \\
\text { *compliment } \\
\text { s of each } \\
\text { other with } \\
\text { flowers } \\
\text { *pass } \\
\text { multiplicatio } \\
\text { n levels }\end{array}$ & $\begin{array}{l}\text { *morning } \\
\text { movements } \\
\text { and stretches } \\
\text { on Mon } \\
\text { morning } \\
\text { *ATT } \\
\text { computer } \\
\text { time *mobile } \\
\text { max }\end{array}$ & $\begin{array}{l}\text { *teachers treat } \\
\text { me nice } \\
\text { *always say hi } \\
\text { to me } \\
\text { *they hug me } \\
\text { *they call } \\
\text { everyone } \\
\text { scholars not } \\
\text { students }\end{array}$ & $\begin{array}{l}\text { *yes, bc the } \\
\text { school have } \\
\text { fun activities }\end{array}$ \\
\hline $\begin{array}{l}\text { Student } \\
3\end{array}$ & $\begin{array}{l}\text { *mom } \\
\text { comes to } \\
\text { watch and } \\
\text { support me } \\
\text { *helps me } \\
\text { and come } \\
\text { to } \\
\text { volunteer } \\
\text { in the class }\end{array}$ & $\begin{array}{l}\text { *schedule } \\
\text { is only M- } \\
\text { Th, we get } \\
\text { F off } \\
\text { *class is 8- } \\
5 \\
\text { *ATT } \\
\text { (achievem } \\
\text { ent } \\
\text { through } \\
\text { technology } \\
\text { ) } \\
\text { *mobile } \\
\text { max 1 hr } \\
\text { every day }\end{array}$ & $\begin{array}{l}* \text { different } \\
\text { from other } \\
\text { school } \\
* \text { (this school } \\
\text { is exciting) } \\
\text { not boring } \\
\text { like other } \\
\text { school }\end{array}$ & $\begin{array}{l}\text { *I walk there } \\
\text { early if my } \\
\text { mom has to } \\
\text { be at work } \\
\text { *there'll be } \\
\text { adult at } \\
\text { school to } \\
\text { watch } \\
\text { *dance after } \\
\text { school } \\
\text { *taekwondo }\end{array}$ & $\begin{array}{l}\text { *I am treated } \\
\text { with respect } \\
\text { *there's not a } \\
\text { lot of mean } \\
\text { people } \\
\text { *teachers treat } \\
\text { me nicely } \\
\text { *being call } \\
\text { scholar is } \\
\text { better }\end{array}$ & $\begin{array}{l}\text { *yes I would } \\
\text { because of the } \\
\text { things I said }\end{array}$ \\
\hline $\begin{array}{l}\text { Student } \\
4\end{array}$ & $\begin{array}{l}\text { *classmate } \\
\text { s are very } \\
\text { nice } \\
\text { *events at } \\
\text { the school } \\
\text { are fun } \\
\text { *principal } \\
\text { is very } \\
\text { nice } \\
\text { *principal } \\
\text { ask kids to } \\
\text { do their } \\
\text { best }\end{array}$ & $\begin{array}{l}\text { *schedule, } \\
4 \text { days a } \\
\text { week, } 10 \\
\text { hrs a day } \\
\text { *school } \\
\text { starts in } \\
\text { August } \\
\text { *field trips } \\
\text { *study } \\
\text { trips } \\
\text { *enrichme } \\
\text { nts }\end{array}$ & & $\begin{array}{l}\text { *school open } \\
\text { up early in the } \\
\text { morning } \\
\text { *zumba dance } \\
\text { class } \\
\text { *taekwondo } \\
\text { *staff are } \\
\text { flexible at the } \\
\text { end of the day }\end{array}$ & $\begin{array}{l}*_{\text {treated very }} \\
\text { good } \\
*_{\text {teachers treat }} \\
\text { me very nice } \\
*_{\text {very friendly }} \\
\text { *very }_{\text {velcoming }}\end{array}$ & $\begin{array}{l}\text { *yes, b/c it's a } \\
\text { friendly school } \\
\text { *do a lot of } \\
\text { events } \\
\text { *have } \\
\text { enrichment } \\
\text { programs } \\
\text { *help us to } \\
\text { dream big } \\
\text { *help kids } \\
\text { think about } \\
\text { college }\end{array}$ \\
\hline
\end{tabular}




\section{Appendix J \\ Summary of Responses}

Summary of Responses

\begin{tabular}{|c|c|c|}
\hline & Overall Responses & Themes \\
\hline Admins & $\begin{array}{l}\text {-Radio announcement/commercials } \\
\text {-Hmong TV programs, } \\
\text {-School brochures, } \\
\text {-Voice messages, } \\
\text {-Email, } \\
\text {-Letters in kids' backpack, } \\
\text {-Remind parents in hallway, } \\
\text {-Ask individual parents to help, } \\
\text {-Remind parents to get kids to bed early } \\
\text {-Before school begin, teacher do h/v } \\
\text {-Meet \& greet } \\
\text {-Back2school night } \\
\text {-Introduce staff \& visit rooms } \\
\text {-Dance, music, taekwondo performances } \\
\text {-Culture night } \\
\text {-Garden for parents } \\
\text {-Multicultural night } \\
\text {-Field trips } \\
\text {-Parent meetings } \\
\text {-Awards } \\
\text {-Assembly } \\
\text {-Re-classification }\end{array}$ & $\begin{array}{l}\text {-Encourages teachers and parents } \\
\text { collaboration before school begin and } \\
\text { throughout school year } \\
\text {-Offers many opportunities for } \\
\text { parents and teachers to meet, } \\
\text { promotes cultural diversity through } \\
\text { celebration } \\
\text {-Support enrichment programs for } \\
\text { students and parents }\end{array}$ \\
\hline
\end{tabular}

Teachers -Mother's day in the class, moms must attend/participate

-Same with father's day

-Involvement is stated in charter mission (40 hrs. per year)

-Parents encourage to participate in study trip (field trips)

-Special meeting to engage parents before trip

-Hmong culture day: skits, play, planning, run booth, embroidery, food station

-PTA allows parents to come and support

-Email to parents as forms communication

-Home visit

-Send letter home update parents on activities

-PTA

-Multicultural day to show support

-A lot of parents show up for conferences to show

their support

-Parents offer to help
-Encourages parents to attend and participate in special events with students

-Make sure parents understand the school mission and requirement of parental volunteer

-Encourage parents to participate in study (field) trips with students -Involve and engage parents to participate in many cultural aspects -PTA brings parents to school and support

-Uses many ways to communicate

-Home visit

-PTA

-Multicultural day brings families together

-Parents attend parent conferences regularly 


\begin{tabular}{|c|c|c|}
\hline Parents & $\begin{array}{l}\text {-school encourages to volunteer } \\
\text {-Parents volunteer } 40 \text { hrs during the year } \\
\text {-Teachers are welcoming } \\
\text {-Chaperone on field trips } \\
\text {-Multicultural day } \\
\text {-Staff are Hmong and help students to learn and } \\
\text { speak Hmong } \\
\text {-Able to support students and parents in learning } \\
\text { Hmong language } \\
\text {-School helps me to plan what I need to do to help } \\
\text { my child } \\
\text {-Teachers tell me what I need to do } \\
\text {-I did not get this help from the previous school } \\
\text {-PTA meeting monthly to fundraise for field trip } \\
\text {-Culture night } \\
\text {-ELAC } \\
\text {-Open door policy } \\
\text {-At will policy } \\
\text {-Room for volunteer for any classroom } \\
\text {-PTA } \\
\text {-Culture day } \\
\text {-Hmong New Year } \\
\text {-Encourage parents to help at home } \\
\text {-Field trips } \\
\text {-Require } 40 \text { hrs. /yr. }\end{array}$ & $\begin{array}{l}\text {-School requires parents to volunteer } \\
40 \text { hrs during the year } \\
\text {-Welcoming \& open-door policy } \\
\text {-Promotes multicultural events and } \\
\text { celebration } \\
\text {-Staff members are Hmong and } \\
\text { competent in speaking language } \\
\text {-Support students in retaining Hmong } \\
\text { language } \\
\text {-School is proactive in helping } \\
\text { parents and student plan for the future } \\
\text { which does not exist in previous } \\
\text { school } \\
\text {-PTA meeting monthly and } \\
\text { fundraising for field (study) trips } \\
\text {-Culture day/night celebration } \\
\text {-Volunteer opportunities in all } \\
\text { classrooms } \\
\text {-PTA } \\
\text {-Culture day/night }\end{array}$ \\
\hline Students & $\begin{array}{l}\text {-Hmong language (at school) } \\
\text {-Parents want me to learn to speak in Hmong } \\
\text {-Parents want me to interact with other Hmong }\end{array}$ & $\begin{array}{l}\text {-Hmong language (program) } \\
\text {-Parents want me to read, write, and } \\
\text { interact in Hmong }\end{array}$ \\
\hline
\end{tabular}

-Movement time/exercise

-Dances and taekwondo

-Different cultures at the school

-PTA
-Movement time and doing exercise at school

-Different cultures at this school

-PTA 
-Performance in the cafeteria

-Mayor at the school, write speech, and do morning announcements

-Study trips
-Performance in the cafeteria -Study (field) trips 